متطلبات الإرشاد النفسي والاجتماعي الفعال بمؤسسات الرعاية الاجتماعية

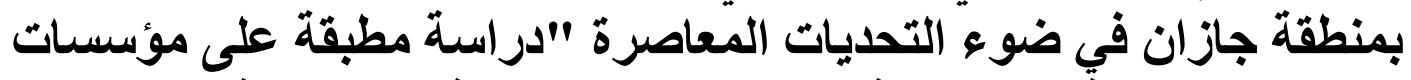

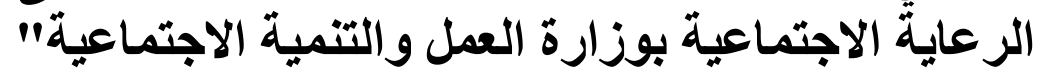

$$
\begin{aligned}
& \text { إعداد } \\
& \text { د/ احمد بن موسى حنتول } \\
& \text { أستاذ علم النفس المشارك ووكيل عمادة خدمة المجتمع موسئ هئ } \\
& \text { والتعليم المستمر - جامعة جازان }
\end{aligned}
$$

$$
\text { د/ محمد عبد الجليل القاضي }
$$

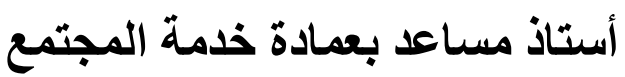

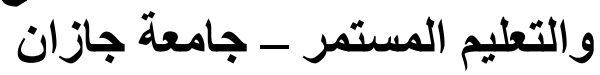

د/ علاء عبد العظيم سليمان

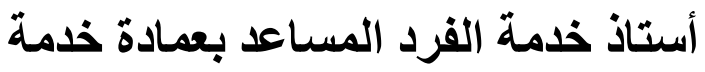
المجتمع والتعليم المستمر جامعة جازان المعان 
متطلبات الإرشاد النفسي والاجتماعي الفعال بمؤسسات الرعاية الاجتماعية

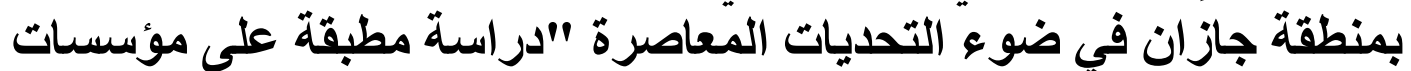

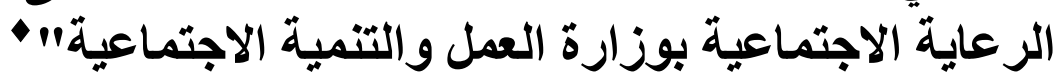

الملخص:

استهدف البحث الوقوف علي أهم المعوقات التي تقف حائلا أمام تقديم خدمات الإرشاد النفسي

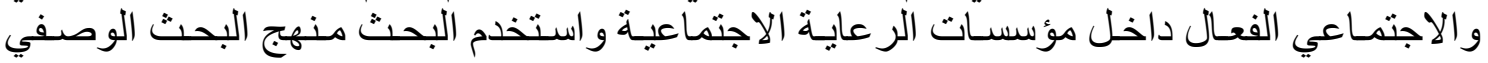

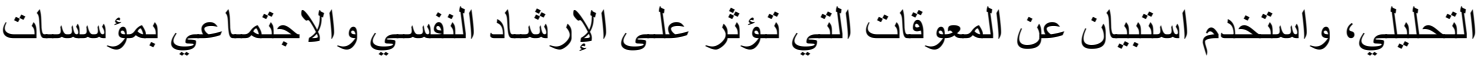

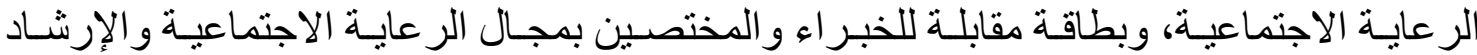

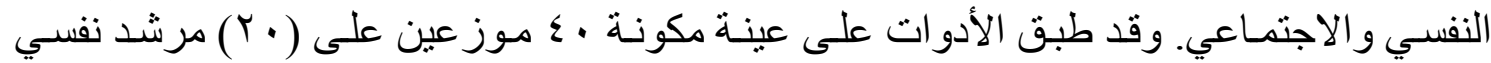

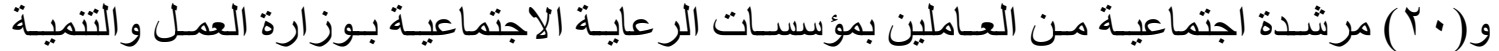

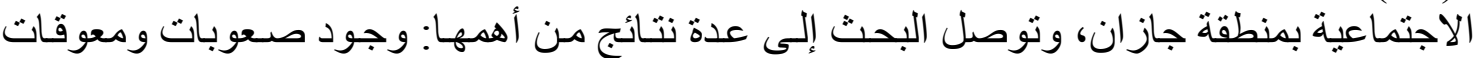

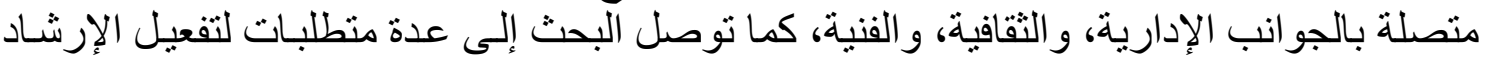

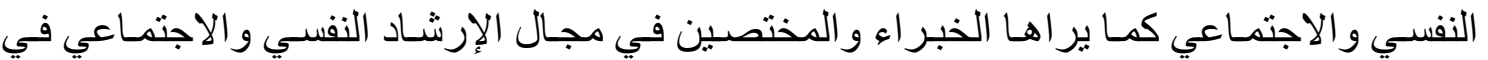

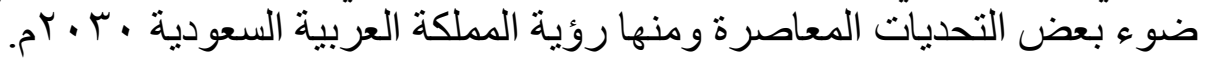

The research aimed to identify the most important obstacles that hindered the provision of effective psychological and social counseling services within the social welfare institutions. The research used descriptive research methodology, a questionnaire on the obstacles that affect social and psychological counseling in social welfare institutions, an interview with experts and specialists in the field of social care, . It was applied to a sample of 164 distributed to (20) mentors and (20) social workers from the social welfare institutions in the Ministry of Labor and Social Development in Jazan region. The research reached several results, the most important of which are the following: Difficulties and obstacles related to administrative, cultural, And the research reached several requirements to activate psychological counseling and social in the light of contemporary challenges

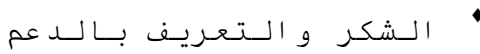

حرصنا على دعم البحث العلمي بما يحقى التكامل. و التوازن في مجالات البحث العلمي وخاصة مجـال العلــوم

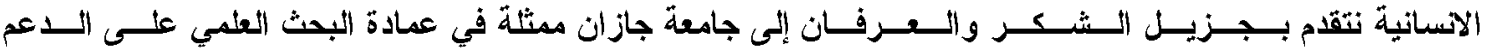

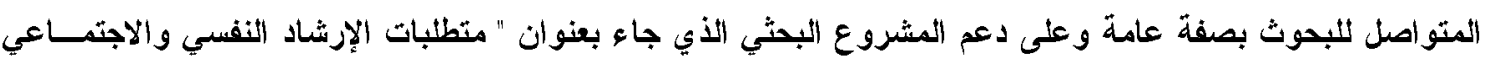
الفعال بمؤسسات الرعاية الاجتماعية بمنطقة جاز ان في ضوع وعاع التحديات المعاصرة ".
} 


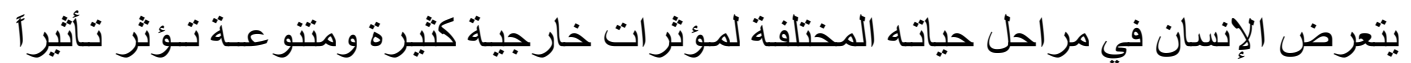

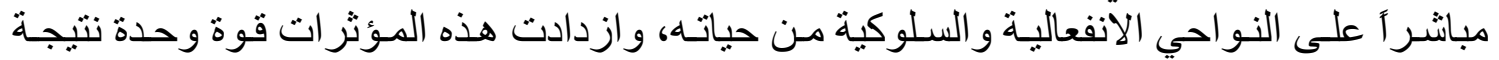

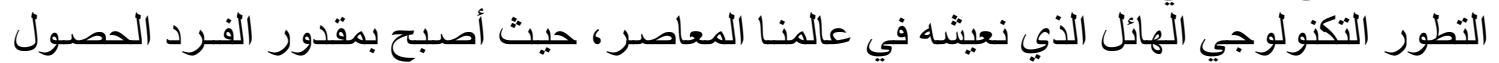

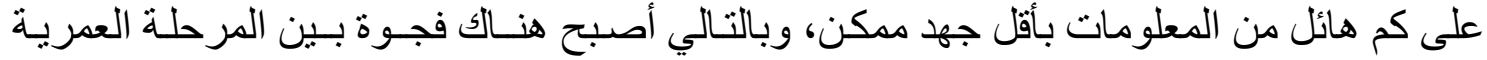

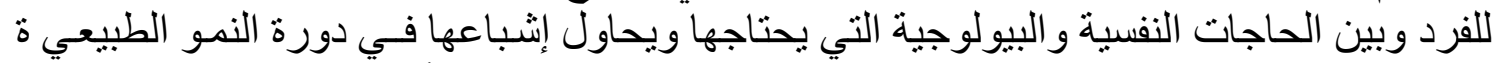

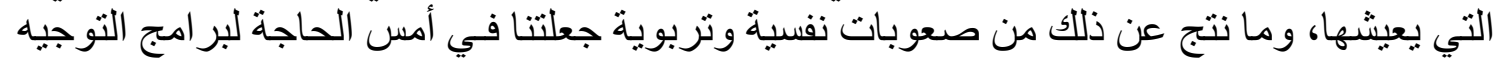

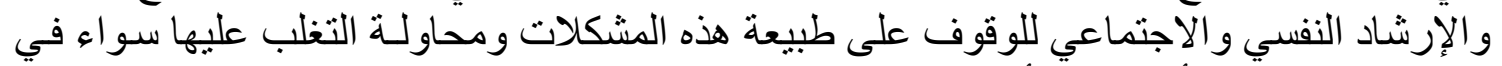

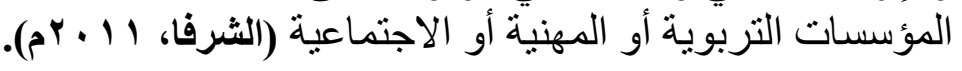

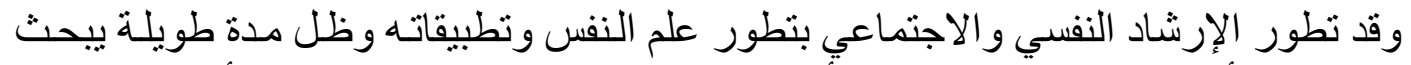

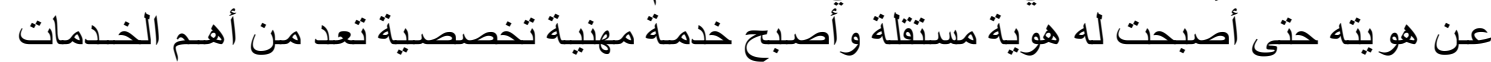

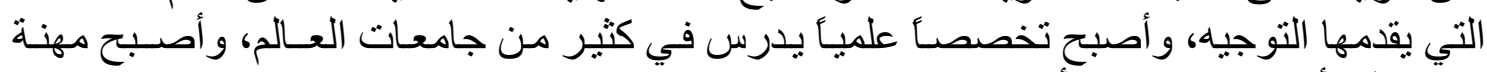

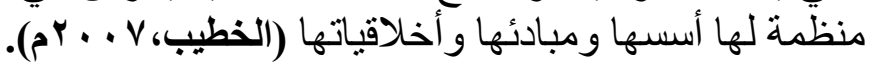

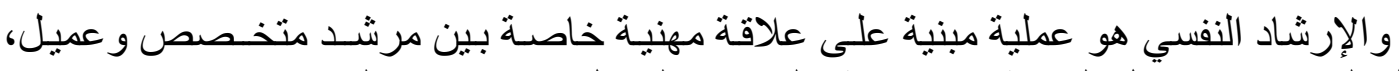

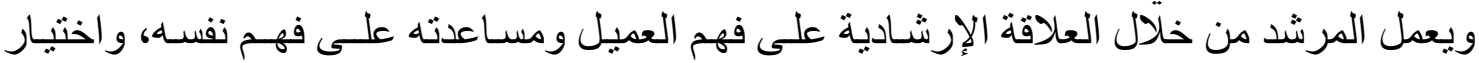

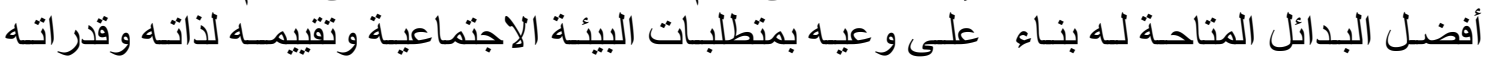

$$
\text { و إمكاناته الو اقعية (القذافي، V } 9 \text { ( } 9 \text { (م). }
$$

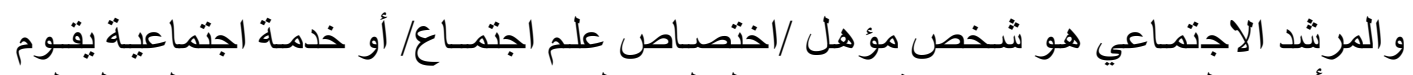

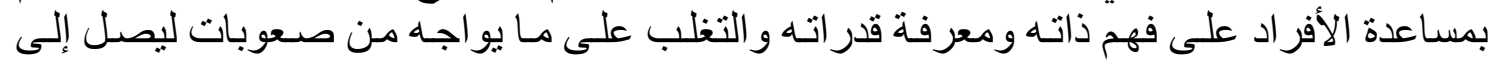
تحقيق التو افق الاجتماعي و التربوي ولى وبناء شخصية سورية.

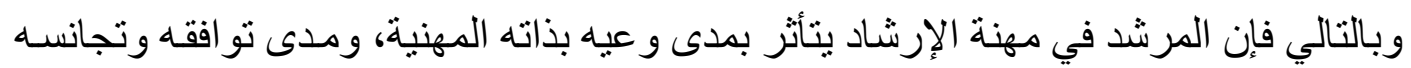

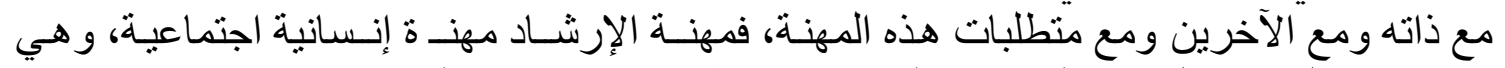

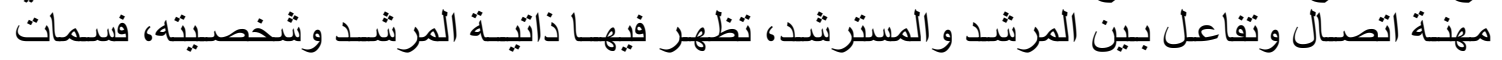

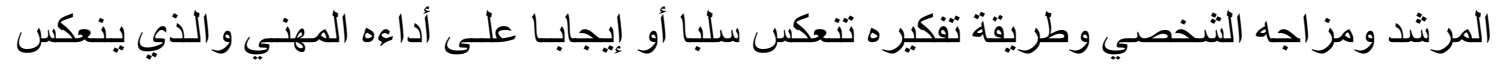

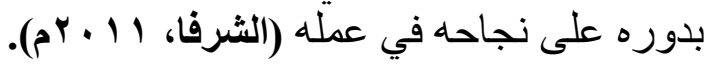

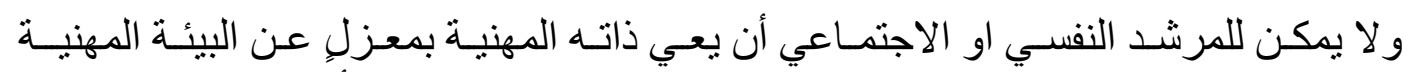

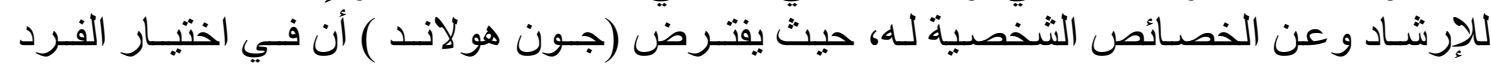

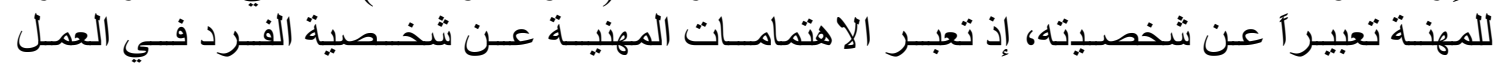

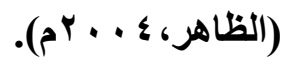

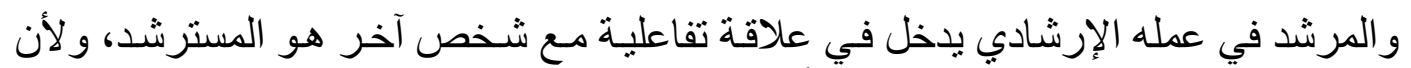

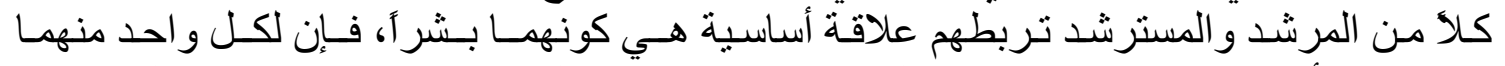

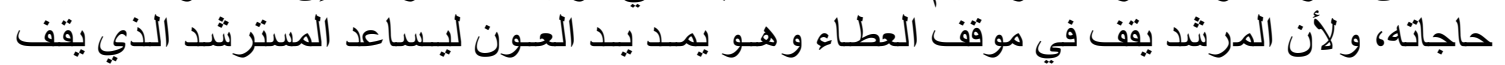

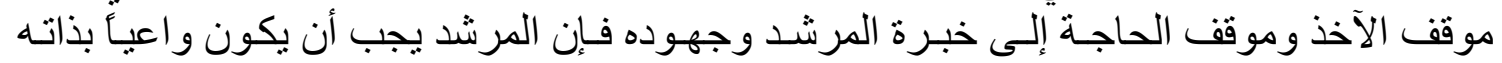

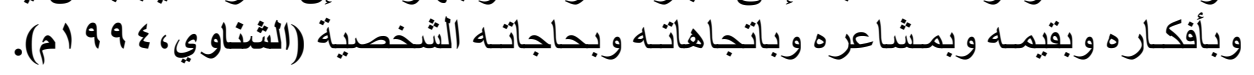

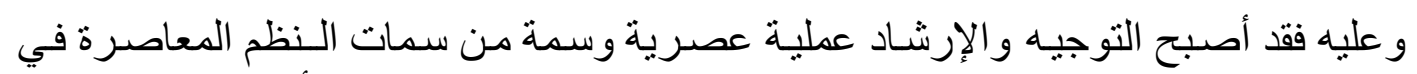

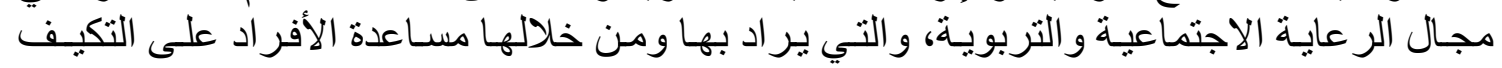

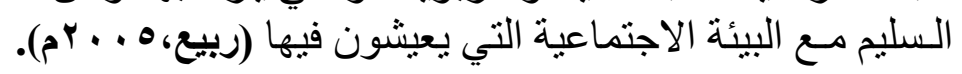

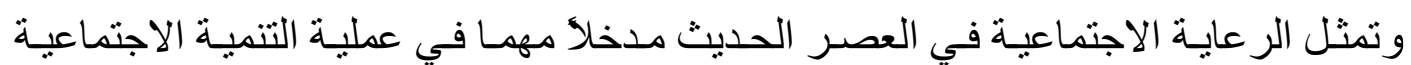

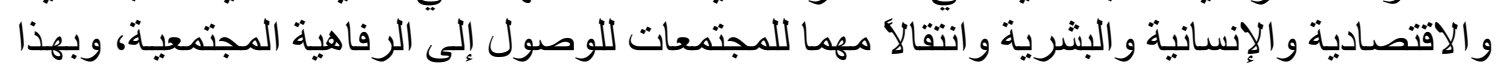


تصبح الرعاية الاجتماعية أحد أهم مصادر التغير الاجتمـاعي وتحسين المستوى المعيثـي، حسب التب التعريفات الحديثة للر عاية الاجتماعية.

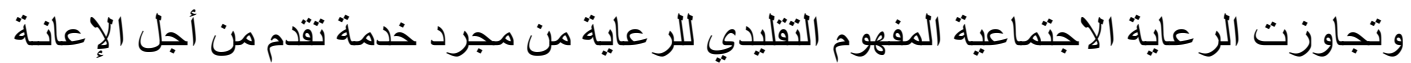

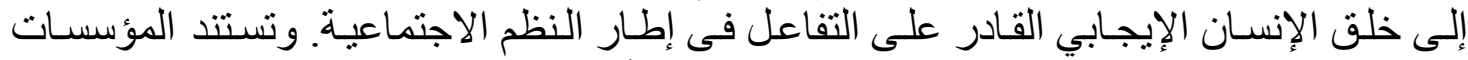

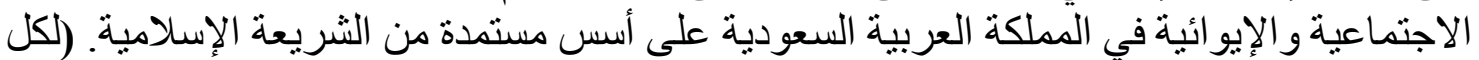

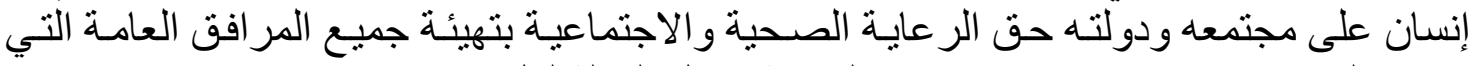

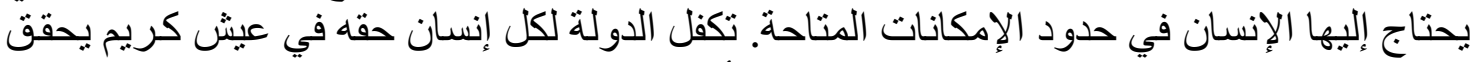

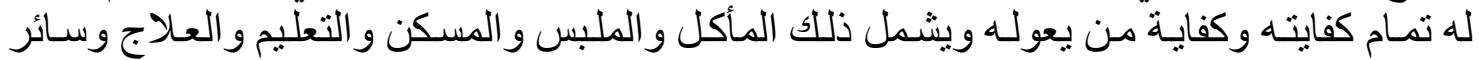

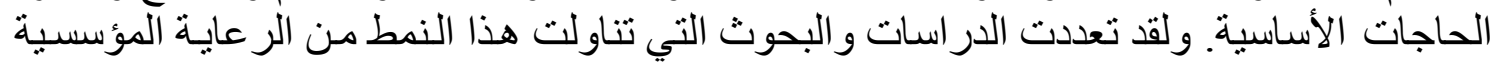

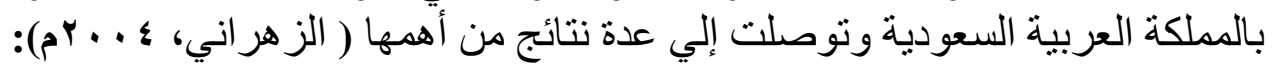

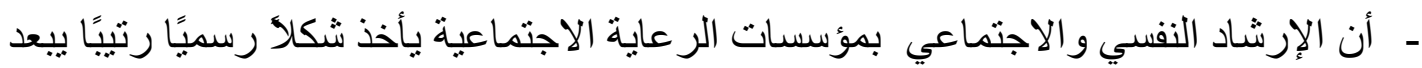

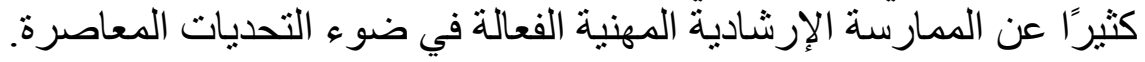
ـ ـتم الرعاية في هذه المؤسسات من قبل موظفين غير مؤ هلين مهنيـا علي المستوي النظري و التطبيقي. تصنية

- ـ تُعد بيئة المؤسسة الإيو ائية غير محفزة للفرد قياسًا إلى الأسرة الطبيعية.

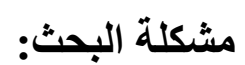

في خلال السنو ات الأخيرة ارتقى الإرشاد النفسي والاجتماعي وازداد الأهمام بـالبر امج التهي

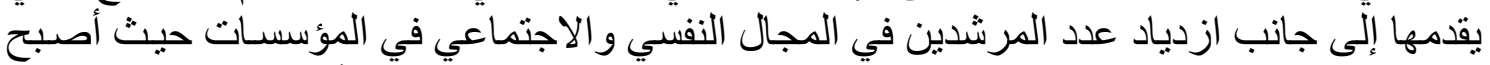

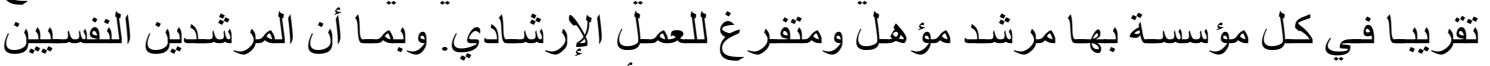

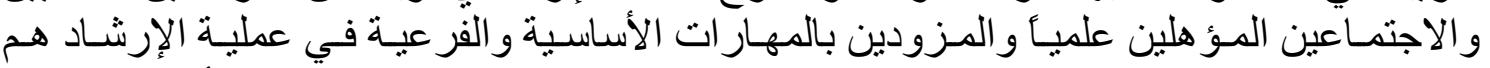

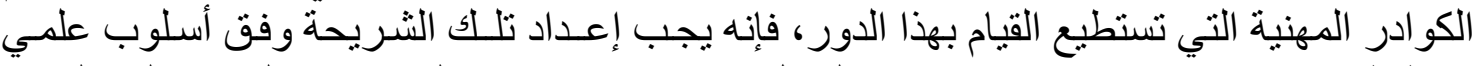

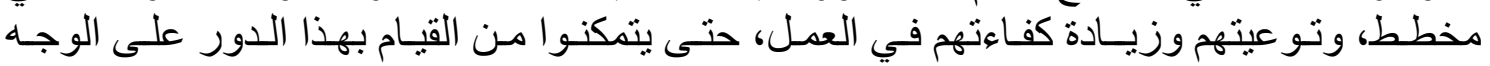
المطلوب، من هذا المنطلق فإن مشكلة البحث تحددت في في قضية رئيسية مؤداهيا:

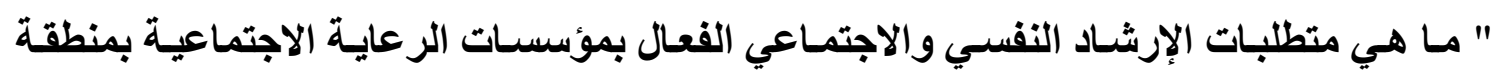

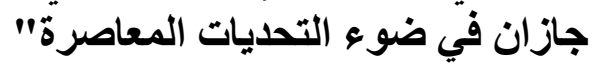
أهمية البحث

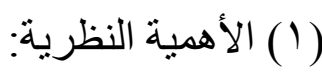
ا ـ تأتي أهمية هذه الدر اسة من أهمية المجال الذي تبحثث فيـه وهو مجـال الرعايـة الاجتماعيـة

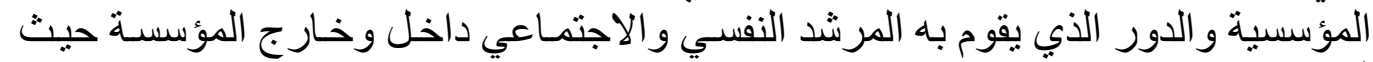

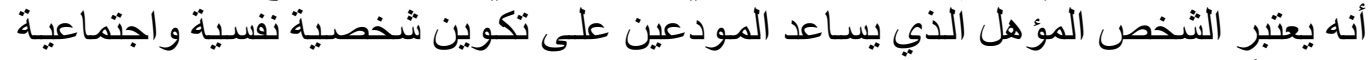

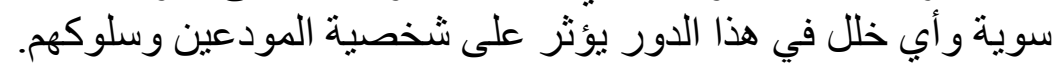

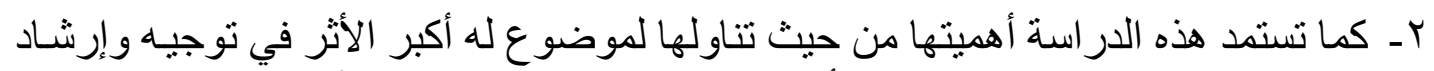
العنصر البشري الذي تعتمد عليه الأمة في تقدمها ونهضنها وانها وتحقيق آمالها.

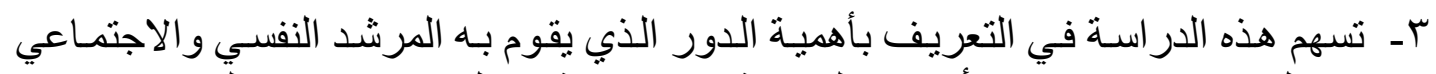

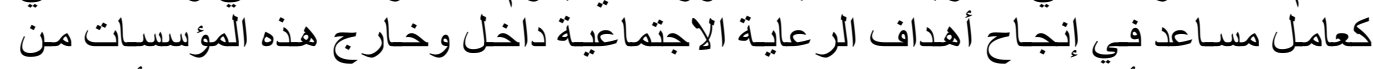
ناحية، وكعامل أسأسي في تحفيق التو افق النفسي والاجتماعي للمودعين من ناحية أخرى.

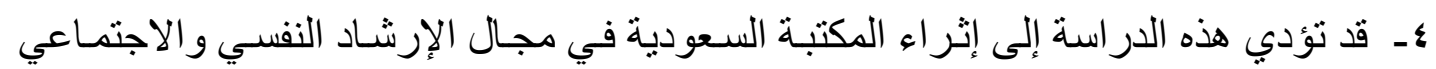


(ب) الأهمبة التطبيقية:

ا ـ قد تؤدي هذه الدر اسـة إلى الوقوف على المعوقـات الفعليـة التي تحـول دون قيـام المرشـ

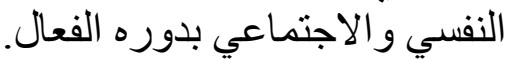

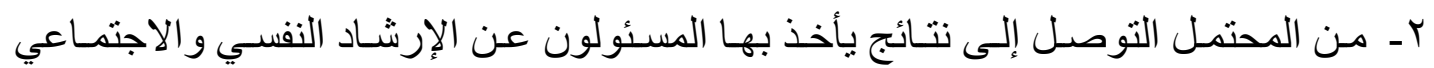

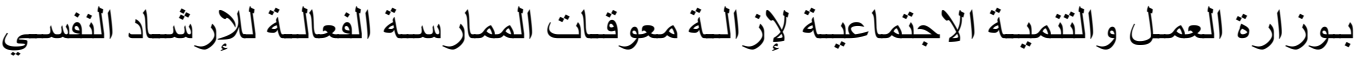
و الاجتماعي.

r- قد تسهم هذه الدر اسة في تتمية الممارسـة الإرشـادية الإيجابيـة للمرشـد النفسي والاجتمـاعي

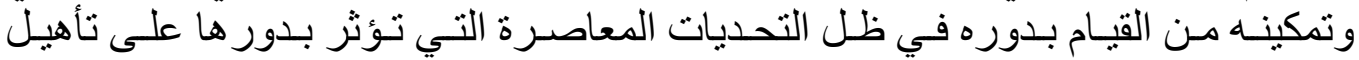

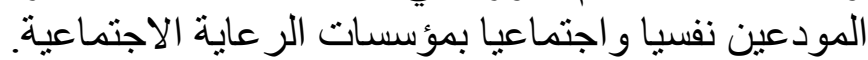
أهداف البحث:

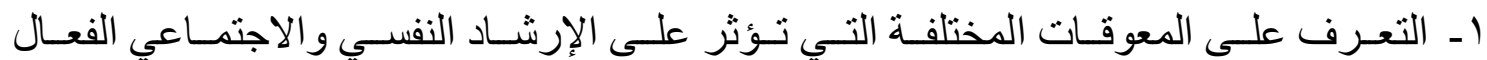

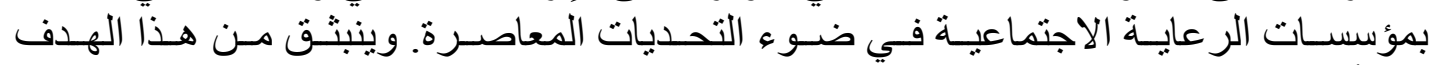
عدة أهداف فر عية: - التعـرف علـي المعوقـات الإداريـة التـي تــؤثر علـى الإرشـاد النفسـي والاجتمــاعي الفعال بمؤسسات الرعاية الاجتماعية.

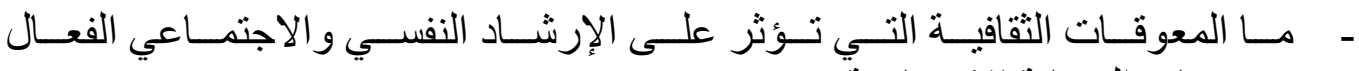
بمؤسسات الرعاية الاجتماعية..

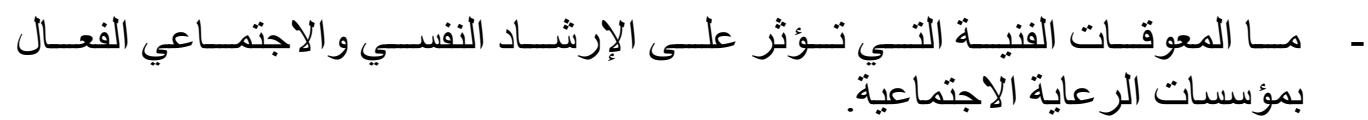

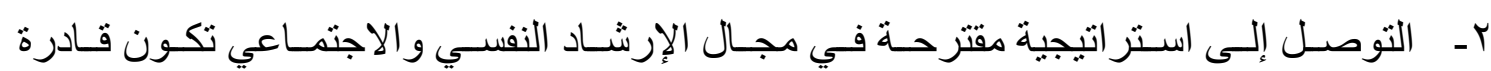

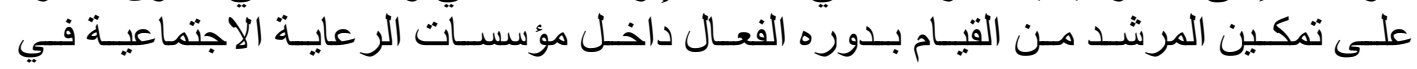
ضوء التحديات المعاصرة.

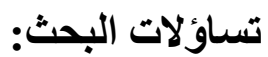

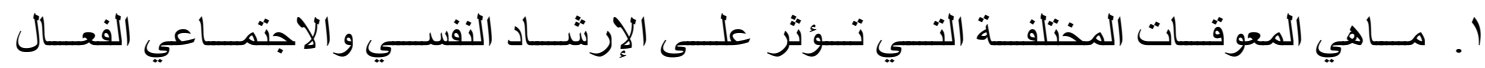

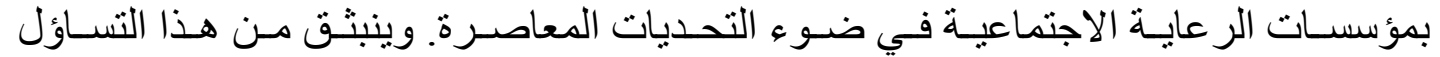
عدة تساؤلات فر عية: التر عابة

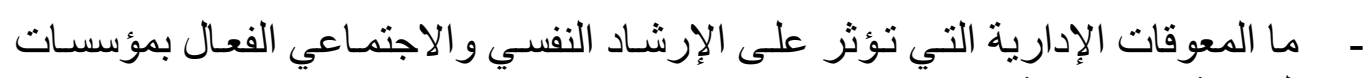
الر عاية الاجتماعية. - مـا المعوقـات الثقافيـة التي تؤثر على الإرشـاد النفسي و الاجتمـاعي الفعـال بمؤسسـات الر عاية الاجتماعية.. - مـا المعوقـات الفنيـة التي تؤُثر على الإرشـاد النفسي والاجتمـاعي الفعـال بمؤسسـات الر عاية الاجتماعية.

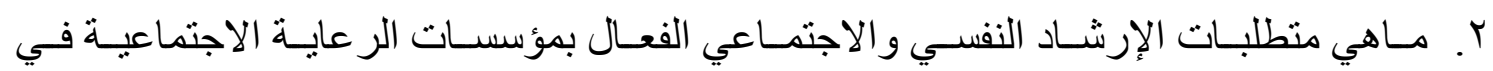




$$
\text { مفاهيم البحث: }
$$

هو عـادة المسئول المتخصص الأول عن العمليـات الرئيسية في التوجيـهـه و الإرشــاد وخاصـة

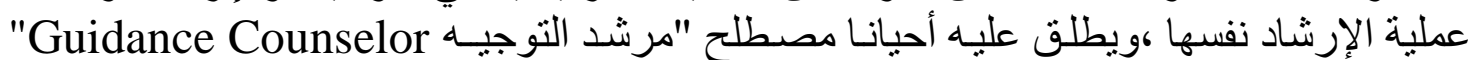
أو" مرشد الصحة النفسية " Counselor Health Mental" (ز هران : 991 (م).

$$
\text { التعريف الإجر ائي للمرشد النفسي : }
$$

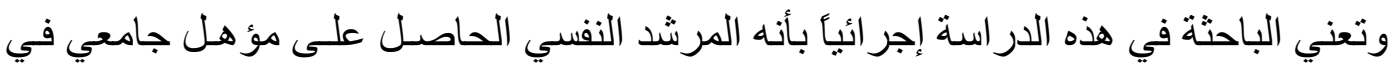

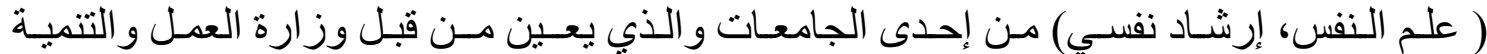

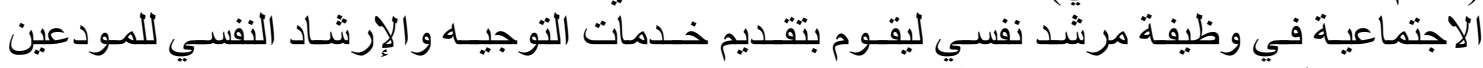
بمؤسسات الرعاية الاجتماعية بمنطقة جاز ان. ثانيا المرشد الاجتماعي:

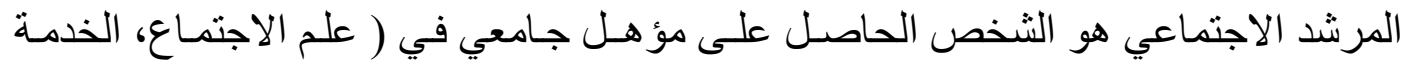

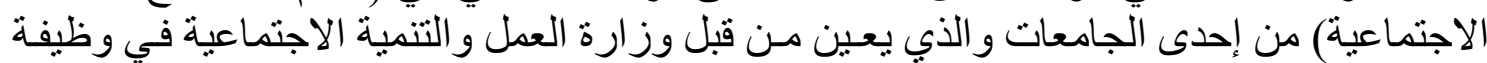

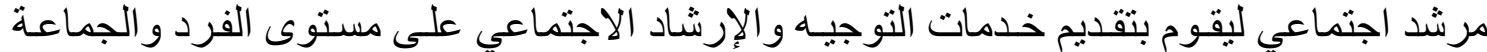

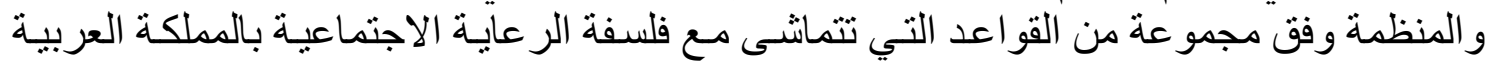
السعودية ومنطقة جاز ان بصفة خاصة.

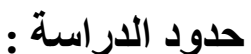

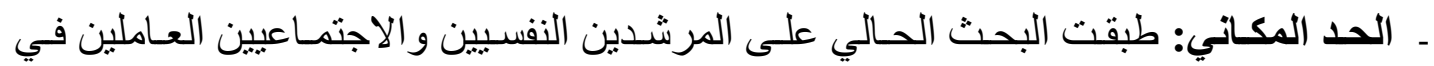
مؤسسات الر عاية الاجتماعية بمنطقة جاز المان.

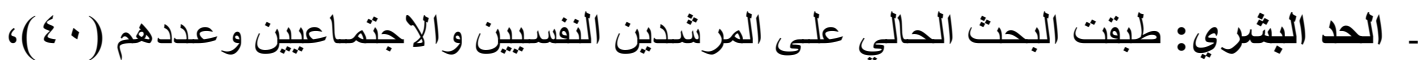

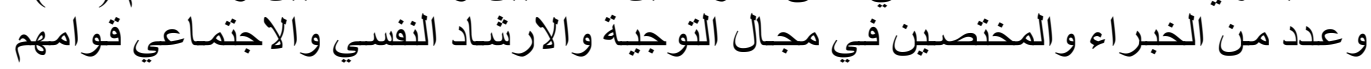

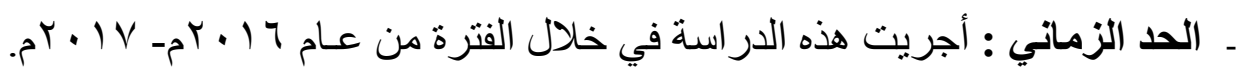

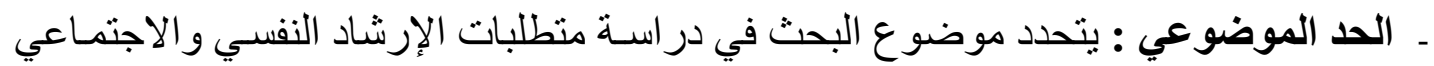

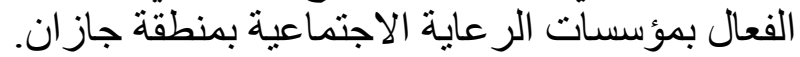
الاطار النظري للبحث

الارشاد النفسي والاجتماعي:

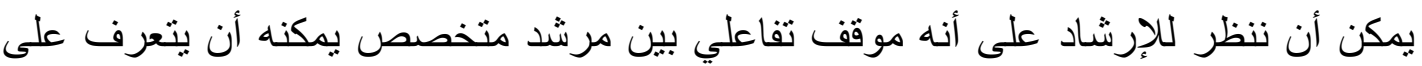

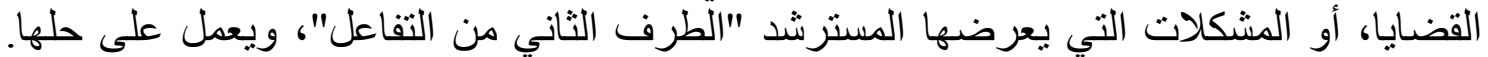
وبذلك فإن التفاعل الذي يتم في الإرشاد يشتمل على أربعة جوانب (زهران : 9 9 ( ام):-

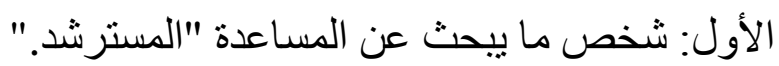

الثاني: شخص ما ير غب في تقديم المساعدة "المرشد. الثالث: هذا المرشد مدرب وقادر على تقديم المساعدة "الإرشاد." الر ابع: وذللك في موقف يسمح بإعطاء، وتلقي المساعدة. 
إن الثخص الذي يقدم المساعدة Helping في موقف الإرشاد، وهو المرشد، ينبغي أن تثو افر

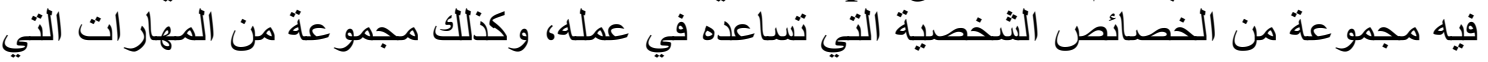

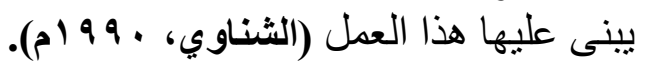

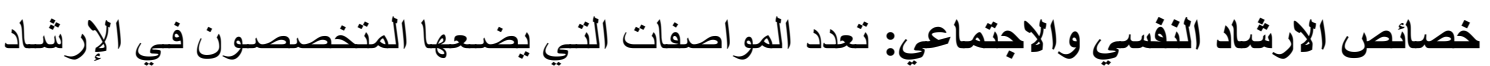

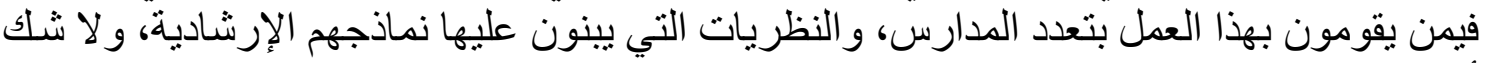

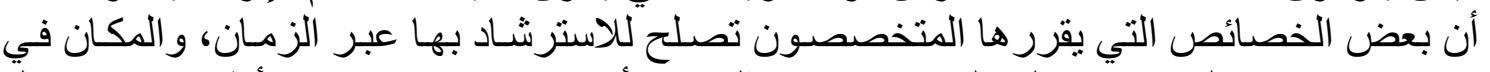

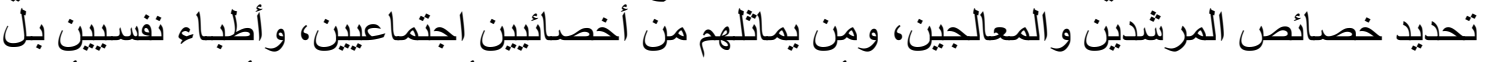

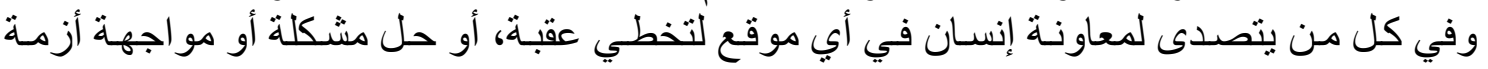

شديدة (1982) "Brammcr, L. M. \& Shostrom, E. L.

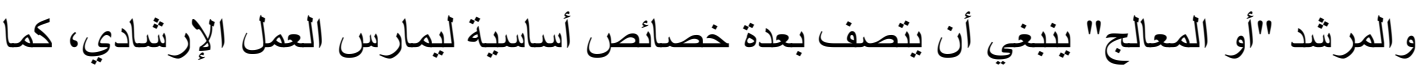

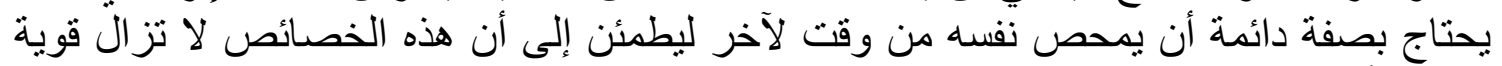

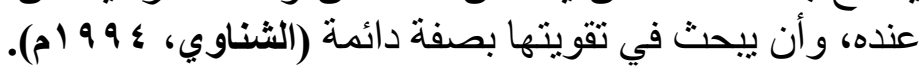

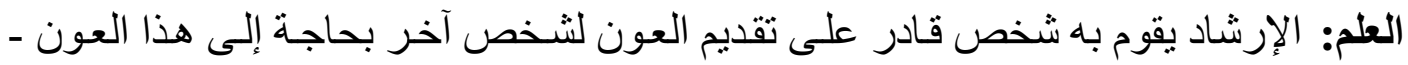

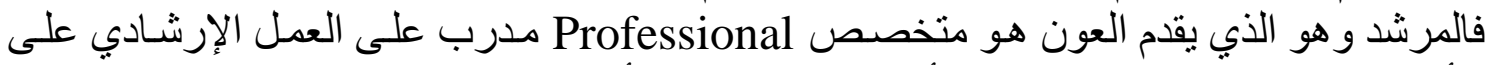

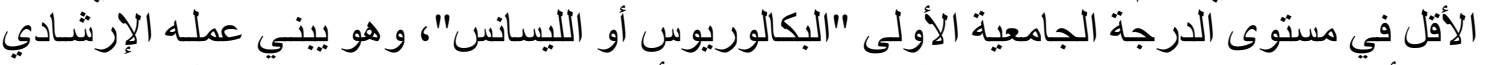

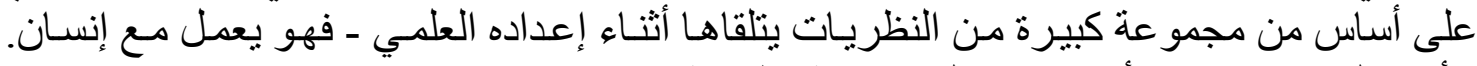

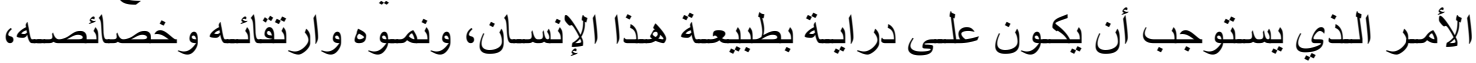

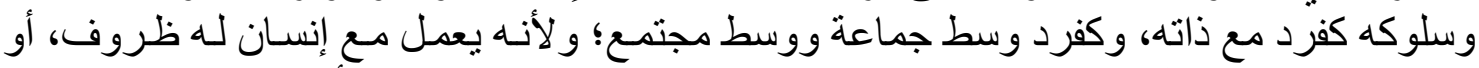

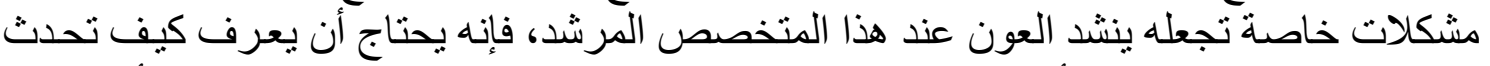

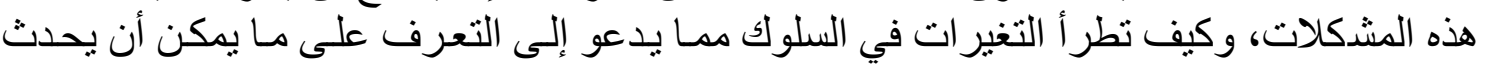

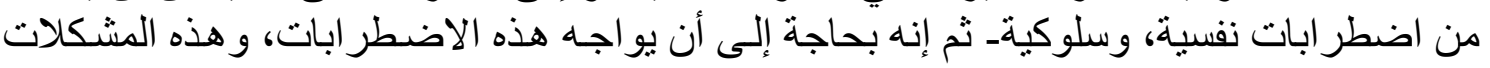

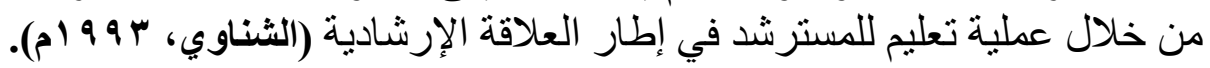

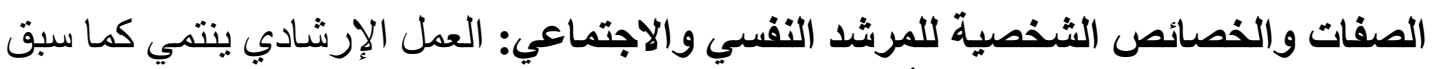

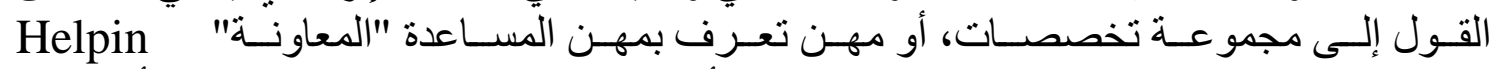

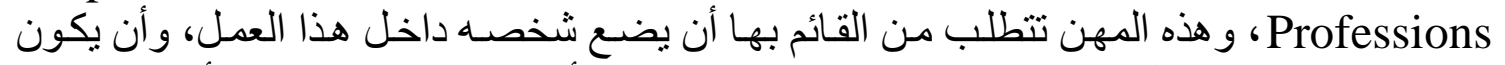

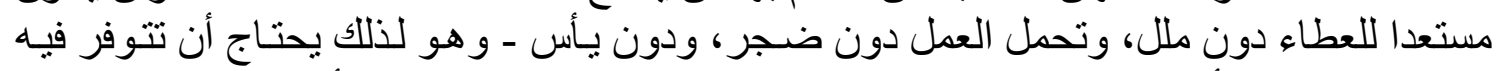

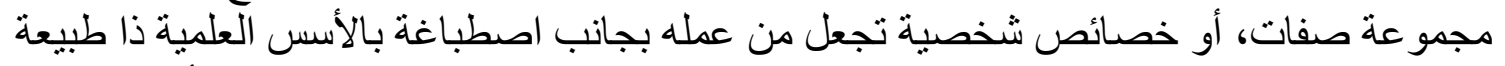

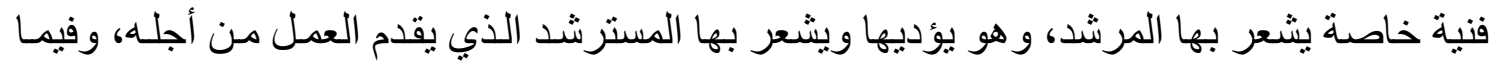

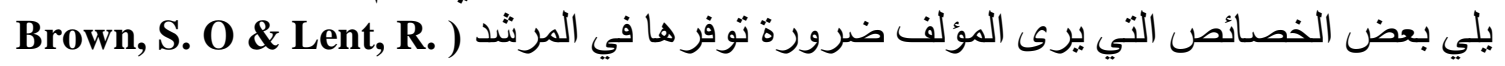
-:(W. Edsl, 1992 الأمانة: و الأمانة كلمة بسيطة ولكنها ذات معنى و اسع، و الأمانة مشتقة من الأمن، ومادة الأمن

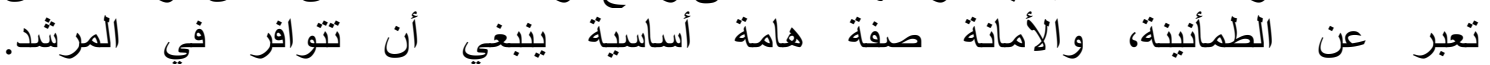

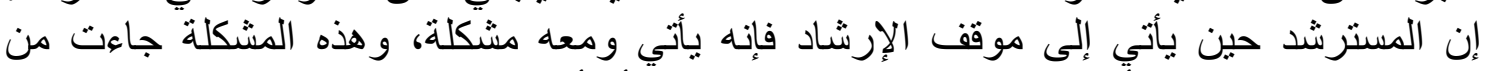

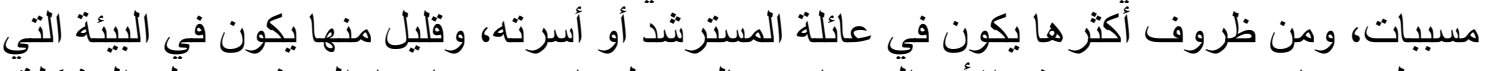

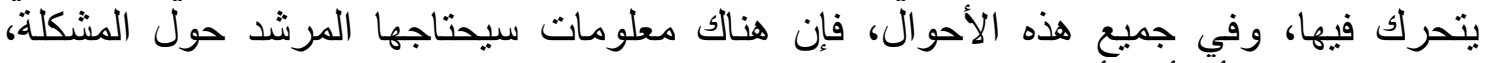

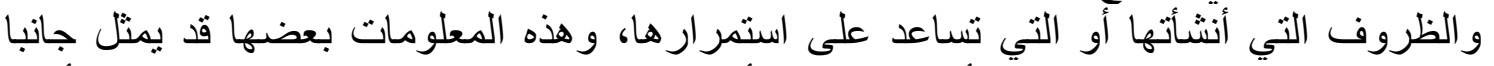

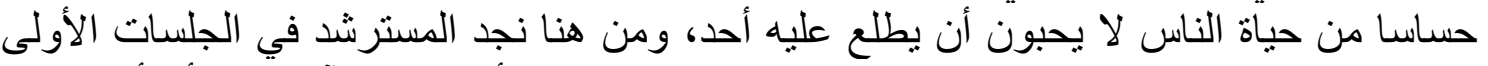

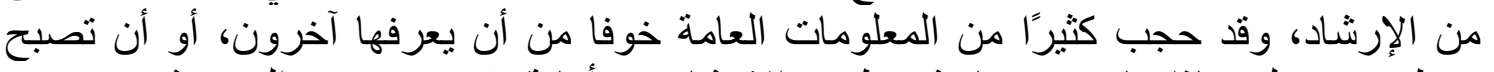

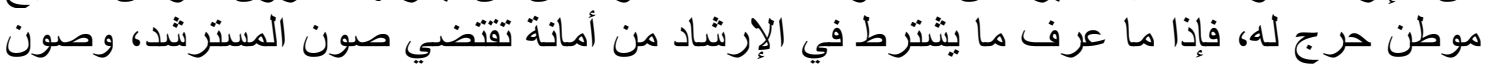


أسراره فإن الثقة في المرشد تنمو لدى المسترشد، ويبدأ في تقديم المعلومات التي بحتاجها المرشد ليساعده.

التطابق "الأصالة": التطابق يعني أن يكون الإنسان أمينًا مع نفسه ظاهره كباطنه، وسره

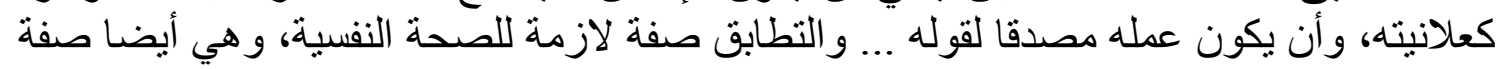
لازمة للمرشد في عمله.

الكفاعة الذهنية: يتطلب الإرشاد من المرشد أن تكون لديه قاعدة معرفية مناسبة، وو اسعة في

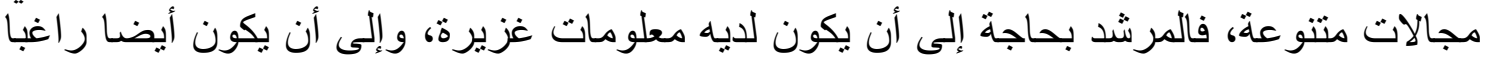

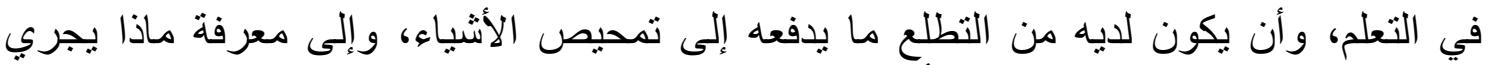

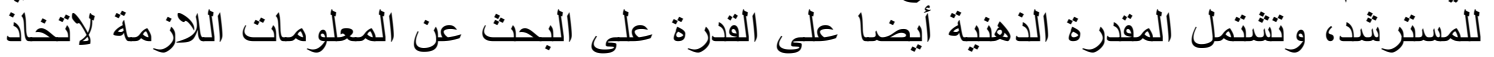

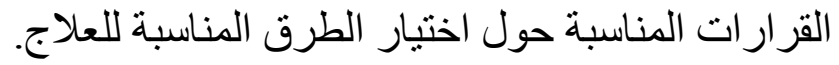

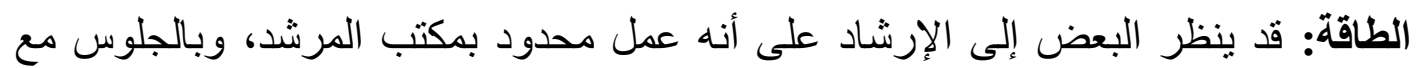

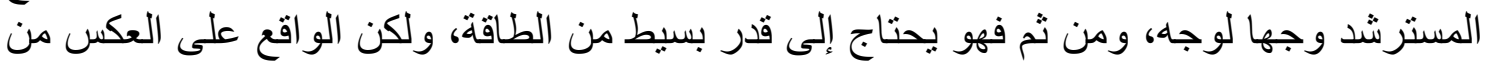

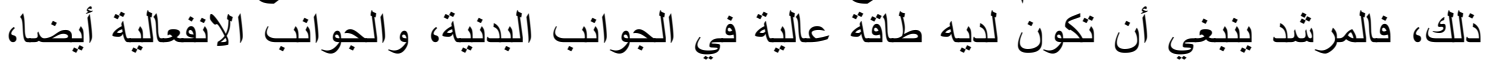

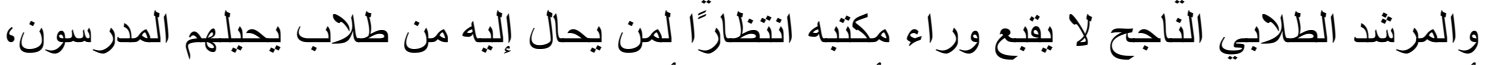

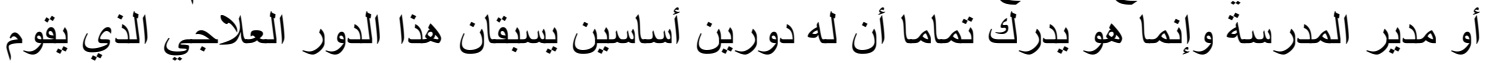

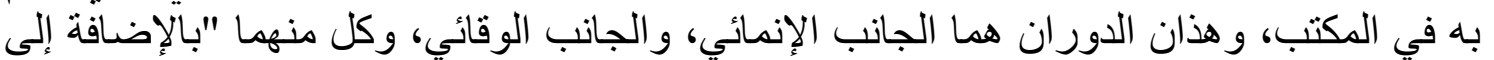

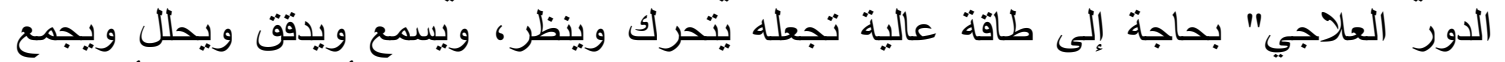

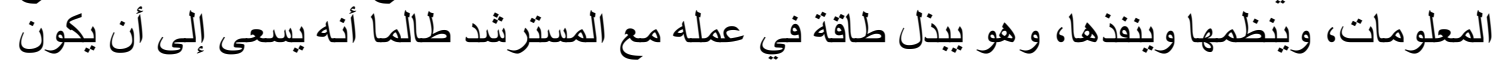

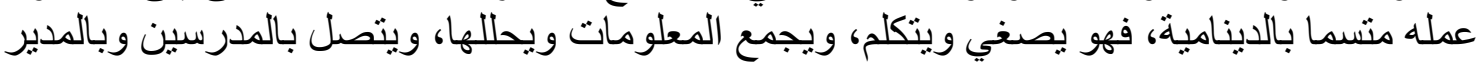

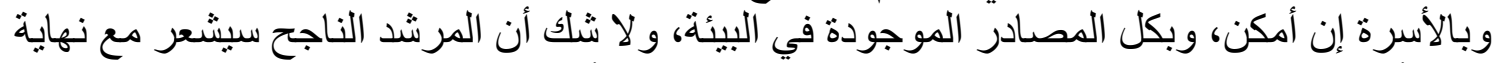

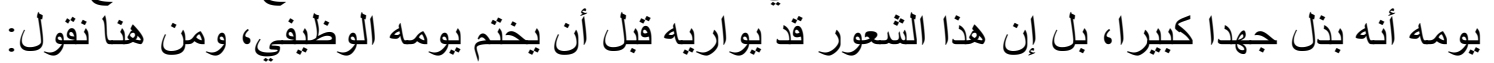

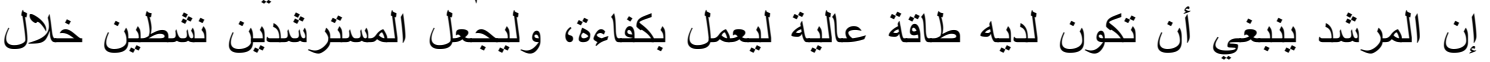
الجلسات الإرشادية.

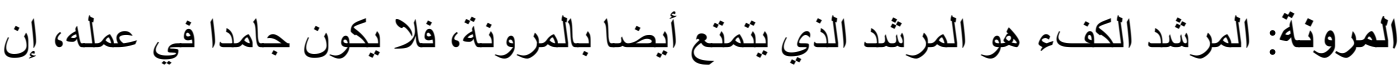

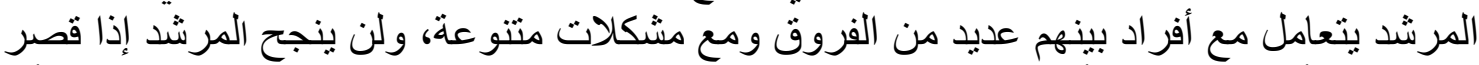

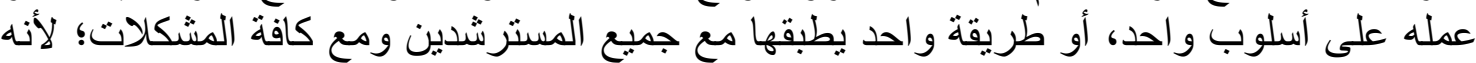

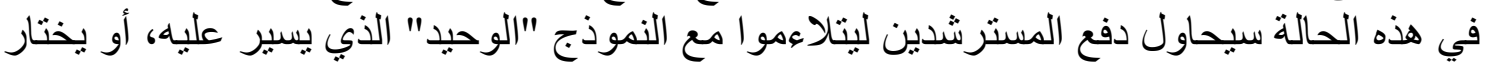

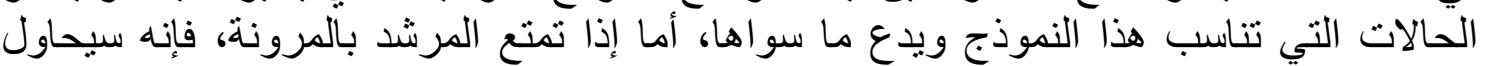

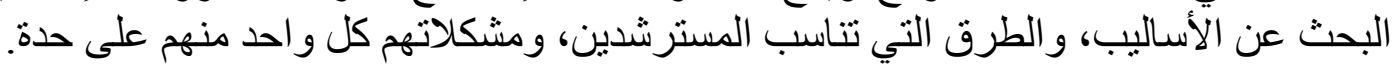

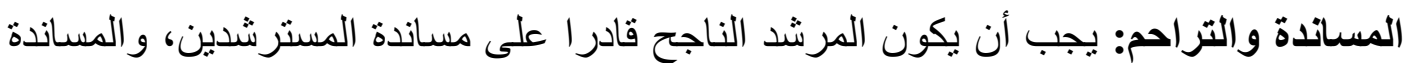

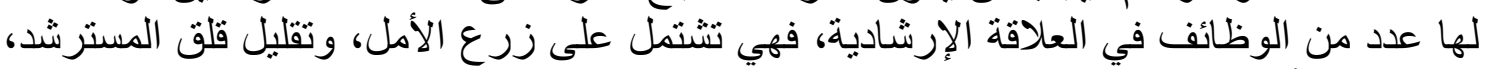

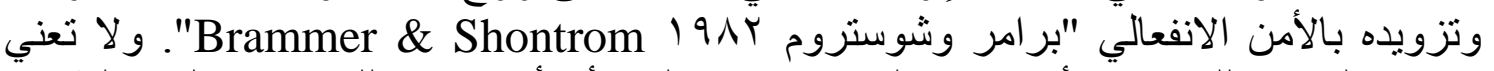

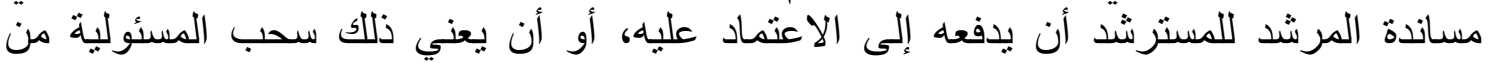

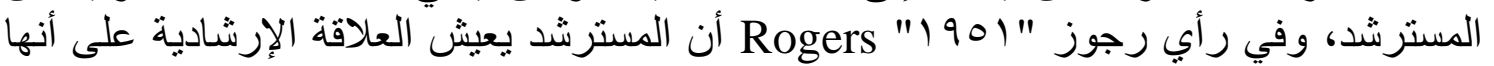

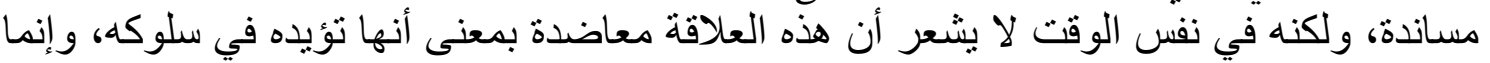

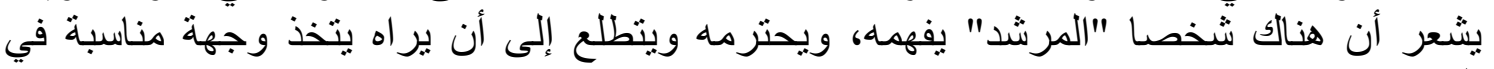
الحياة.

القدرة على التأثير: إن المرشد بالنسبة للمسترشد هو بمثابة المعلم، وهدفه الأساسي في العملية

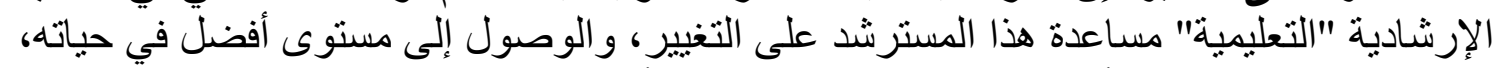

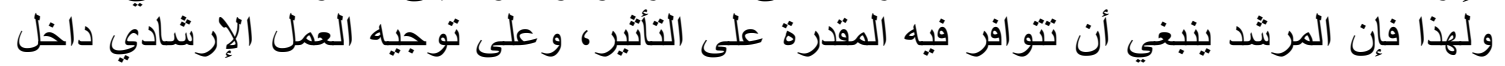


جلسات الإرشاد وخارجها، بمعنى آخر أن يكون لايه القدرة على توجيه مسار العملية الإرشادية في

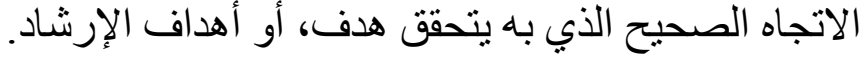

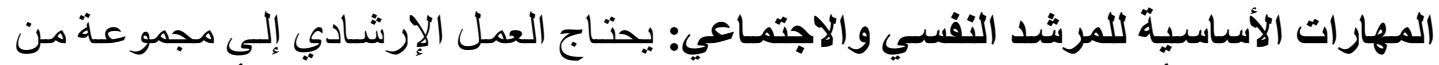

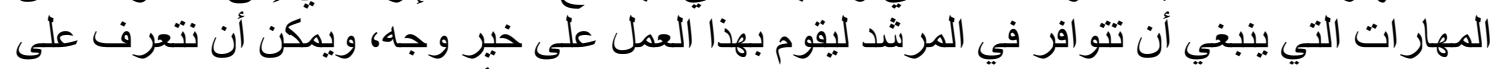

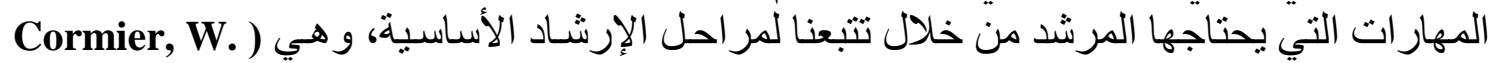

:(H. \& Cormier, L. S,1985

$$
\begin{aligned}
& \text { - } \\
& \text { - - التعرف على المشكلة وتحديدها. } \\
& \text { ـ - إعداد الأهداف الإرشادية. } \\
& \text { - اختيار طريقة للإرشاد و استخدامها. } \\
& \text { - - - تقويم النتائج. } \\
& \text { إقفال الحالة. }
\end{aligned}
$$

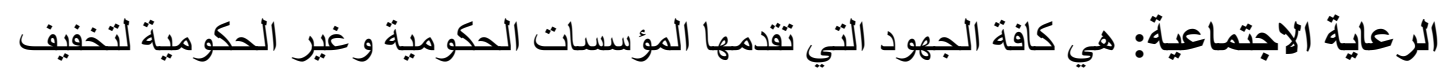

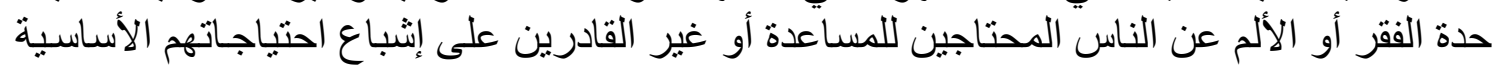

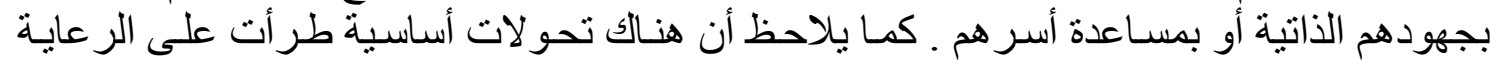

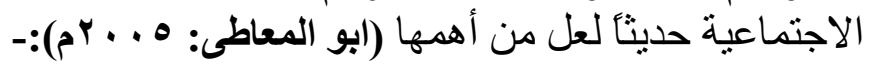

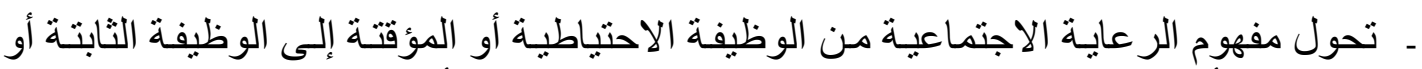
الإنمائية أي من النموذج العلاجي إلى النموذج المؤسسي في أغلب الماعن المجتمعات.

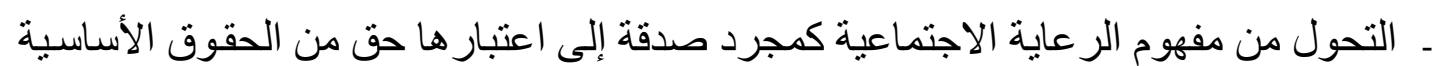

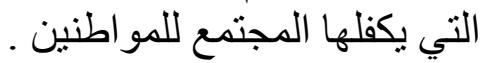
نماذج الرعاية الاجتماعية المعصرة (السدحان: 11 ـ بم):

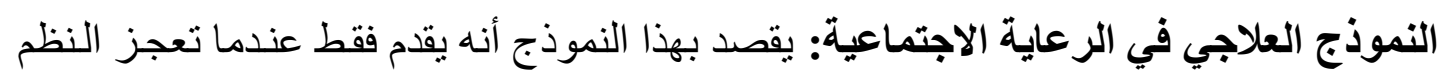

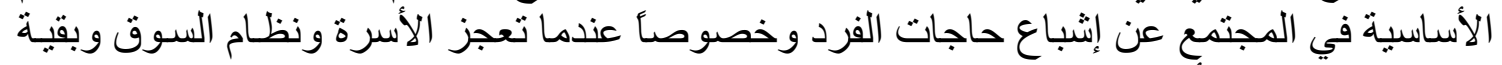

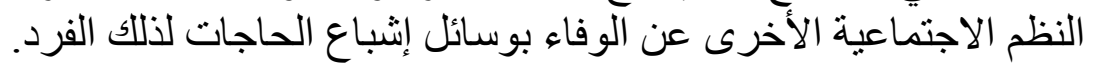

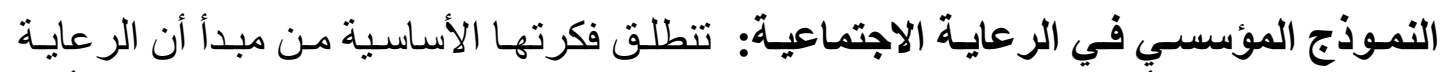

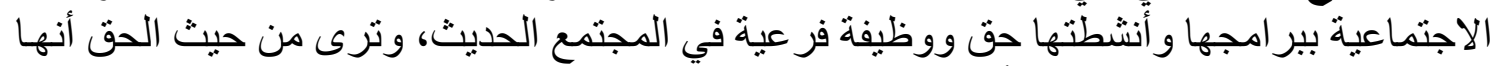
حق للفرد في إثباع احتياجاته الأساسية .

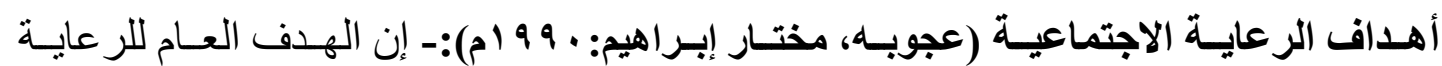

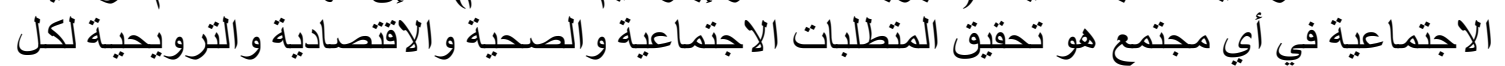
أفر اد المجتمع وذللك من خلاعل أهداف علاجية ووقائية و إنشائية يمكن تحديدها فئية فيما يلي : -

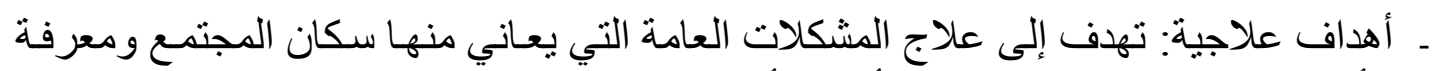

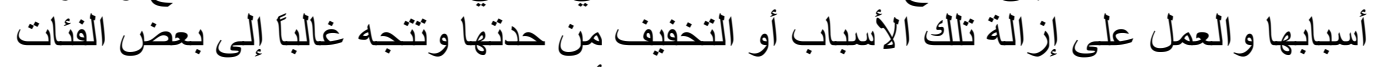

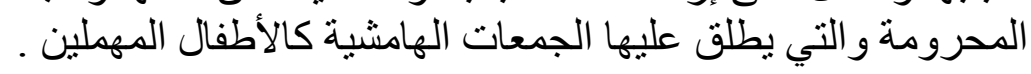

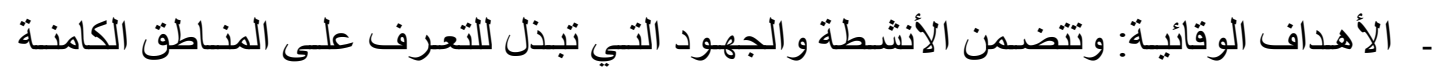

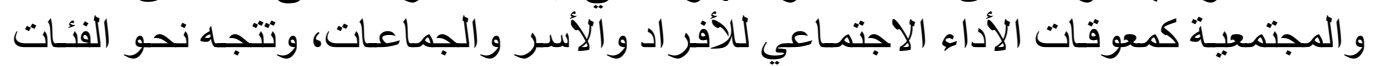
التي يمكن أن تكون عرضة للتأثير السلبي في المستقبل من عمليـة التغير الاجتمـاعي الذي ولي الاتي 
يمر به المجتمع أي أنها تسبق حدوث تداعيات سلبية وتعد للتعامل معها سلفأ وليس بعد

ـ الأهداف الإنشائية: بهدف المساهمة في إيجاد ر أي عام لتحمل المسئولية وتقليل الفاقد المـادي

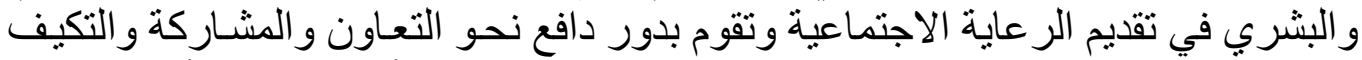

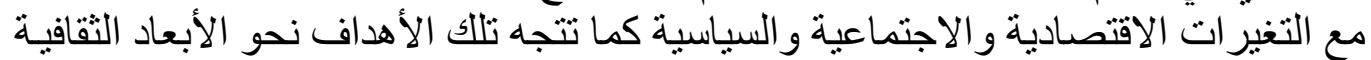

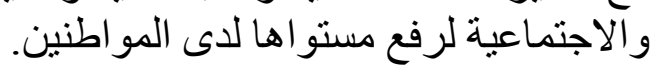

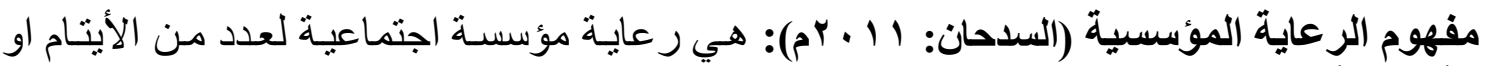

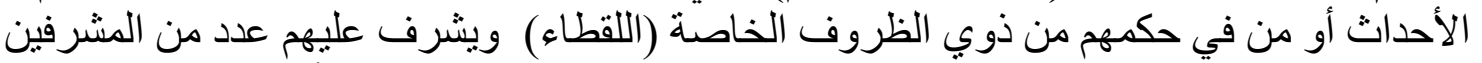

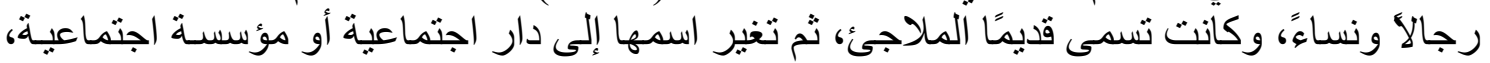

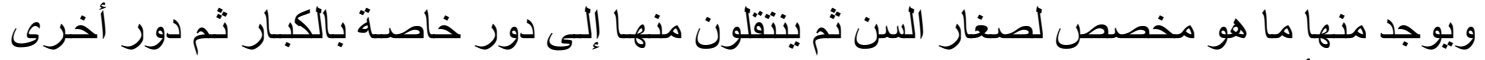

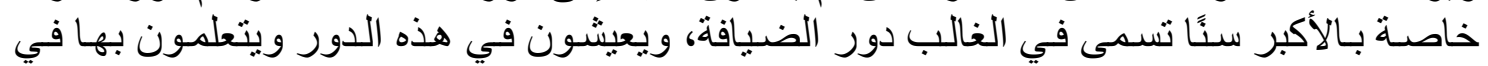

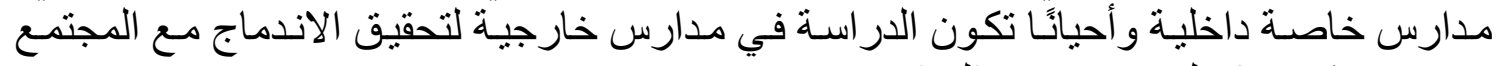
وسوف نركز هنا علي نوعين من البراهو امج: بر امج رعاية الايتام: (برنامج الأسر الكافلة. برنامج الأسر الكافلة، الرعائة الرئة الإيو ائية، الجمعيات

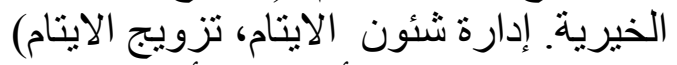

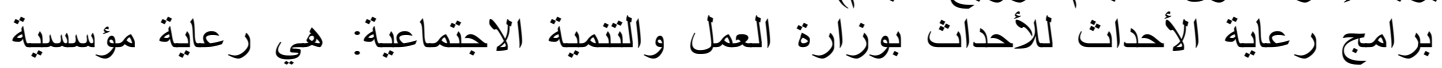

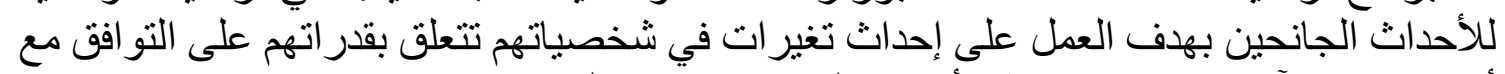

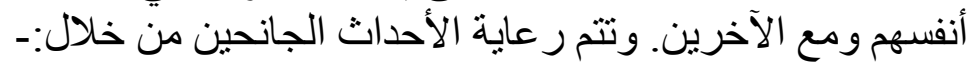
ـ ـ البر امج الوقائية لر عاية الأحداث المعرضين للانحر اف (دور التوجيه الاجتماعي). ـ البر امج العلاجية لر عاية الأحداث المنحرفين (دور الملاحظة الاجتماعية).

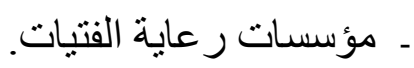

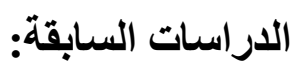

أولا: الاراسات العربية:

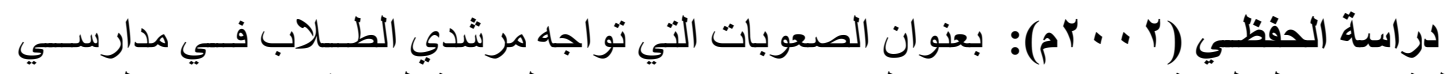

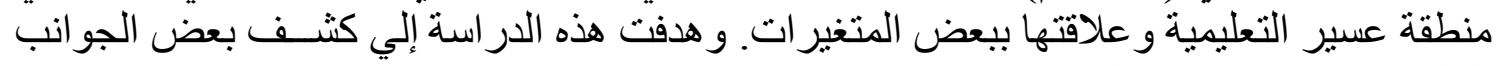

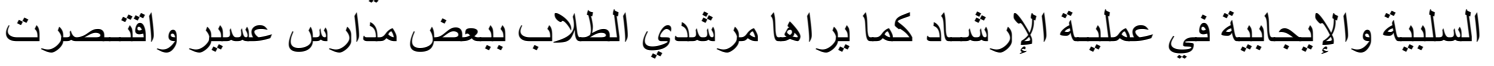

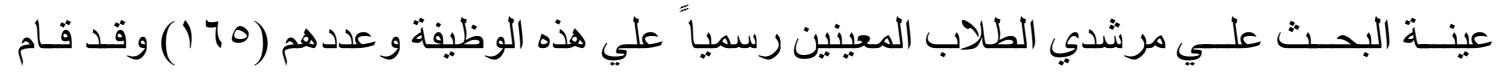

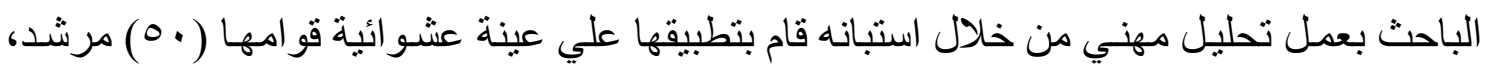

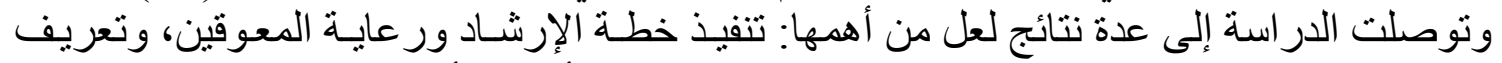

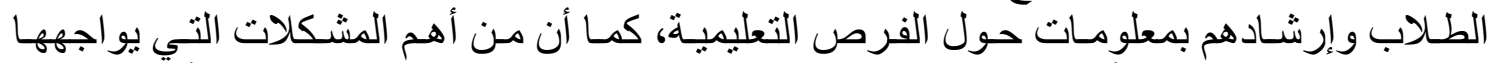

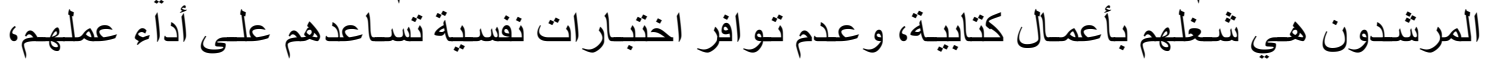

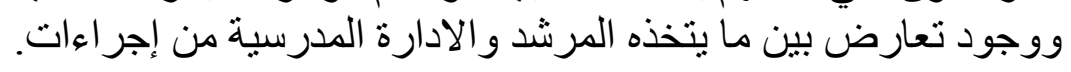

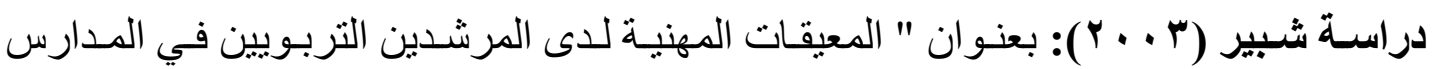

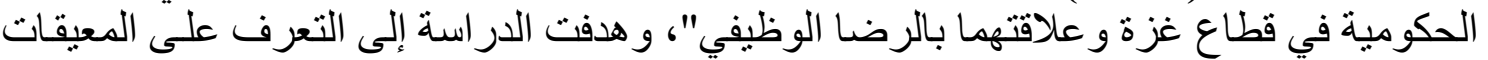

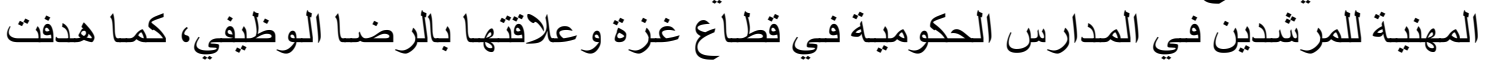

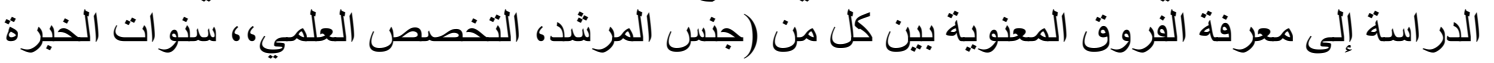

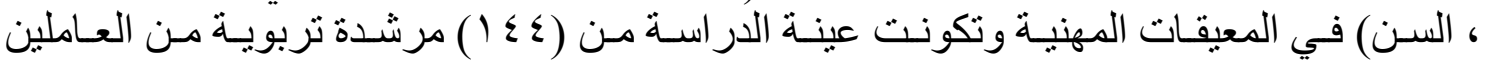
بالمدارس الحكومية، واستخدم الباحث استبانة المعيقات المهنيـة واستبانة الرضـا الوضية الوظيفي، وبينت 
النتائج أنه توجد علاقة سالبة دالة احصائيا بين الدرجة الكلية للمعيقات المهنية في حين توجد علاقة

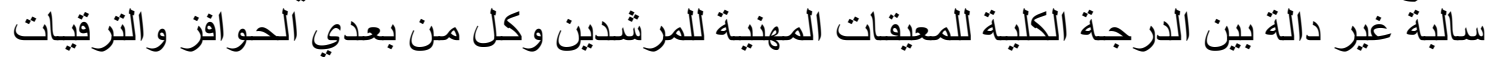
والإمكانيات.

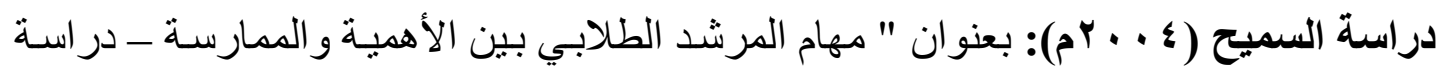

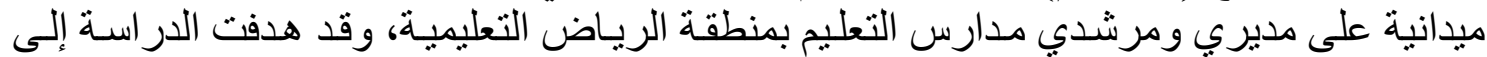

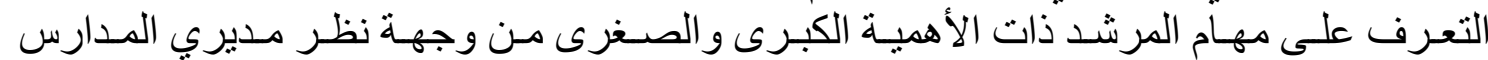

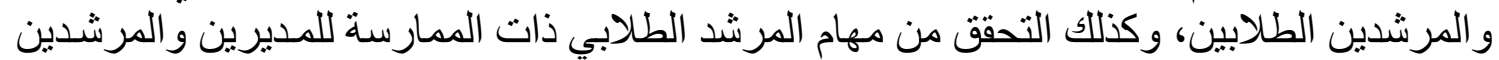

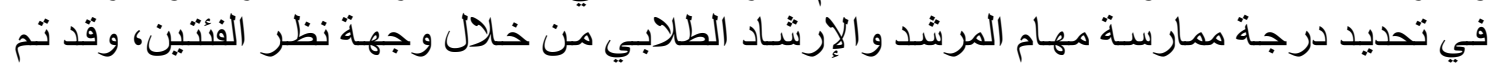
اختيار العينة بطريقة عشو ائية طبقية وكان قو امها (10 (10)، وقد صمدت استبانة من أجل تحقيق تلكي

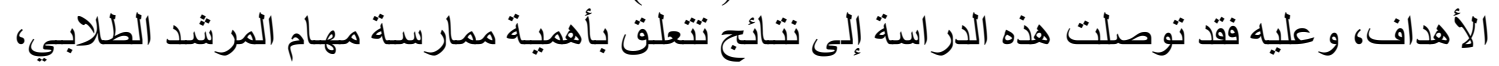

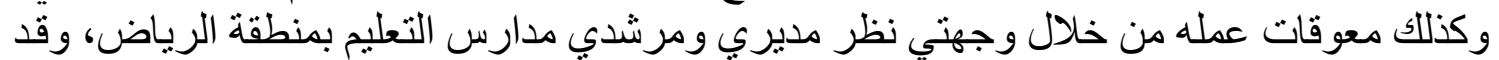

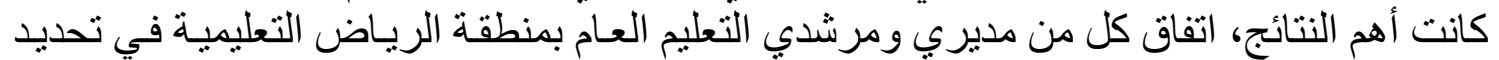

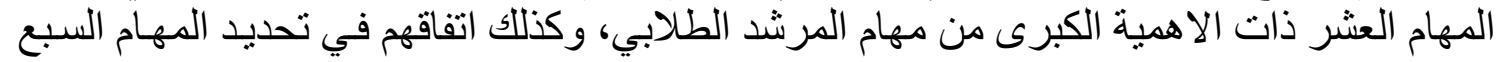

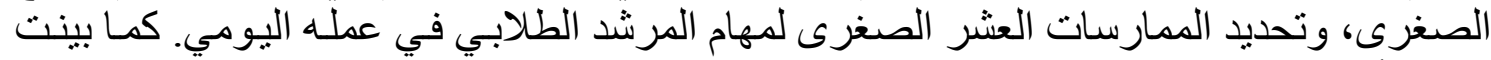
النتائج أن معظم المرشدين ليسو ا بمتخصصين في التوجية والارشاد المشئ بالمجال التعليمي.

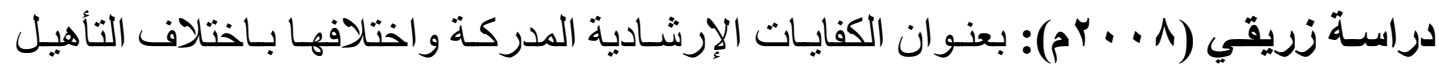

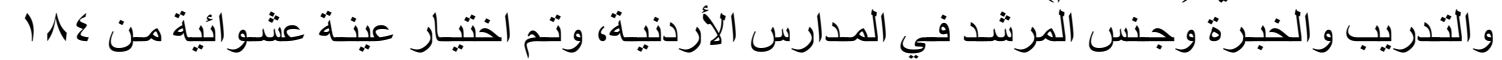

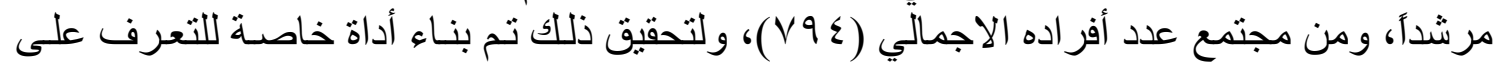

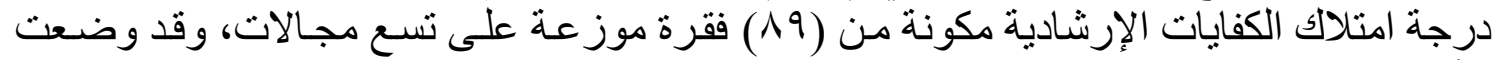

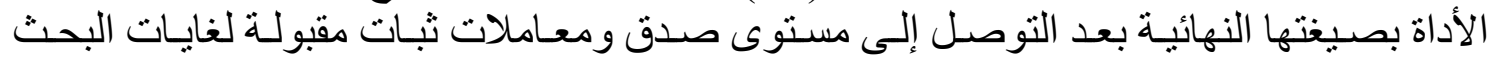

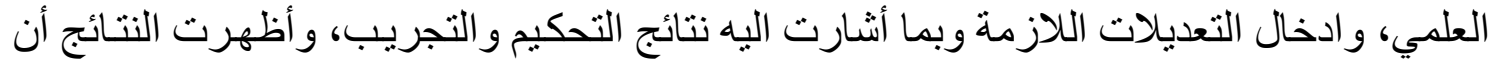

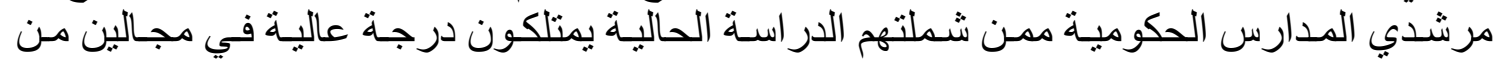

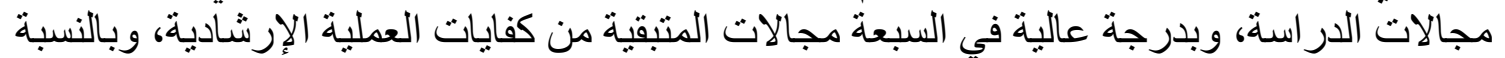

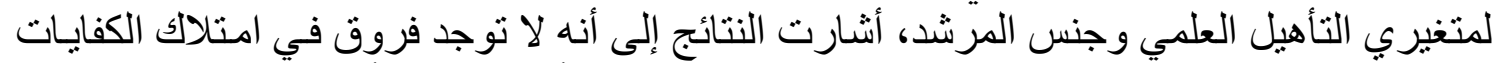

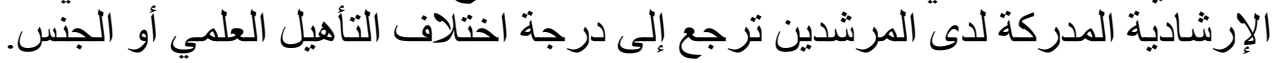
ثانيا: الاراسات الاجنبية:

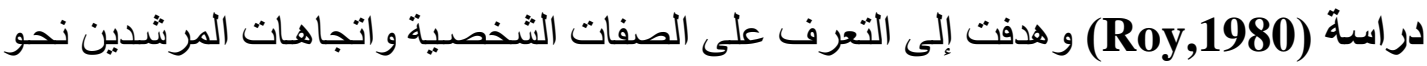

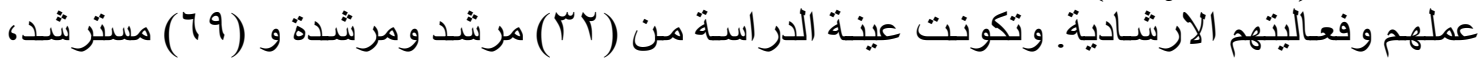

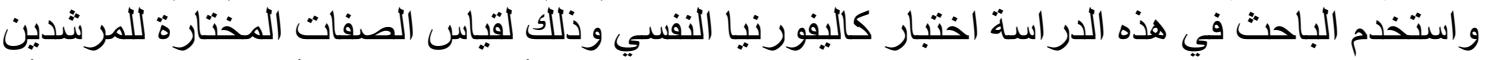

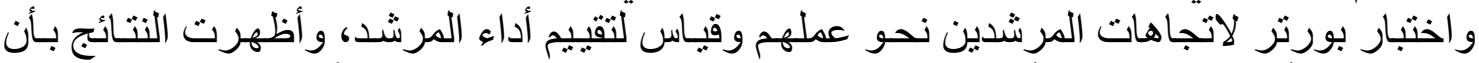

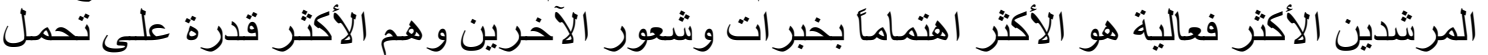

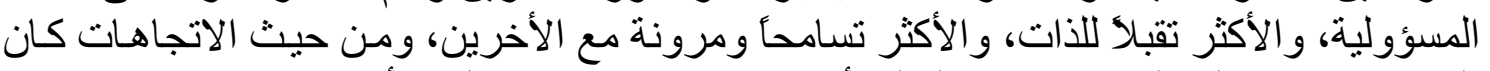

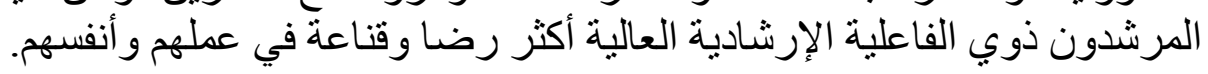

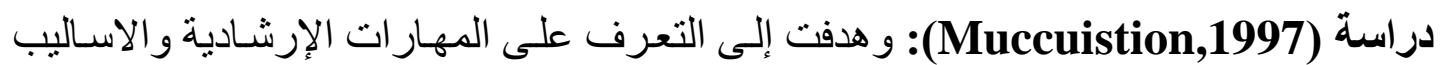

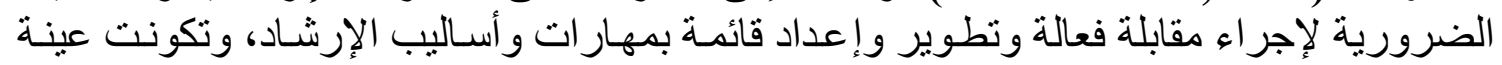

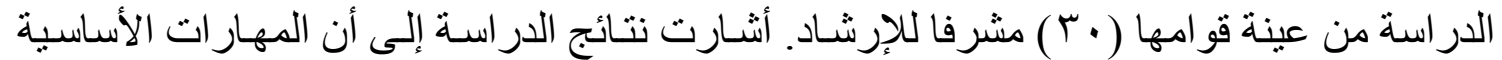

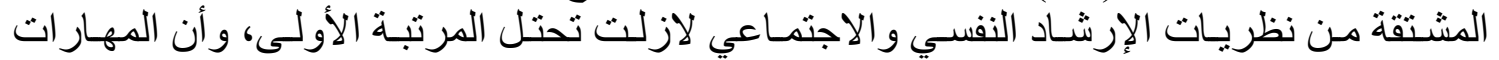

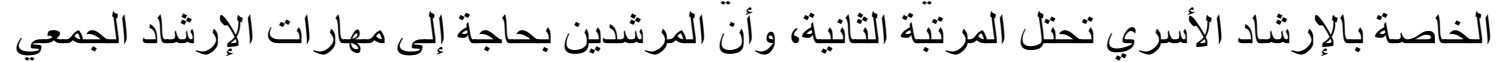
وللإرشاد متعدد الثقافات. 
دراسة (Coustantine,2001) هدفت الدراسة إلى التعرف على أثر التوجه النظري للمرشد

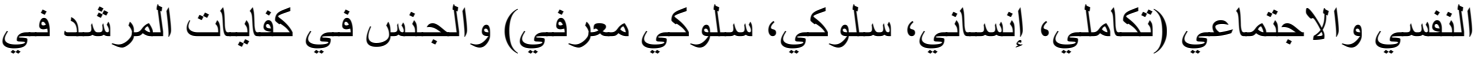

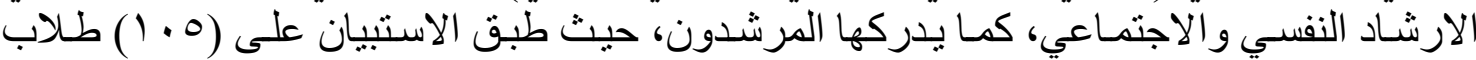

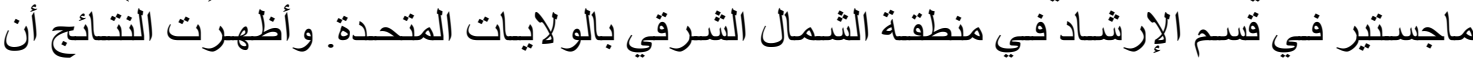

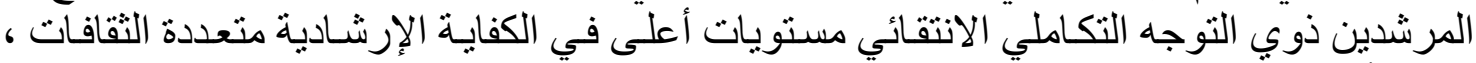
وبينت أثر لكل من متغير الجنس على كفايات المرشدين.

دراسـة (Goodnough, Rashelle \& Carolyn,2001) وهدفت الدر اسـة إلى قياس

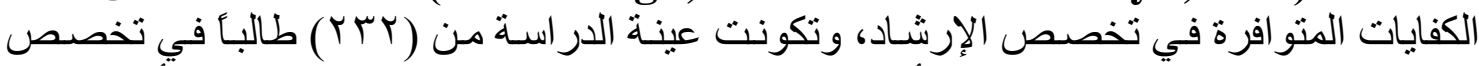

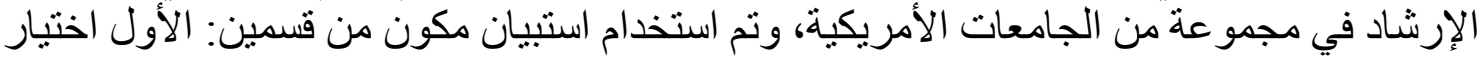

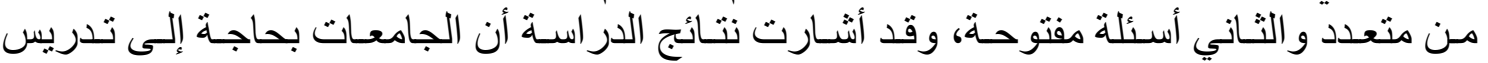

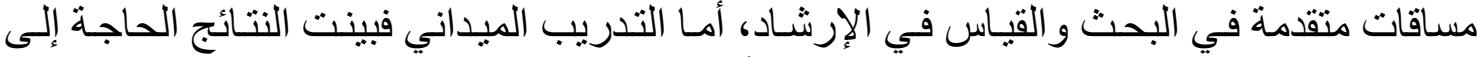
تدريب المرشدين إقامة علاقة إرشادية ومهار ات أساليب در اسة المسترشّد.

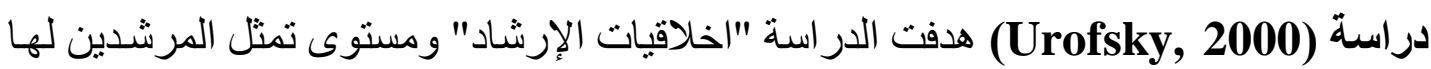

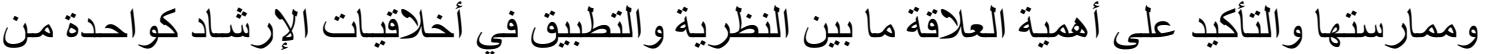

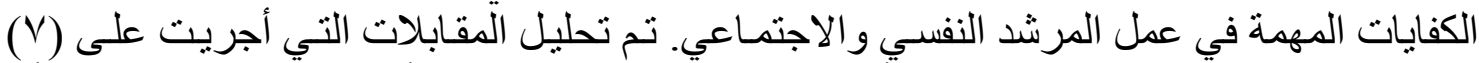

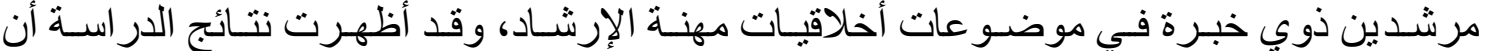

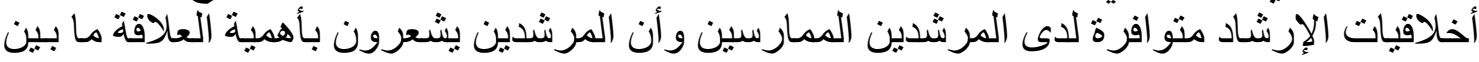
النظرية و التطبيق في أخلاقيات الإرشاد النفي النفي و الاجتماعي.

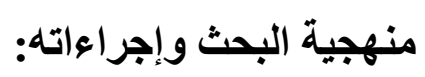

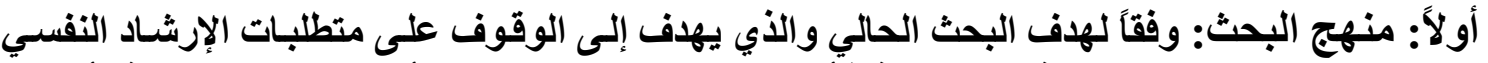

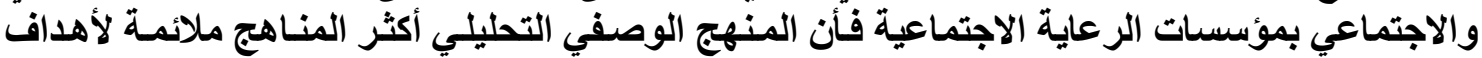

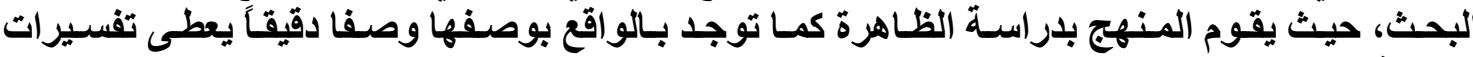

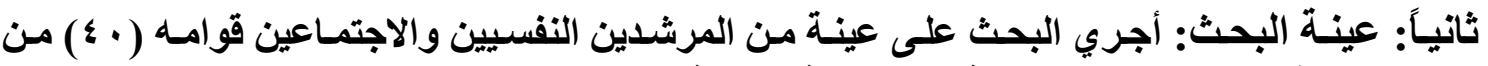
المرشدين الذكور بمؤسسات الرعاية الاجتماعية بمنطقة جازان.

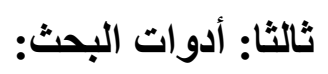

مقياس معوقات الإرشاد النفسي والاجتماعي الفعال بمؤسسات الرعاية الاجتماعية (إعداد الإداء الباحثين) ولبناء المقياس تم إتباع عدد من الخطو الات لعل من أهمها:-

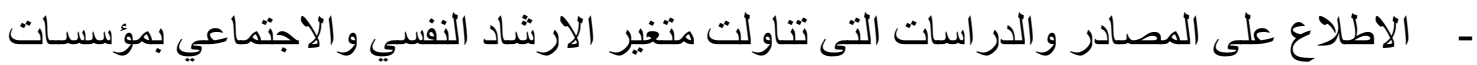

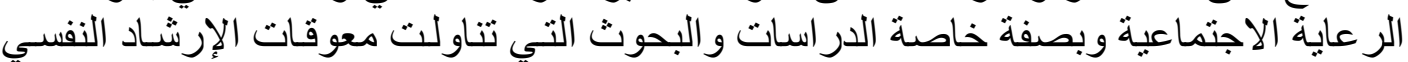

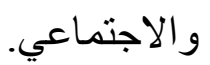

- الاطلاع على نتائج الدراسات والبحوث التي ركزت على الأبعاد الفرعية المرتبطة بمتطلبات الإرشاد النفسي و الاجتماعي.

- الاطلاع على المقاييس التى تناولت الإرشاد النفسي و الاجتماعي سو اء في صورتها الأجنيـة أو في صورتها العربية.

- تحديد الابعاد الرئيسية للمقياس و التي تمثلت في المستويات الأتية: (معوقات اداريـة بمؤسسـات

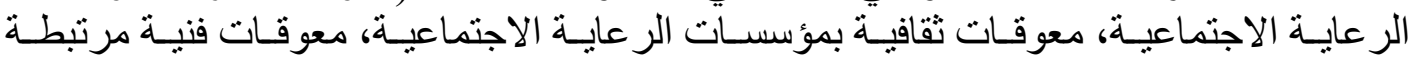


- التحقق من صدق وثبات الأداة ونم ذلك من خلال:-

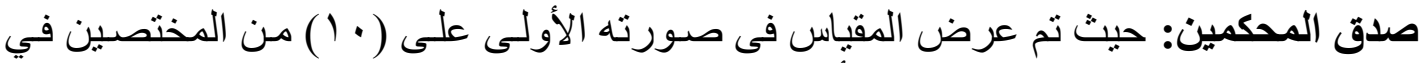

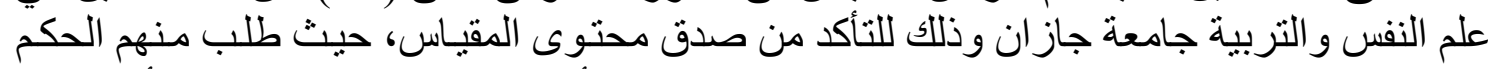

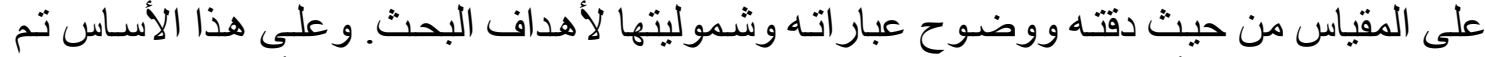

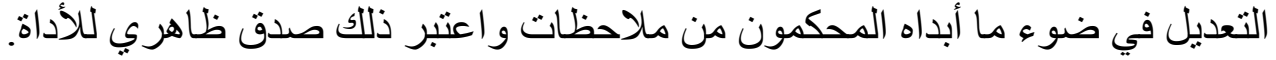

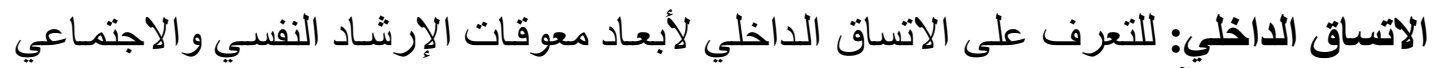

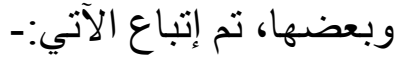
- - حساب الاتساق الداخلي بين كل مفردة لمقياس معوقات الإرشاد النفسي والاجتماعي و الدرجة

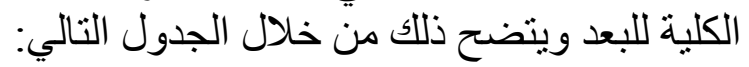
جدول () الاتساق الداخلي بين كلّ مفردة لمقياس معوقات الإرشاد النفسي والاجتماعي والارجة الكلية للبعد

\begin{tabular}{|c|c|c|c|c|c|c|c|}
\hline مستوي & الارتباط & المفردة & رقم البعد & مستوي & الارتباط & المفردة & رقبم \\
\hline$\cdot,+1$ & $\cdot, 0 \leq$ & IV & r & $\cdot,+1$ & $\cdot, 0 \wedge$ & 1 & 1 \\
\hline$\cdot, \cdot 1$ & $\cdot, 00$ & 11 & $r$ & $\cdot, \cdot 1$ & $\cdot, O V$ & r & r \\
\hline$\cdot, \cdot 1$ & $\cdot, v_{1}$ & 19 & 1 & $\cdot,+1$ & זד, • & $r$ & $r$ \\
\hline$\cdot,+1$ & ז'ד, י & $r$. & Y & $\cdot, \cdot 1$ & זד, י & $\varepsilon$ & 1 \\
\hline$\cdot, \cdot 1$ & $.7 r$ & $r_{1}$ & $r$ & $\cdot, \cdot 1$ & $\cdot, 04$ & 0 & r \\
\hline$\cdot,+1$ & $\cdot, v_{1}$ & rr & 1 & $\cdot,+1$ & $\cdot, \otimes \wedge$ & 7 & $r$ \\
\hline$\cdot, \cdot 1$ & ז'T, י & rr & r & $\cdot,+1$ & r T, • & V & 1 \\
\hline$\cdot,+1$ & צ ד, • & $r \varepsilon$ & $r$ & $\cdot, \cdot 1$ & •, OT & $\Lambda$ & r \\
\hline$\cdot,+1$ & $\cdot, V \leq$ & ro & 1 & $\cdot, \cdot 1$ & $\cdot, 7$ & 9 & $r$ \\
\hline$\cdot,+1$ & . & Y & r & $\cdot,+1$ & צ 7, & 1. & 1 \\
\hline$\cdot,+1$ & ז & YV & $r$ & $\cdot,+1$ & $\cdot, V \varepsilon$ & 11 & r \\
\hline$\cdot, \cdot 1$ & .74 & r^ & 1 & $\cdot,+1$ & $\cdot, \otimes \wedge$ & Ir & $r$ \\
\hline$\cdot,+1$ & $\cdot, v_{1}$ & rq & r & $\cdot, \cdot 1$ & $\cdot, v 1$ & $1 T$ & 1 \\
\hline$\cdot, \cdot 1$ & צ' & $r$. & $r$ & $\cdot, \cdot 1$ & ז & $1 \varepsilon$ & r \\
\hline$\cdot,+1$ & .,Or & ${ }_{1}$ & 1 & $\cdot,+1$ & .94 & 10 & $r$ \\
\hline & & & & & & 17 & 1 \\
\hline
\end{tabular}

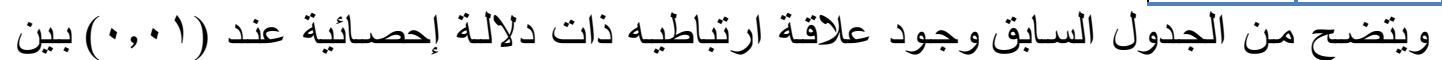

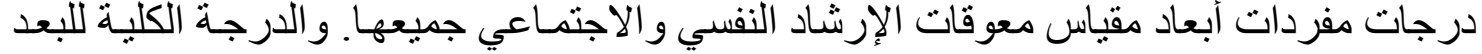

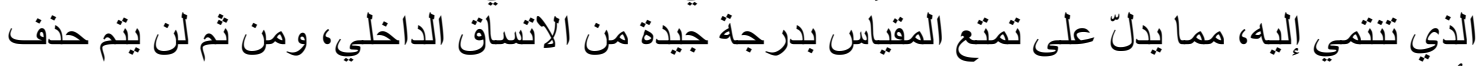
أي مفردة من مفردات المقياس.

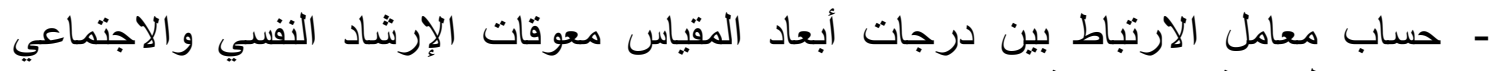
بمؤسسات الر عاية الاجتماعية وبعضها:- 
جدول رقم (r) الاتساق الداخلي بين للأبعاد الفرعية لمقياس معوقات الإرشاد النفسي والاجتماعي

\begin{tabular}{|c|c|c|c|}
\hline$r$ & $r$ & 1 & أبعاد المقياس \\
\hline & & - & البعد الاول \\
\hline & - & $* *, 0 T$ & البعد الثاني \\
\hline - & $* \cdot, \varepsilon Y$ & $* *,, \leqslant\rceil$ & البعد الثالث \\
\hline
\end{tabular}

وبالنظر في نتائج الجدول السابق نلاحظ وجود علاقة ارتباطية دالة عند مستوى ( ال . • •) بين

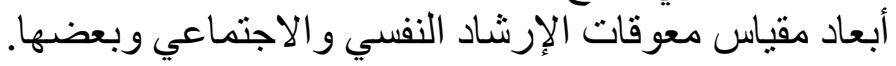

(ج) ثبات المقياس: تم حساب معاملات ثبات مقياس معوقات الإرشاد النفسي والاجتماعي بطريقة

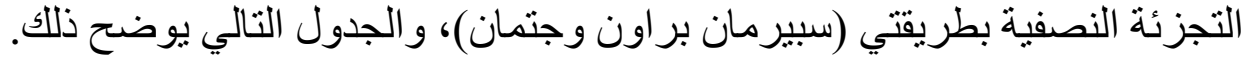
جدول ( \&) معامل الثبات لأبعاد مقياس معوقات الإرشاد النفسي والاجتماعي وني

\begin{tabular}{|c|c|c|}
\hline \multicolumn{2}{|c|}{ معامل الثبات بطريقة التجزئة النصفية } & \multirow[t]{2}{*}{ أبعاد مقياس } \\
\hline 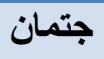 & سبيرمان وبراون & \\
\hline$\cdot, \mathrm{Vr}$ & $\cdot, 7 r$ & البعد الاول \\
\hline $.7 \varepsilon$ & 每 & البعد الثاني \\
\hline .07 & $\cdot, v_{1}$ & البعد الثالث \\
\hline
\end{tabular}

يتضح من نتائج الجدول السابق تمتع أبعاد مقياس معوقات الإرشاد النفسي والاجتماعي بدرجة مقبولة من الثبات وموثوق بها، تجعلنا نطمئن على ثبات المقياس وتطبيقه على عينة البحث الحئ الحالي.

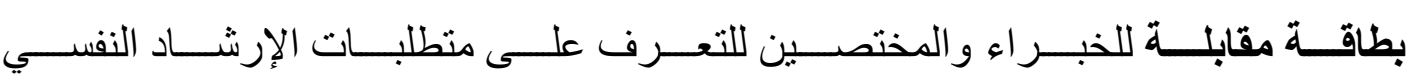

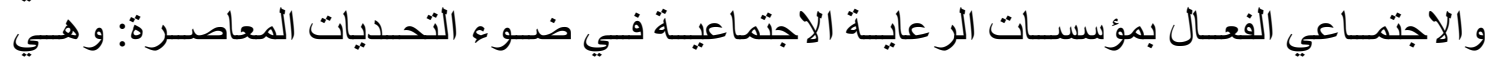

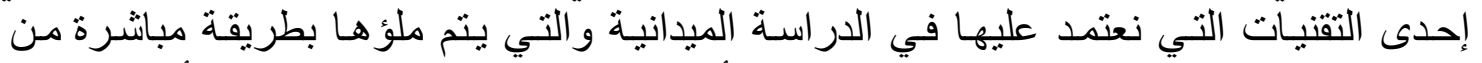

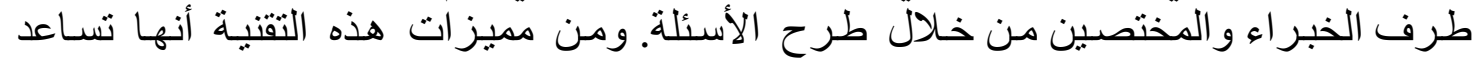

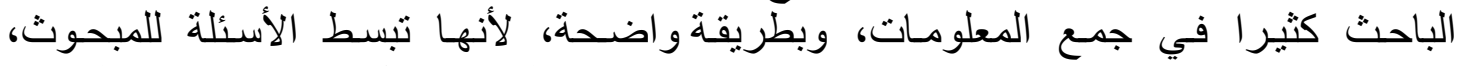

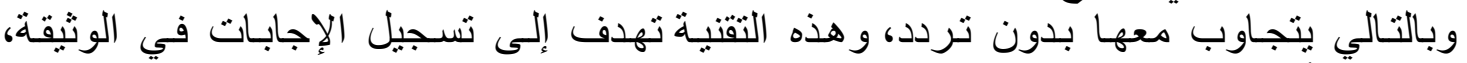

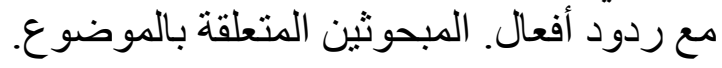

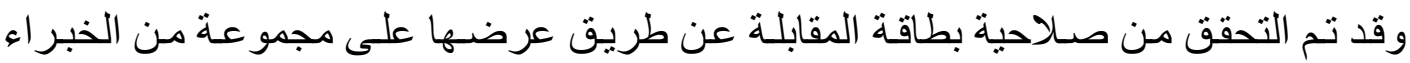

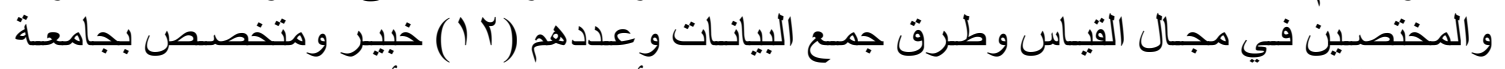

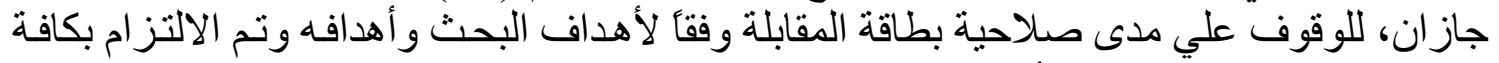

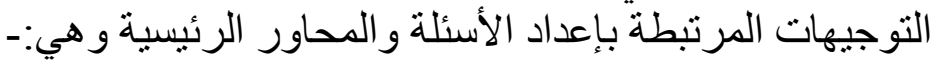

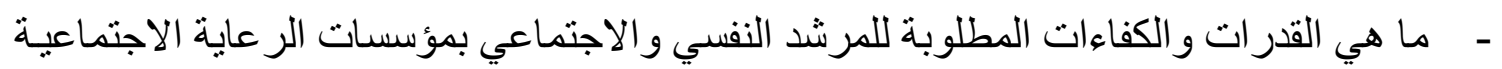
بمنطقة جاز ان؟ مان - مـا هي مهام المرشـد النفسي والاجتمـاعي بمؤسسـات الرعايـة الاجتماعيـة بمنطقة جـاز ان في

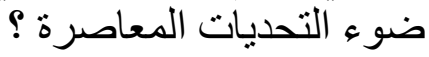
- ماهي مهار ات المرشد النفسي والاجتماعي بمؤسسات الرعاية الاجتماعية في ضوء التحديات المعاصرة ؟ ـ ماهي الاخلاقيات المهنية الو اجب تو افر ها في المرشـ النفسي و الاجتمـاعي بمؤسسـات الرعايـة الاجتماعية الاجية 


\section{نتائج البحث:}

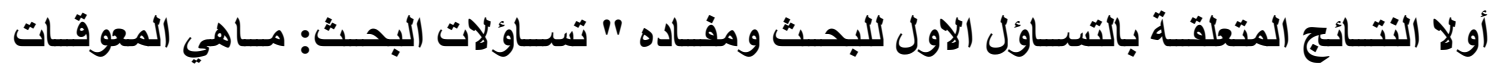

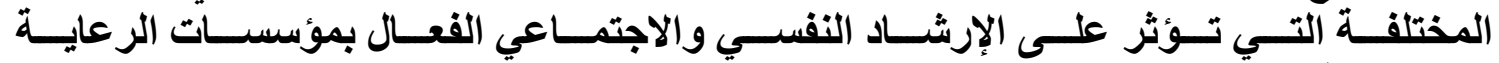

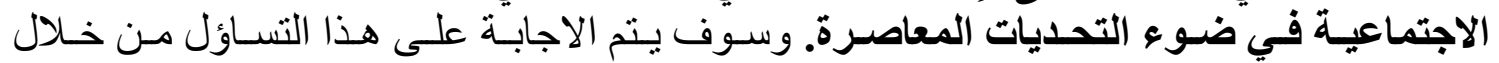

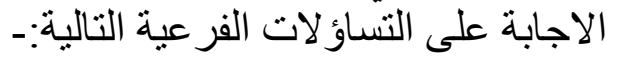

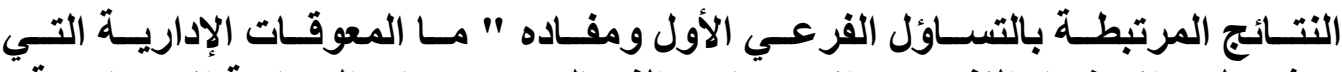

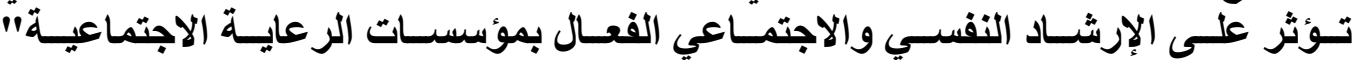

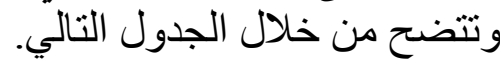

جدول رقم () يبين استجابات عينة الدراسة من المرشدين النفسيين والاجتماعية تجاه التساؤل الفرعي

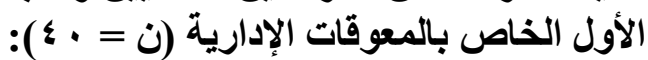

\begin{tabular}{|c|c|c|c|c|c|c|}
\hline \multirow{2}{*}{ الترتيب } & \multirow{2}{*}{ SL } & \multirow{2}{*}{ 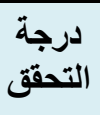 } & \multicolumn{3}{|c|}{ الاستجابات } & \multirow{2}{*}{ العبارة } \\
\hline & & & 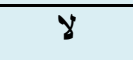 & إلى حد ما & نعم & \\
\hline \multirow{3}{*}{$r$} & \multirow{3}{*}{ rY,IT } & \multirow{3}{*}{ Y, $\leqslant 1$} & 11 & $r$ & צ & 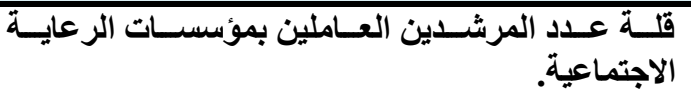 \\
\hline & & & $\%$ YV,1 & $\% 0^{0, \xi}$ & $\%$ \% & النسبة المئوية \% \\
\hline & & &., .0 & $\cdot, \cdot r$ &., .0 & الوزن النسبى \\
\hline \multirow{3}{*}{9} & \multirow{3}{*}{$r \checkmark, \wedge \wedge$} & \multirow{3}{*}{$1, \leqslant 0$} & $\wedge$ & ؛ & rı & 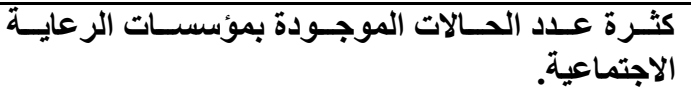 \\
\hline & & & $\% 19$ & $\% \wedge$ & $\% \vee r$ & النسبة المئوية \% \\
\hline & & & $\cdot, \cdot r$ & $\cdot, \cdot r$ &., .0 & الوزن النسبى \\
\hline \multirow{3}{*}{ r } & \multirow{3}{*}{17,97} & \multirow{3}{*}{$r, \varepsilon r$} & 9 & 7 & ro & 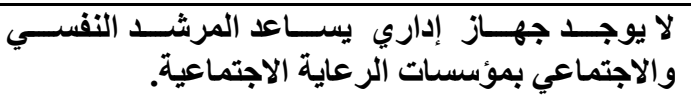 \\
\hline & & & $\%$ \% l,0 & $\% 1 r, 0$ & $\% 90$ & النسبة المئوية \% \\
\hline & & & $\cdot, \cdot \varepsilon$ &., .0 & $\cdot, \cdot \varepsilon$ & الوزن النسبى \\
\hline \multirow{3}{*}{$\varepsilon$} & \multirow{3}{*}{$11, \leqslant \pi$} & \multirow{3}{*}{$r, \mu v$} & rr & $\wedge$ & 9 & الرعاية الاجتماعية. بالاسترار الوظيفي للعمل فى مؤسســات \\
\hline & & & $\% \bullet 9,0$ & $\%{ }^{19}$ & $\% \%^{Y}, 0$ & النسبة المئوية \% \\
\hline & & & $\cdot, 11$ & $\cdot, \cdot V$ & $\cdot, \cdot 1$ & الوزن النسبى \\
\hline \multirow{3}{*}{1} & \multirow{3}{*}{$r \cdot, 9 \varepsilon$} & \multirow{3}{*}{ Y,0 } & $\wedge$ & $r$ & rq & 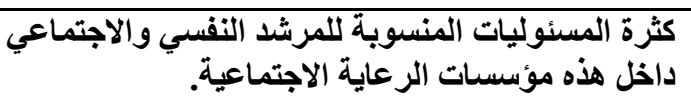 \\
\hline & & & $\% 19,0$ & $\% 0^{0}$ & $\% \vee 0,0$ & النسبة المئوية \% \\
\hline & & & $\cdot, \cdot r$ & $\cdot, \cdot r$ & $\cdot, .0$ & الوزن النسبى \\
\hline \multirow{3}{*}{7} & \multirow{3}{*}{$1 \leqslant, O r$} & \multirow{3}{*}{$1, \pi$} & 1. & 9 & $r \varepsilon$ & بالنواحى إلإدارية. بعض المرشــين النفسيين والاجتمـاعيين \\
\hline & & & $\% r \leqslant, 0$ & $\%$ \%'r,0 & $\%$ & النسبة المئوية \% \\
\hline & & & $\cdot, \cdot \varepsilon$ & $\cdot, .0$ & $\cdot, \cdot \xi$ & الوزن النسبى \\
\hline \multirow[t]{2}{*}{0} & \multirow[t]{2}{*}{11,87} & \multirow[t]{2}{*}{$1,7 \varepsilon$} & 1. & $v$ & r & 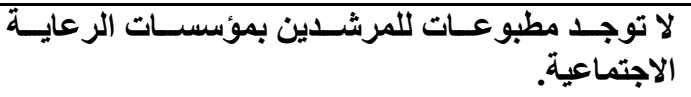 \\
\hline & & & $\% r \leqslant, 0$ & $\% 19$ & $\% 09,0$ & |النسبة المئوية \% \\
\hline
\end{tabular}




\begin{tabular}{|c|c|c|c|c|c|c|}
\hline \multirow{3}{*}{ الترتيب } & \multirow{3}{*}{ SL } & \multirow{3}{*}{ التحقق } & \multicolumn{3}{|c|}{ الاستجابات } & \multirow{2}{*}{ 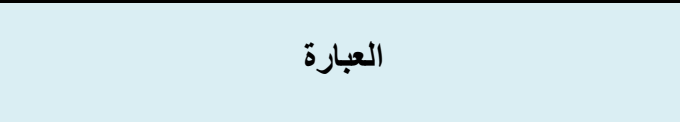 } \\
\hline & & & 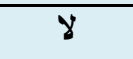 & إلى حد ما & 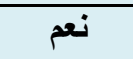 & \\
\hline & & & $\cdot, \cdot \varepsilon$ & $\cdot, .9$ & $\cdot, \cdot \varepsilon$ & الوزن النسبى \\
\hline \multirow{3}{*}{ V } & \multirow{3}{*}{$r \cdot, r$} & \multirow{3}{*}{$1,0 \leqslant$} & 9 & $\bullet$ & Y & 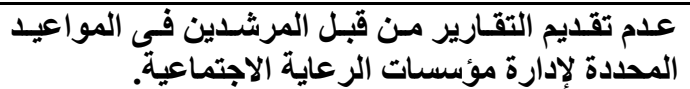 \\
\hline & & & $\%$ \%, & $\% 11,0$ & $\%$ & النسبة المئوية \% \\
\hline & & & $\cdot, \cdot \varepsilon$ & $\cdot, \cdot \xi$ & $\cdot, .0$ & الوزن النسبى \\
\hline \multirow{3}{*}{$\wedge$} & \multirow{3}{*}{$r r, v q$} & \multirow{3}{*}{1,01} & 9 & $\varepsilon$ & rV & النفسي والمرشد الاجتماعي. تصدئوليات بين كل من المرشد \\
\hline & & & $\%{ }^{Y}$ & $\%^{\wedge} \wedge$ & $\%^{\vee}$. & النسبة المئوية \% \\
\hline & & & $\cdot, \cdot \varepsilon$ & $\cdot, \cdot r$ & $\cdot, .0$ & الوزن النسبى \\
\hline \multirow{3}{*}{$r$} & \multirow{3}{*}{$1 \leqslant, \cdot r$} & \multirow{3}{*}{$r, \leqslant 1$} & 9 & V & $r \varepsilon$ & دور الإرشـاد النفسي والداجتماعي.ت الرعايـة الاجتماعية لأهمية \\
\hline & & & $\%$ \%Y & $\% 17$ & $\%$ & النسبة المئوية \% \\
\hline & & & $\cdot, \cdot \varepsilon$ & $\cdot, .9$ & $\cdot, \cdot \varepsilon$ & الوزن النسبى \\
\hline \multirow{3}{*}{0} & \multirow{3}{*}{$11, V^{\prime}$} & \multirow{3}{*}{$1,7 \varepsilon$} & 1. & v & r & مع المسترشدين. أماكن مخصصة ومجهزة لإجراء المقابلات \\
\hline & & & $\% r \leqslant, 0$ & $\% 19$ & $\% 09,0$ & النسبة المئوية \% \\
\hline & & & $\cdot, \cdot \varepsilon$ & $\cdot, .9$ & $\cdot, \cdot \varepsilon$ & الوزن النسبى \\
\hline \multirow{3}{*}{ r } & \multirow{3}{*}{$r, \cdot r$} & \multirow{3}{*}{$r, \varepsilon r$} & 1. & $\varepsilon$ & r & الرعام وجـود واعتية. دينـى بين فريق العمل بمؤسســات \\
\hline & & & $\% r \leqslant, 0$ & $\%$ & $\%$ \%V & النسبة المئوية \% \\
\hline & & & $\cdot, \cdot \varepsilon$ & $\cdot, \cdot r$ & $\cdot, .0$ & الوزن النسبى \\
\hline
\end{tabular}

\section{ويالنظر إلى نتائج الجدول السابق يتضح لنا عدة نتائج لعل من أهمها:-}

- توجد فروق ذات دلالة إحصائية بين استجابات المرشدين النفسيين والاجتمـاعيين حول كثرة

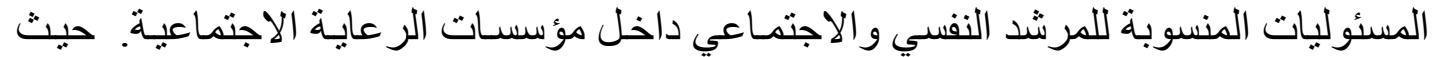

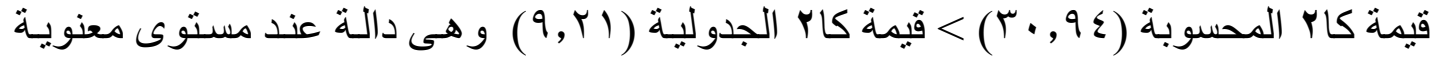

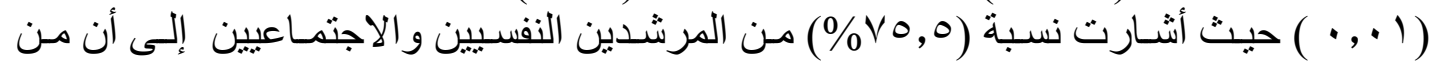

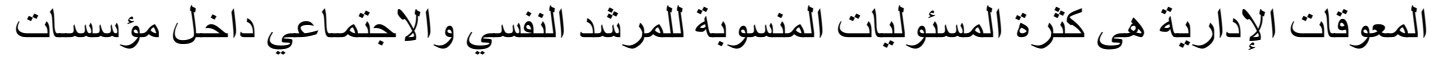

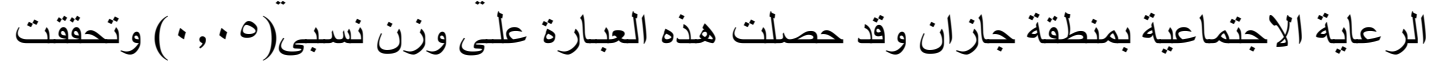

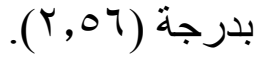

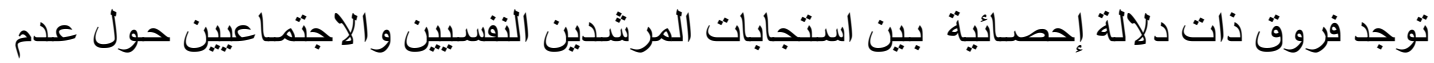

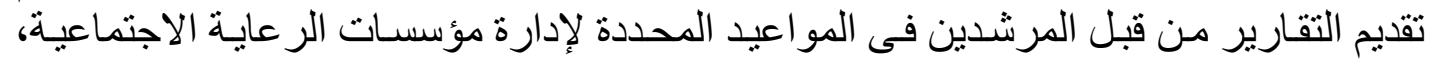

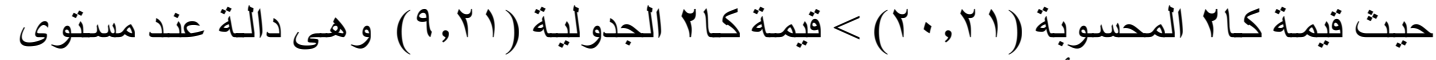

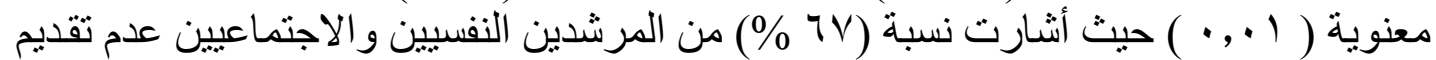

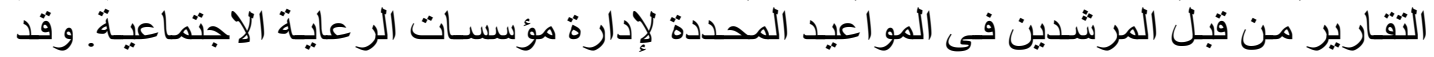

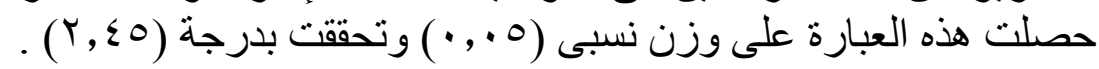




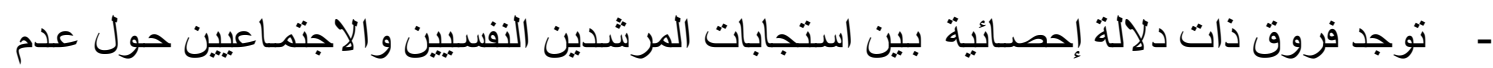

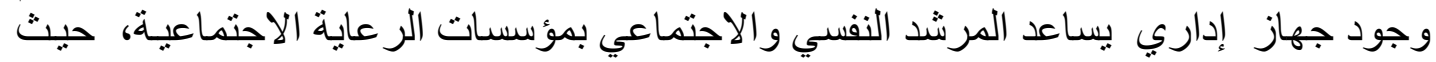

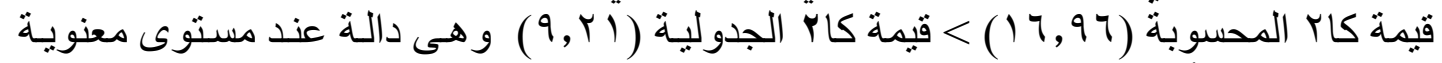

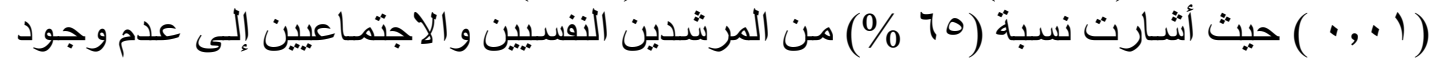

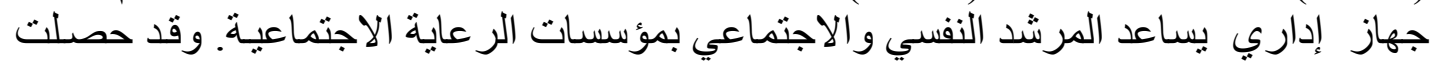

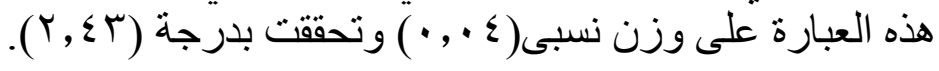

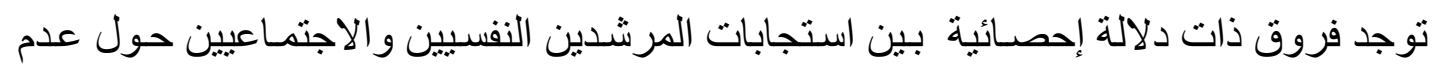

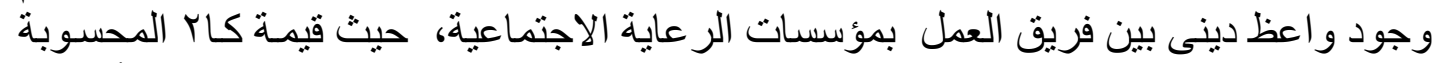

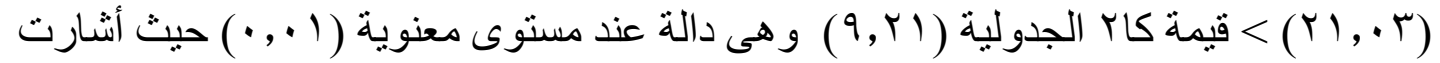

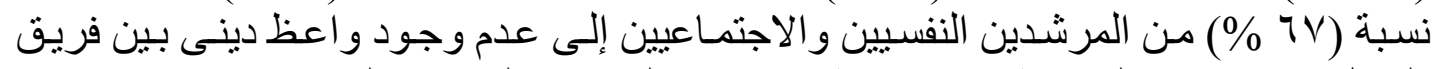

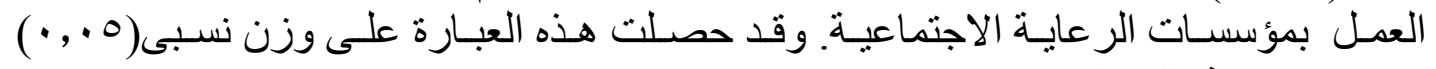

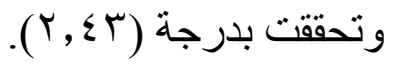

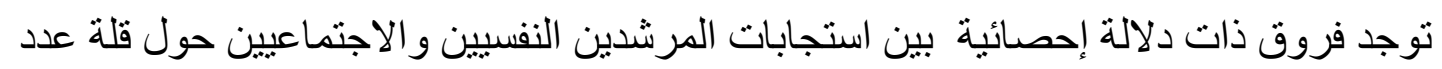

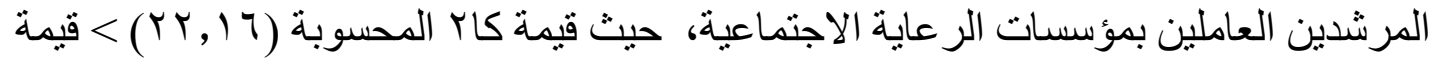

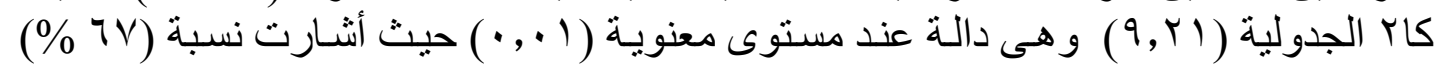

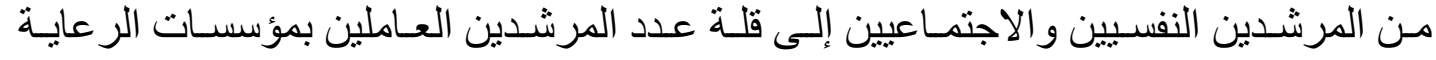

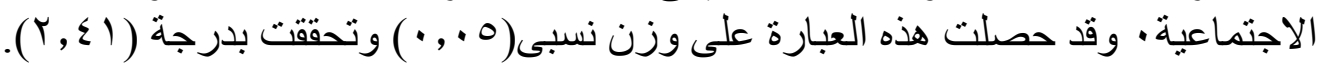

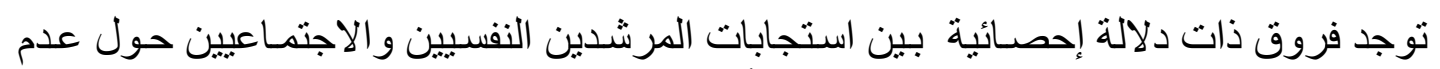

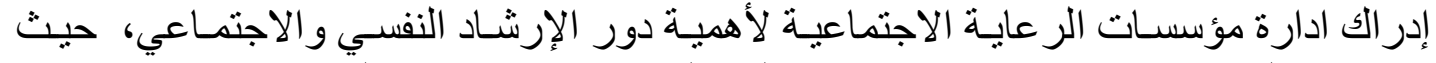

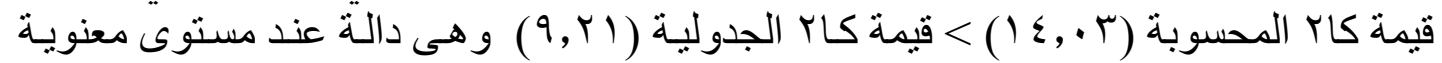

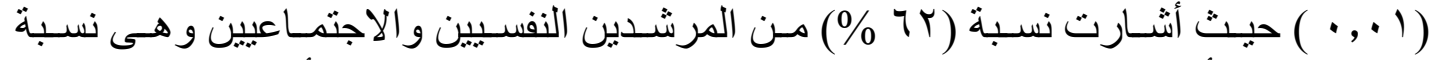

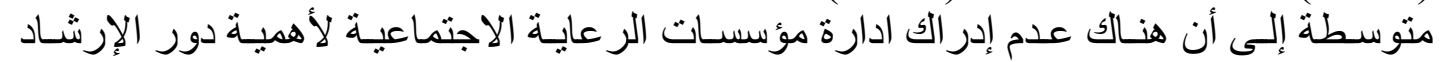

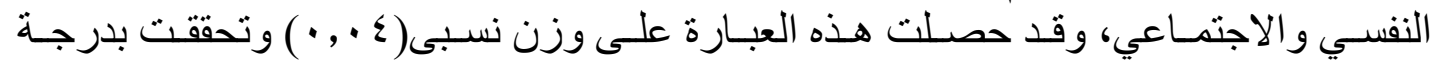

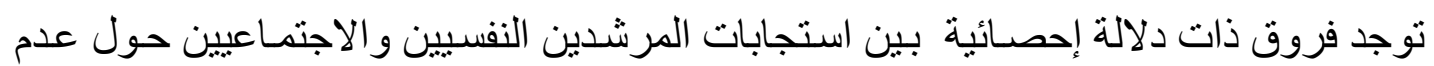

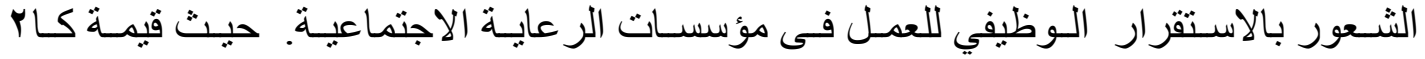

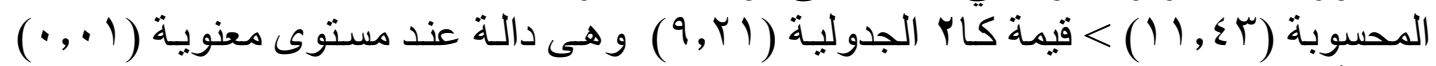

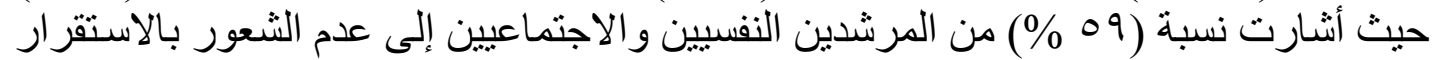

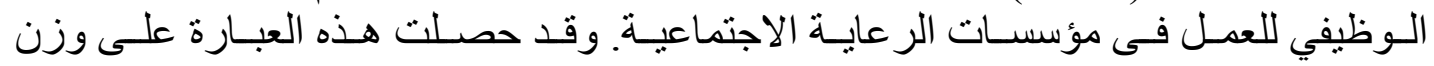

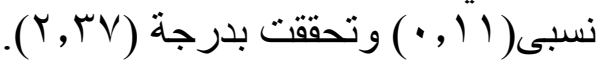

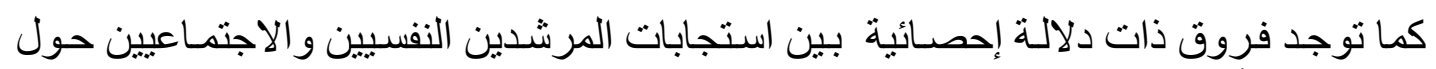

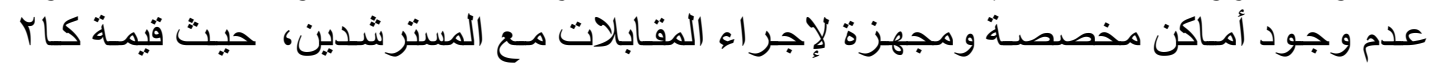

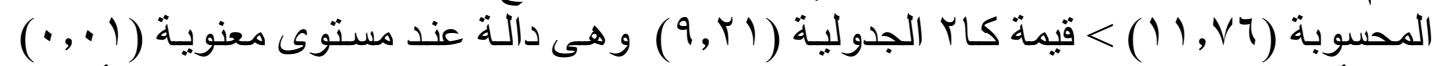

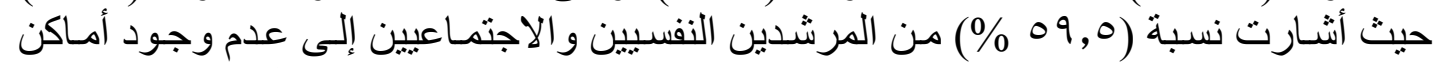

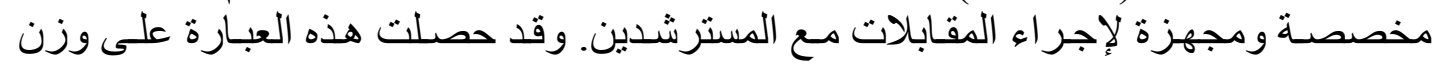

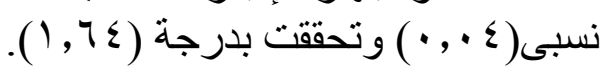




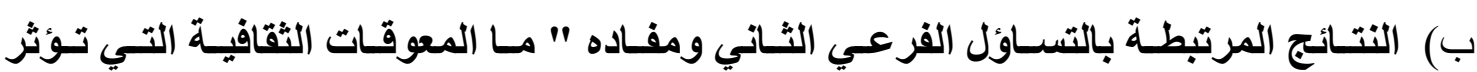

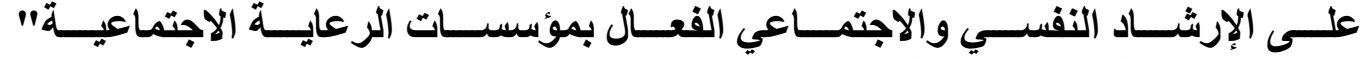

وتتضح من خلال نتائج الجدول التالي.

جدول رقم () ويوضح استجابات عينة الدراسة من المرشدين النفسيين والاجتماعية تجاه التساؤل الفرعي الثاني الخاص بالمعوقات الثة الثقافية (ن= - ع ع).

\begin{tabular}{|c|c|c|c|c|c|c|}
\hline \multirow{2}{*}{ الترتيب } & \multirow{2}{*}{ SL } & \multirow{2}{*}{ 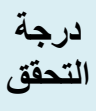 } & \multicolumn{3}{|c|}{ الاستجابات } & \multirow{2}{*}{ العبارة } \\
\hline & & & $\gamma$ & إلى حد ما & نعم & \\
\hline \multirow{3}{*}{1} & \multirow{3}{*}{ rq,१V } & \multirow{3}{*}{ Y, Tะ } & 0 & 7 & rq & 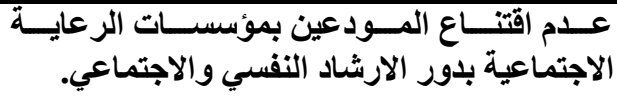 \\
\hline & & & $\% \backslash 1$ & $\% / r, 0$ & $\% \vee \theta, \theta$ & النسبة المئوية \% \\
\hline & & & •,,$\xi$ &., .9 & $\cdot, \cdot \Lambda$ & الوزن النسبى \\
\hline \multirow{3}{*}{ r } & \multirow{3}{*}{$r \varepsilon, O r$} & \multirow{3}{*}{$r, T r$} & v & $r$ & $r$. & بعض التأثير على المرشين وكسب النفسيدي والاجتمـاعي من قبل \\
\hline & & & $\% \backslash V$ & $\% 0$ & $\% \vee \wedge$ & النسبة المئوية \% \\
\hline & & &., .7 & $\cdot, \cdot r$ & $\cdot, \cdot 1$ & الوزن النسبى \\
\hline \multirow{3}{*}{$r$} & \multirow{3}{*}{$r \cdot, r_{1}$} & \multirow{3}{*}{$r, \leqslant 0$} & v & 0 & Y & الإرشـادية. أطـراف أخـرى يـوئثر سـلباً علـى العمليـة \\
\hline & & & $\%^{Y Y}$ & $\% 11$ & $\%$ \%V & النسبة المئوية \% \\
\hline & & & $\cdot, \cdot \wedge$ & $\cdot, \cdot V$ & $\cdot, \cdot V$ & الوزن النسبى \\
\hline \multirow{3}{*}{$\wedge$} & \multirow{3}{*}{ rᄉ, 11} & \multirow{3}{*}{$1, r V$} & $\varepsilon$ & 0 & $\mu$ & عن طريق البعض إخفاء بعضل المرشلو النفسي والاجتمـاعي \\
\hline & & & $\% \wedge$ & $\% 11$ & $\%^{\wedge 1}$ & النسبة المئوية \% \% \\
\hline & & & $\cdot, \cdot r$ & $\cdot, \cdot V$ & $\cdot, \cdot 1$ & الوزن النسبى \\
\hline \multirow{3}{*}{0} & \multirow{3}{*}{$11, V^{4}$} & \multirow{3}{*}{$1, v_{0}$} & ir & 0 & rr & من الحالات الفردية. \\
\hline & & & $\%$ \%Y & $\% \backslash 1$ & $\% \circ \mathrm{V}$ & النسبة المئوية \% \\
\hline & & & $\cdot, 1 Y$ & $\cdot, \cdot V$ &., .9 & الوزن النسبى \\
\hline \multirow{3}{*}{7} & \multirow{3}{*}{$19, V Y$} & \multirow{3}{*}{$1, \leqslant 0$} & 7 & $\Lambda$ & צ & 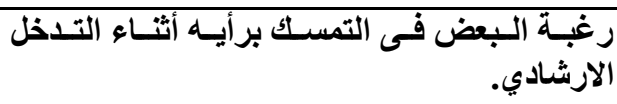 \\
\hline & & & $\%$ \% & $\%{ }^{19}$ & $\%$ TV & النسبة المئوية \% \\
\hline & & & $\cdot, .0$ & $\cdot, 1 T$ & $\cdot, \cdot v$ & الوزن النسبى \\
\hline \multirow{3}{*}{ V } & \multirow{3}{*}{$r r, \wedge v$} & \multirow{3}{*}{$1, r r$} & 0 & 0 & $r$. & 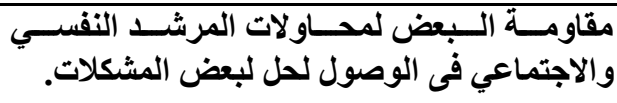 \\
\hline & & & $\% 11$ & $\% \backslash 1$ & $\% \vee \wedge$ & النسبة المئوية \% \\
\hline & & & $\cdot, \cdot \varepsilon$ & $\cdot, \cdot V$ & $\cdot, \cdot r$ & الوزن النسبى \\
\hline$\varepsilon$ & $1 ., \leq 4$ & 1,11 & $1 \varepsilon$ & 0 & rl & 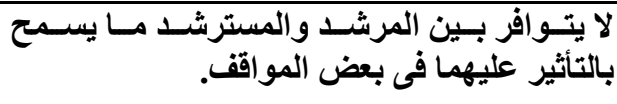 \\
\hline
\end{tabular}




\begin{tabular}{|c|c|c|c|c|c|c|}
\hline \multirow{4}{*}{ الترتيب } & \multirow{2}{*}{ كاr } & \multirow{2}{*}{ التحقق } & \multicolumn{3}{|c|}{ الاستجابات } & \multirow{2}{*}{ العبارة } \\
\hline & & & ע & إلى حد ما & نعم & \\
\hline & & & $\%$ ro & $\% 11$ & $\% 0 \leq$ & النسبة المئوية \% \\
\hline & & & $\cdot, 1 T$ & $\cdot, \cdot v$ & $\cdot, .0$ & الوزن النسبى \\
\hline
\end{tabular}

باستقراء بيانات الجدول السابق يتضح عدة نتائج كان من أهمها:

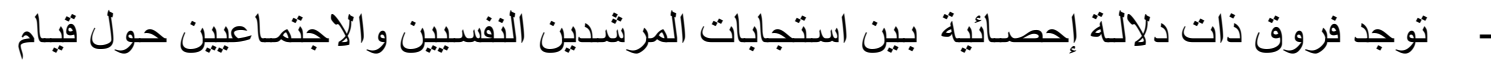

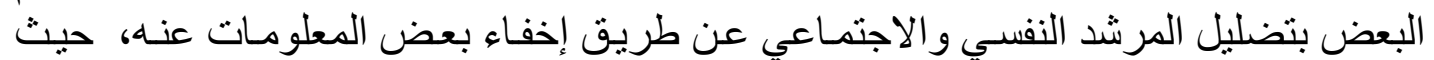

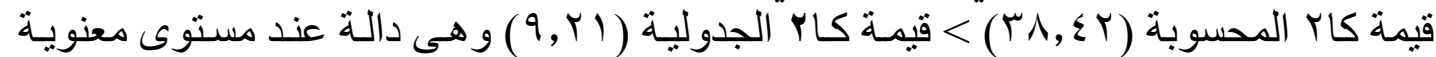

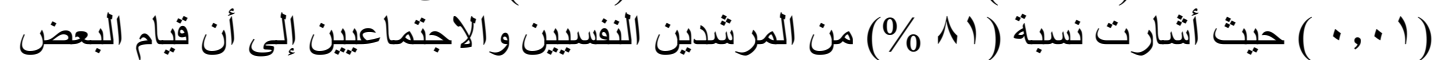

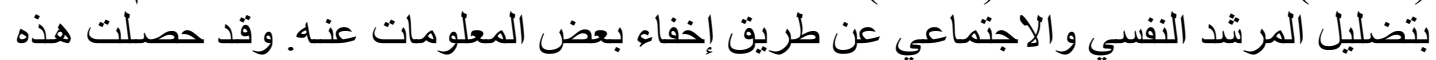

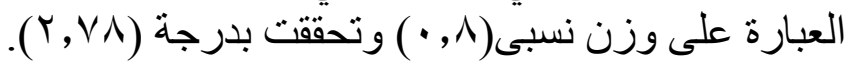

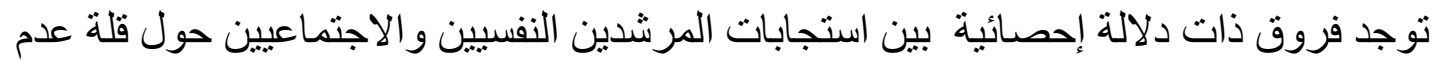

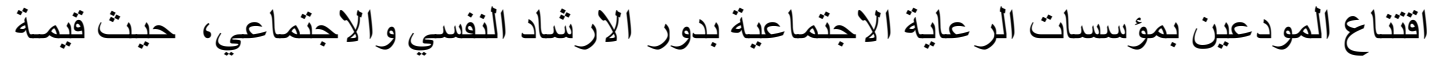

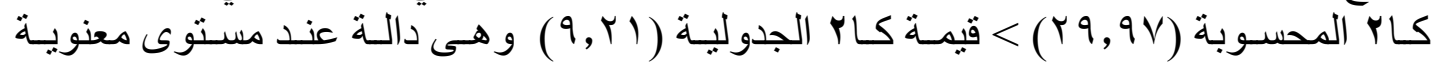

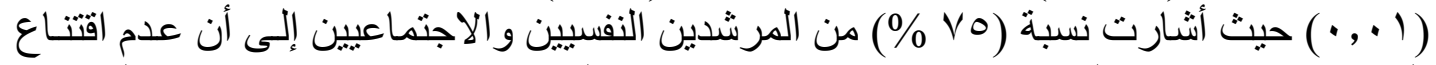

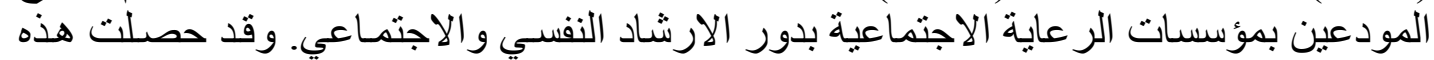

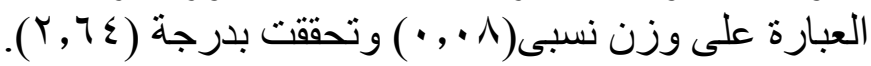

توجد فروق ذات دلالة إحصائية بين استجابات المرشدين النفسيين والاجتمـاعيين حول ولئ التأثير

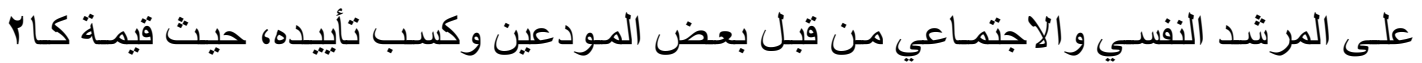

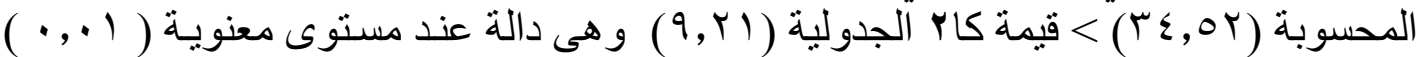

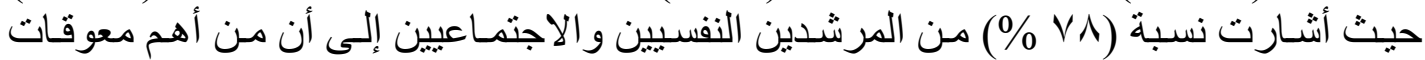

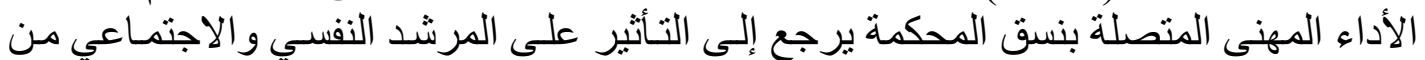

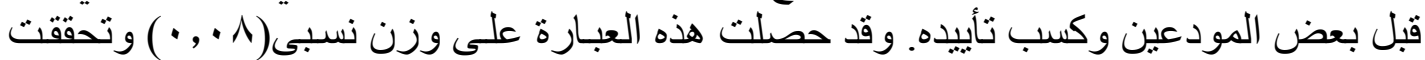

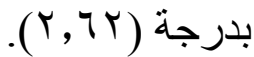

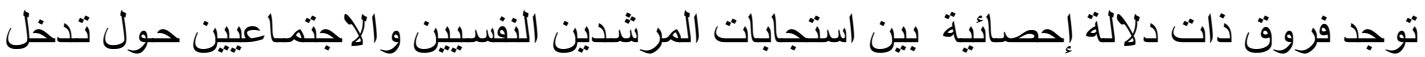

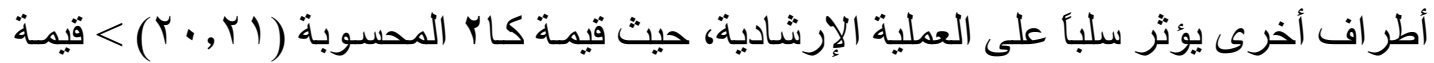

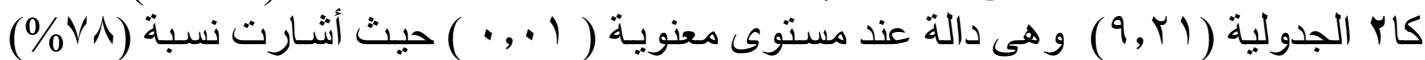

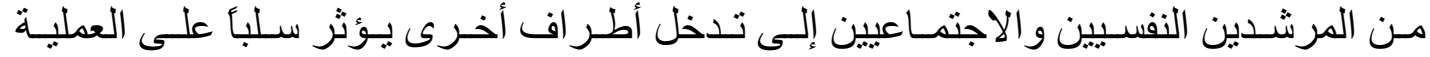

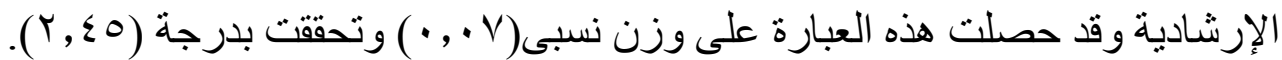

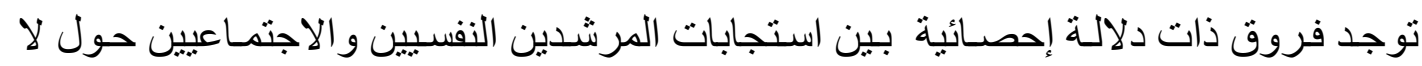

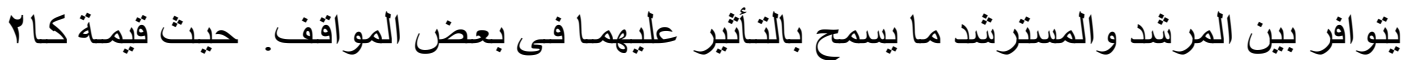

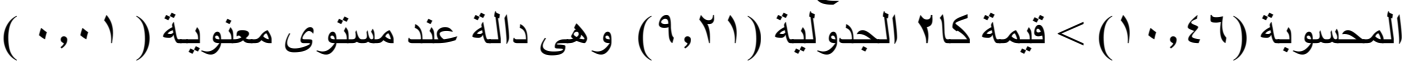

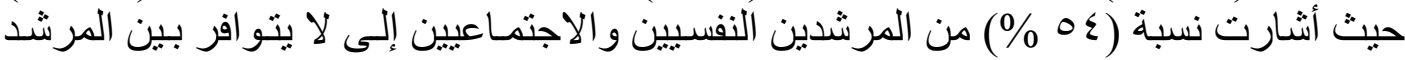

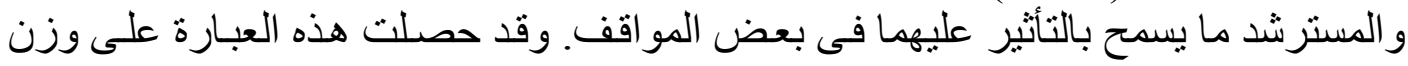

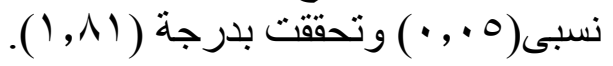

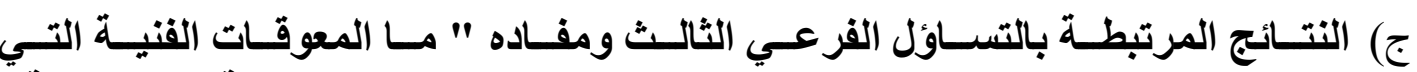

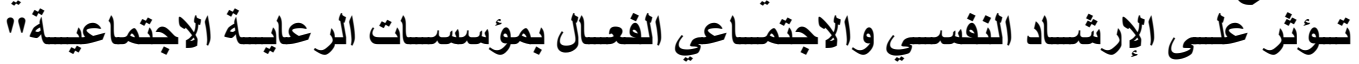

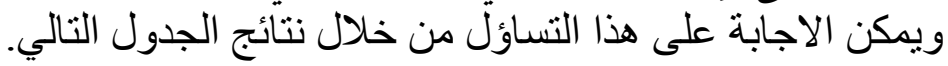


جدول رقم () ويوضح استجابات عينة الدراسة من المرشدين النفسيين والاجتماعية تجاه التساؤل الفرعي الثاني الخاص بالمعوقات الفنية (ن= • ؛ ).

\begin{tabular}{|c|c|c|c|c|c|c|}
\hline \multirow{2}{*}{ 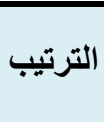 } & \multirow{2}{*}{ كاץ } & \multirow{2}{*}{ 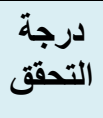 } & \multicolumn{3}{|c|}{ الاستجابات } & \multirow{2}{*}{ 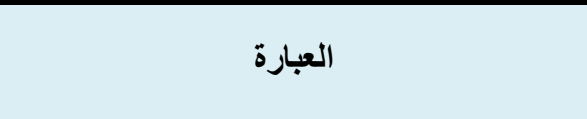 } \\
\hline & & & نعم & إلى حـ ما & نعم & \\
\hline \multirow{3}{*}{0} & \multirow{3}{*}{$r r, q$} & \multirow{3}{*}{ 1, } & $\mathrm{v}$ & $r$ & r. & 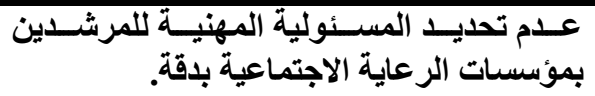 \\
\hline & & & $\%$ IV & $\%^{0}$ & $\% \vee \wedge$ & النسبة المئوية \% \\
\hline & & & $\cdot,+7$ & $\cdot, \cdot r$ & $\cdot, \cdot 1$ & الوزن النسبى \\
\hline \multirow{3}{*}{1} & \multirow{3}{*}{$r V, V$} & \multirow{3}{*}{1,07} & $\mathrm{v}$ & 0 & Yq & عدم ضمان مبدأ السرية لكافة الحالات. \\
\hline & & & $\% \%^{Y r}$ & $\% 11$ & $\%$ TV & النسبة المئوية \% \\
\hline & & & $\cdot,+\Lambda$ & $\cdot, \cdot V$ & $\cdot, 1 \leqslant$ & الوزن النسبى \\
\hline \multirow{3}{*}{9} & \multirow{3}{*}{ iv, } & \multirow{3}{*}{1,71} & $\mathrm{v}$ & $r$ & r. & 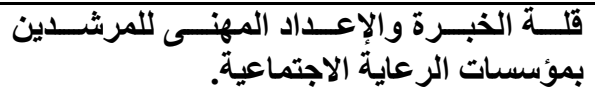 \\
\hline & & & $\%$ IV & $\%^{0}$ & $\% \vee \wedge$ & النسبة المئوية \% \\
\hline & & & $\cdot, .7$ & $\cdot, \cdot r$ & $\cdot, \cdot 1$ & الوزن النسبى \\
\hline \multirow{3}{*}{$r$} & \multirow{3}{*}{ ro,q } & \multirow{3}{*}{$1,7 r$} & 0 & 9 & rq & الحالات كتابة التقردية. بصورة شاملة وواضحة عن \\
\hline & & & $\% 11$ & $\% 1 \%, 0$ & $\% \vee \bullet, 0$ & النسبة المئوية \% \\
\hline & & & $\cdot, \cdot \varepsilon$ & $\cdot, .9$ & $\cdot, \cdot 1$ & الوزن النسبى \\
\hline \multirow{3}{*}{$\wedge$} & \multirow{3}{*}{$r \cdot, l$} & \multirow{3}{*}{1,70} & $\mathrm{v}$ & $r$ & r. & 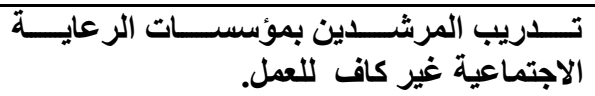 \\
\hline & & & $\%$ IV & $\%^{0}$ & $\% \vee \wedge$ & النسبة المئوية \% \\
\hline & & & $\cdot, .9$ & $\cdot, \cdot r$ & $\cdot, \cdot \wedge$ & الوزن النسبى \\
\hline \multirow{3}{*}{1.} & \multirow{3}{*}{ Ir, } & \multirow{3}{*}{1,7} & 0 & 1 & rq & اكتسبوه من من مهارات وخبرات. على توظيف مـا \\
\hline & & & $\% 11$ & $\% 1 \%, 0$ & $\% \vee \theta, 0$ & النسبة المئوية \% \\
\hline & & & $\cdot, \cdot \varepsilon$ & $\cdot, .9$ & $\cdot, 1 Y$ & الوزن النسبى \\
\hline \multirow{3}{*}{ r } & \multirow{3}{*}{$r v, r$} & \multirow{3}{*}{$r, 01$} & $\mathrm{v}$ & $r$ & r. & 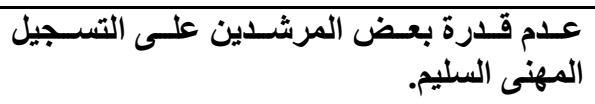 \\
\hline & & & $\%$ IV & $\%^{0}$ & $\% \vee \wedge$ & النسبة المئوية \% \\
\hline & & & $9,+9$ & $\cdot, \cdot r$ & $\cdot, \cdot 1$ & الوزن النسبى \\
\hline \multirow{3}{*}{0} & \multirow{3}{*}{ IV,o } & \multirow{3}{*}{$1,7 v$} & v & 0 & rq & تعواطسفت بعض الرعاية الاجنتماعية. بعض الحالات داخل \\
\hline & & & $\%$ Or $^{\prime}$ & $\% 11$ & $\% \otimes 1$ & النسبة المئوية \% \\
\hline & & & $\cdot, \cdot \Lambda$ & $\cdot, \cdot V$ & $\cdot, \cdot V$ & الوزن النسبى \\
\hline \multirow{2}{*}{$\varepsilon$} & \multirow{2}{*}{$r 0, q$} & \multirow{2}{*}{1,71} & 。 & 7 & rq & 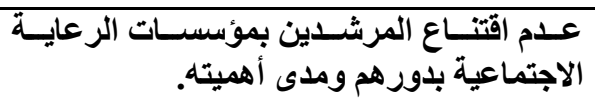 \\
\hline & & & $\% 11$ & $\% \backslash r, 0$ & $\%$ & النسبة المئوية \% \\
\hline
\end{tabular}




\begin{tabular}{|c|c|c|c|c|c|c|}
\hline \multirow{3}{*}{ 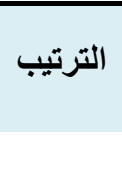 } & \multirow{3}{*}{ SL } & \multirow{3}{*}{ التحقق } & \multicolumn{3}{|c|}{ الاستجابات } & \multirow{2}{*}{ 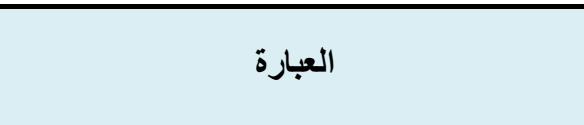 } \\
\hline & & & نعم & إلى حل ما & نعم & \\
\hline & & & $\cdot, \cdot \varepsilon$ & $\cdot, .9$ & $\cdot, \cdot \wedge$ & الوزن النسبى \\
\hline \multirow{3}{*}{7} & \multirow{3}{*}{$r \cdot, \Lambda$} & \multirow{3}{*}{$1,7 v$} & $v$ & $r$ & r. & 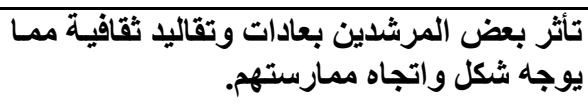 \\
\hline & & & $\%$ IV & $\%{ }^{0}$ & $\%$ & النسبة المئوية \% \% \\
\hline & & & $\cdot, .9$ & $\cdot, \cdot r$ & $\cdot, .9$ & الوزن النسبى \\
\hline \multirow{3}{*}{$v$} & \multirow{3}{*}{$r \cdot, l$} & \multirow{3}{*}{1,70} & $\checkmark$ & $\bullet$ & rq & 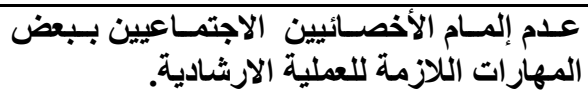 \\
\hline & & & $\%{ }^{Y Y}$ & $\% 11$ & $\%$ TV & النسبة المئوية \% \\
\hline & & & $\cdot, \cdot 1$ & $\cdot, \cdot V$ & $\cdot, \cdot V$ & الوزن النسبى \\
\hline
\end{tabular}

باستقراء بيانات الجدول السابق يتضح عدة نتائج كان من أهمها:

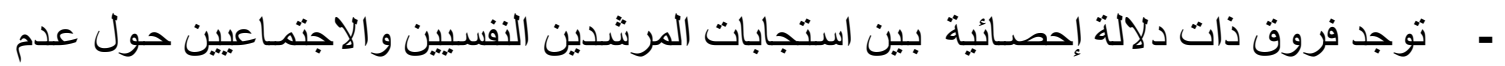

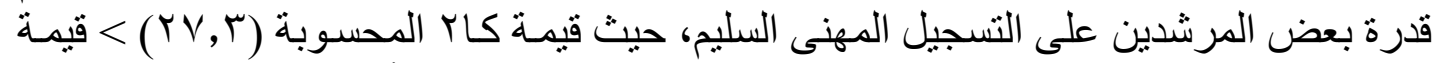

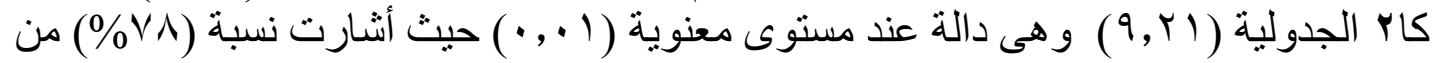

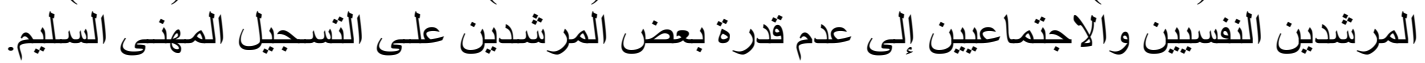

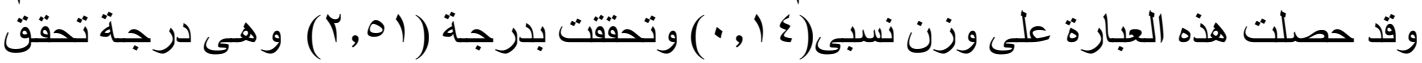
عالية.

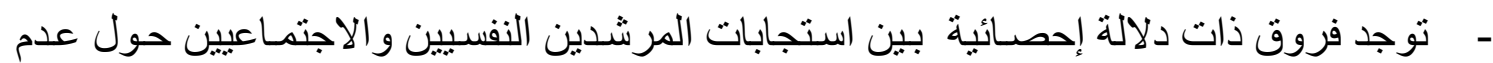

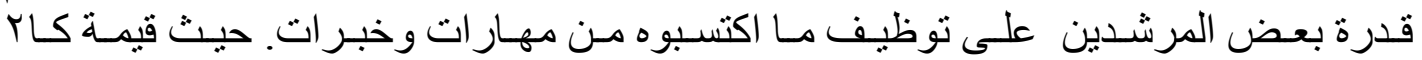

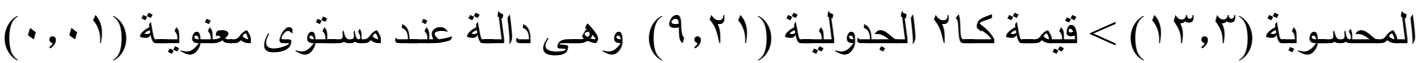

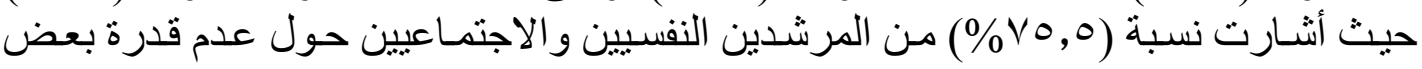

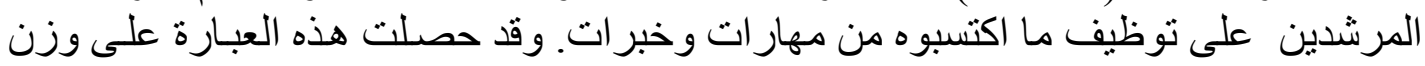

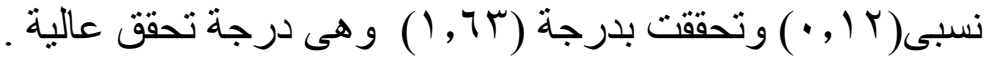

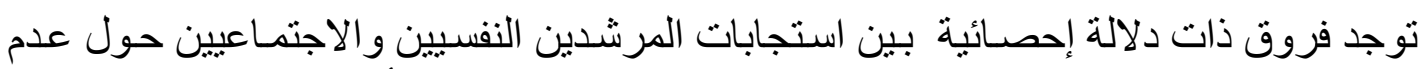

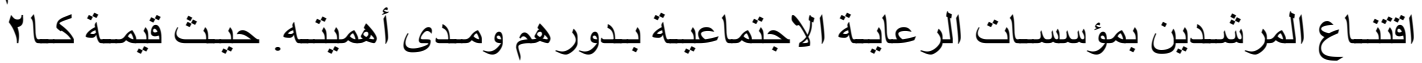

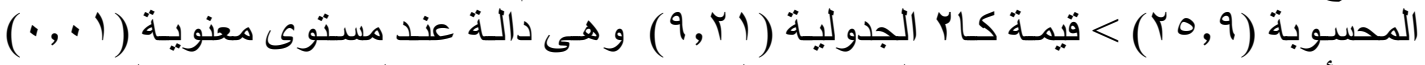

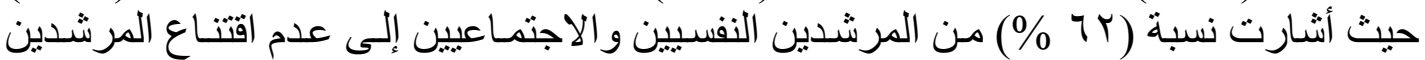

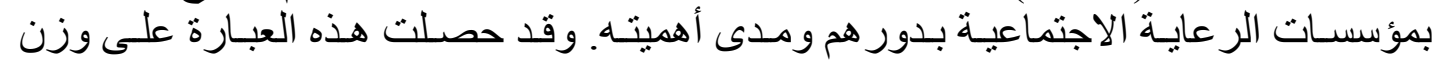

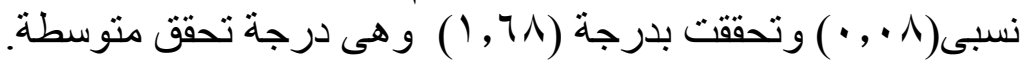

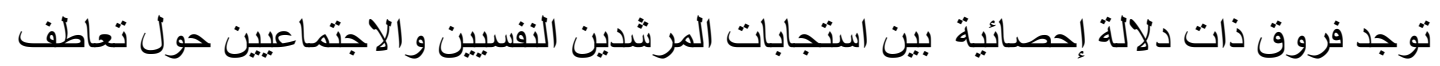

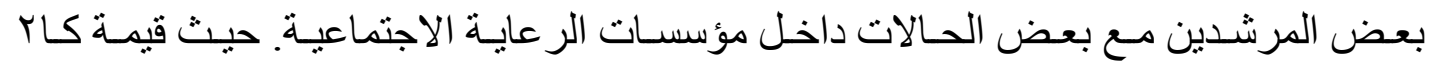

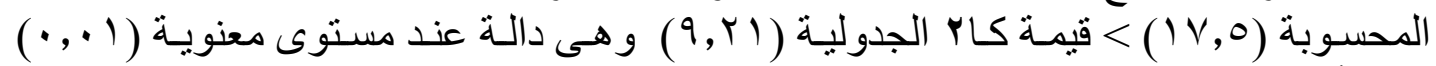

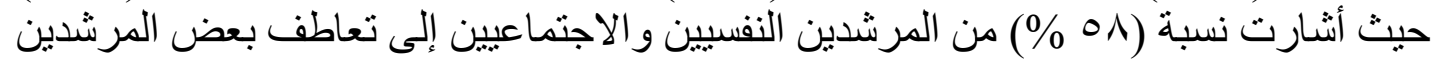

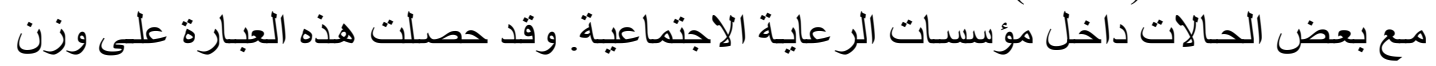

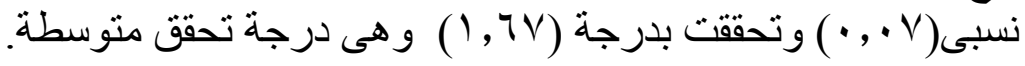

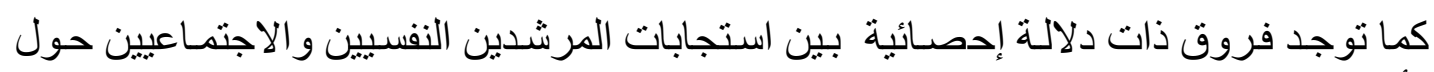

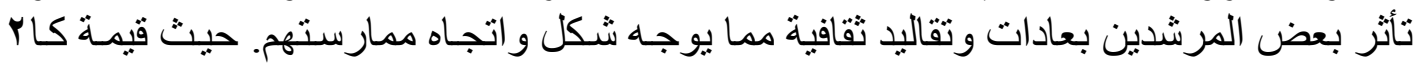

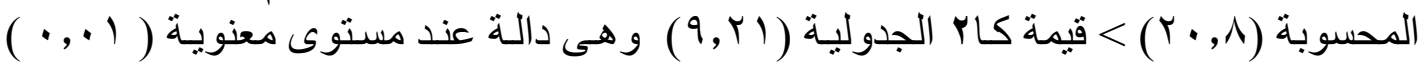


حيث أشتارت نسبة ( • \% \%) من المرشدين النفسيين والاجتماعيين إلى أن تأثر بعض المرشدين

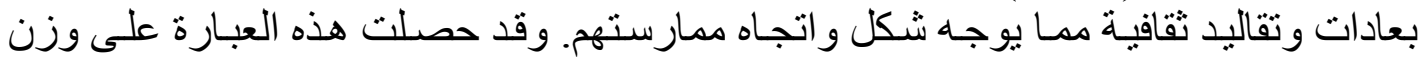

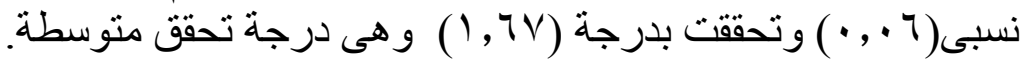

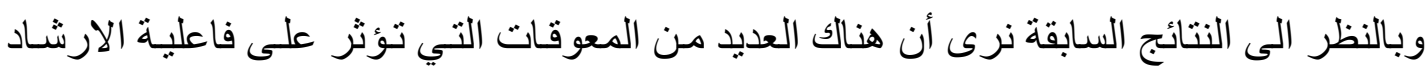

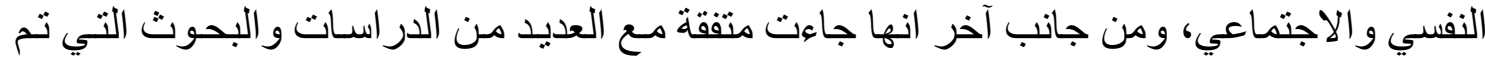

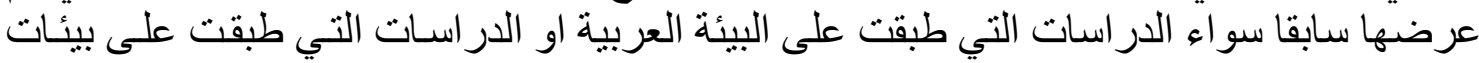

الأمر الذي دفع البحث نحو العديد من الخبر اء لتحديد مـاهي المتطلبـات الارشـادية لتفعيل دور

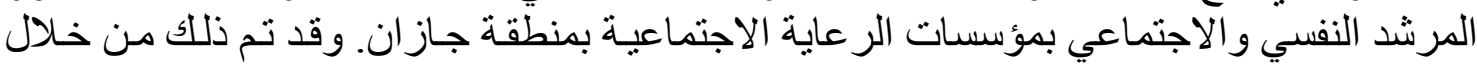

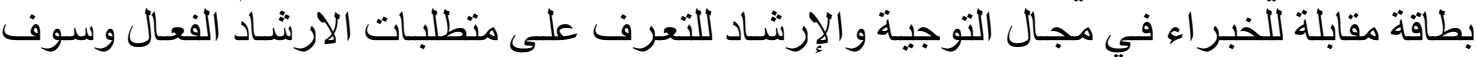
يتضح ذلك من خلال نتائج التساؤل الثاني الرئيس.

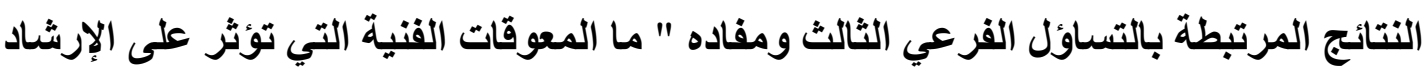

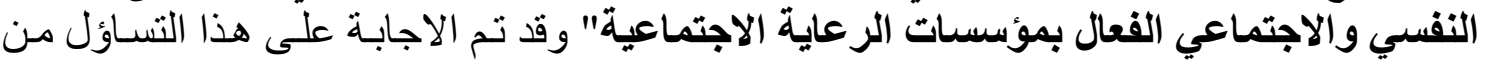

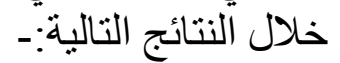

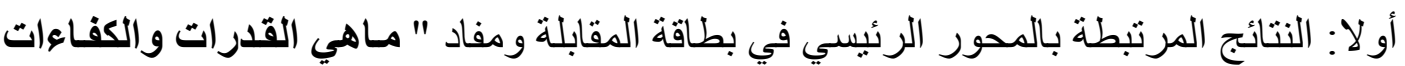

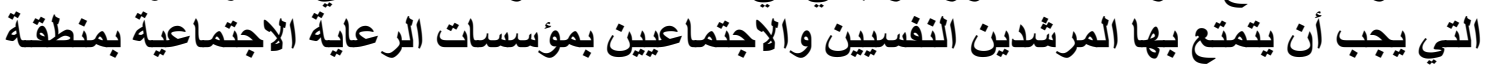
جازان " وجات النتائج من خلان بال تحليل المحتوى على النى النحو التالي:(أ) من حيث القدرة على إعداد برنامج إرشادي من قبـ المرشـد النفسي والاجتمـاعي بمؤسسـات

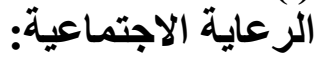
ـ أن يكون لاى المرشد القدرة على الأهى تحديد أهداف البرنامج الإرشادي.

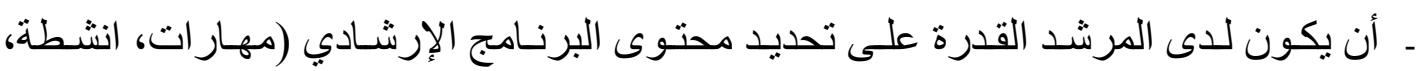
معارف و عمليات عقلية). - مر اعاة حدود البرنامج الإرشادي. ـ ان يتمتع بالمهارة و الموضو عية في تحديد الوسائل والطرق و الفنيات المستخدمة في تحقيق الأهداف الإرشادية.

$$
\begin{aligned}
& \text { ـ قدرة المرشد على تحديد ميز انية البرنامج الإرشادي. } \\
& \text { ـ ـ تحديد الخدمات التي يقدّمها البرنامج الإرشادي. } \\
& \text { ـ ـ تحكيم البرنامج الإرشادي. } \\
& \text { ـ ـ التدريب على تنفيذ البرنامج الإرشادي. } \\
& \text { ـ - ت ت تفيذ البرنامج الإرشادي. } \\
& \text { ـ - تقويم البرنامج الإرشادي. }
\end{aligned}
$$

(ب) من حيث المهارات الخاصة بالمرشد النفسي والاجتماعي بمؤسسات الرعاية الاجتماعية: - أن ينمتع بمهار ات الاستماع الفعال. ـ مهارة عكس المشاعر وهي عكس المحتوى الانفعالي لعبار ات المسترشد. ـ مهارة عكس المحتوى و هي عكس المحتوى المعرفي لعبار ات المسترشد. 
ـ ـ مهارة الاستيضاح تجيء على صيغة سؤ ال، للوقوف على أب حذف أو تثويهات في عبار ات المسترشد حول المشكلة أثناء جلسة العلاج. ـ مهارة التلخيص و هي تلخيص المحتوى المعرفي و الانفعالي لعبار ات المسترشد، في حال استرساله في الحديث و عدم السماح للمرشد بالتحدث. ـ ـ مهارة المو اجهة و هي مواجهة المسترشد بأي تناقضـات لفظية كانت ام جسدية تصدر عنهـ أثناء جلسات العلاج. ـ ـ مهارة التفسير و هي ضرورية للافع بالمسترشد لتفسير عبار اته ومشاعره أكثر.

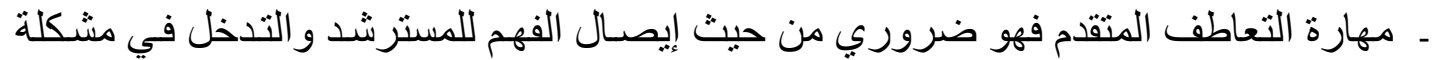
المسترشد دون استفزاز أو نقل المسترشد من اطر العارئل العاقة إلى علاقات دفاعية. (ج) من حيث مهام المرشد النفسي والاجتماعي بمؤسسات الرعاية الاجتماعية:

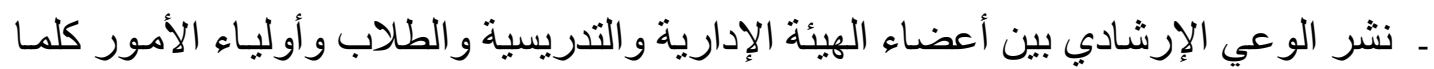
وجد ضرورة ل لذلك. - وضع خطة إرشاد سنوية تمند على مدار العام تتناسب مع حاجات المسترشدين. ـ ـ العمل على تنفيذ الخطة الإرشادية وتقويمها.

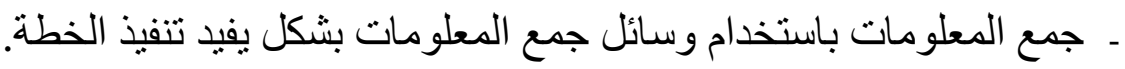
ـ ـ إجر اء المقابلات الفردية بهدف تقديم المشورة في مو اجهة الصعوبات و المشكلات التي تو اجه

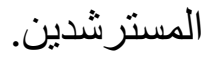
ـ ـ القيام بعملية الإرشـاد و المسـاعدة من خـلال الجلسـات على فهم المشكلة و اقتـراح الحلول المناسبة لها.

- ـ القيام بعملية التوجيه الجمعي ،في الصفوف لمناقتشة الطلاب بقضايا تهمهم.

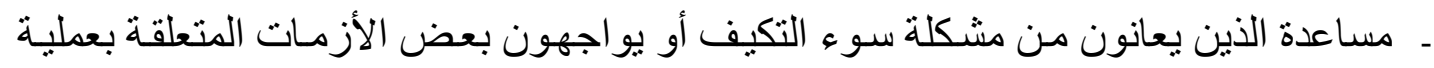
النمو وتوجيهـم إلى السبل السوية. ـ مساعدة الإدارة بمؤسسات الرعاية الاجتماعية على حل المشكلات. ـ ـ إعداد نشر ات إرشادية توضح طبيعة عمل المرشد.

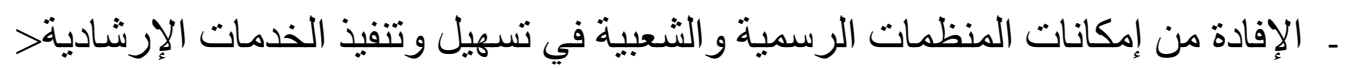
ـ ـ تنظيم السجلات الخاصة بالعملية الإرشادية. ـ ـ القيام بالأبحاث و الدر اسات التي تخدم عملية الإرشاد. ـ ـ إحالة الحالات التي تتعدى حدود إمكانات المرشد واختصاصده إلى الجهات المختصة.

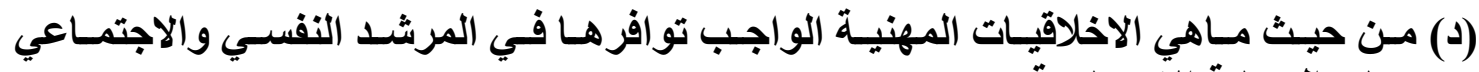
بمؤسسات الزعاية الآجتماعية: ـ ـققبل العميل كما هو دون إبداء نقد، أو تعنيف، أو انفعال، أو انزعاجة أو استنكار لما يعبر عنـهـ

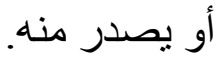

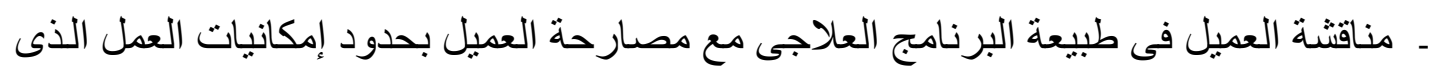
يمارسه معه من تشخيص، أو إرشاد، أو علاج دون مديع مبالغة. 
ـ ـ الالتز ام التام بجدول المواعيد الخاصة بالعميل.

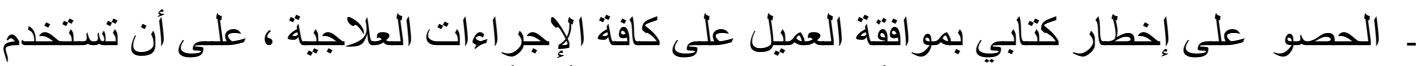

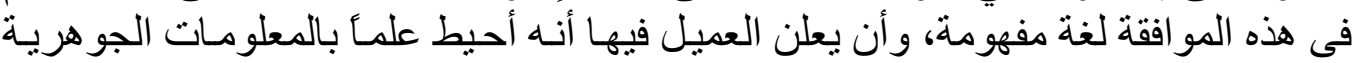

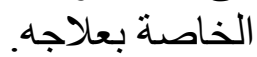

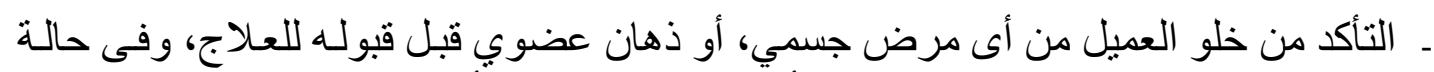

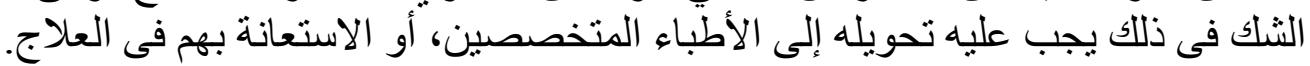

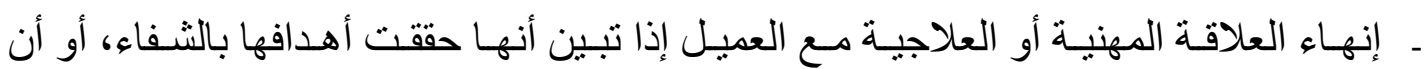

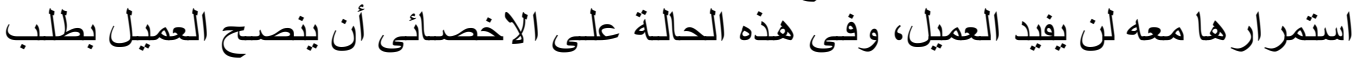

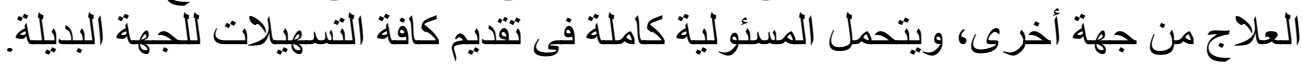

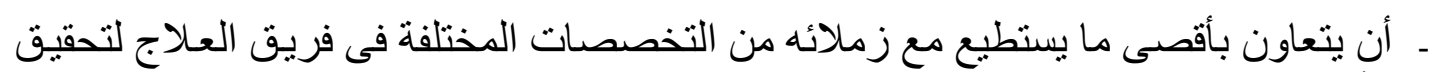
أفضل ما يمكن تقديمه من خدمة للعميل.

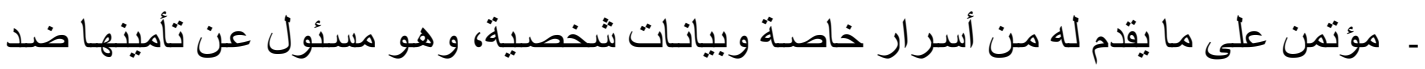
إطلاع الغير، فيما عدا ما يقتضيه الموقف ولصنالح العيل العيل.

\section{مراجع البحث}

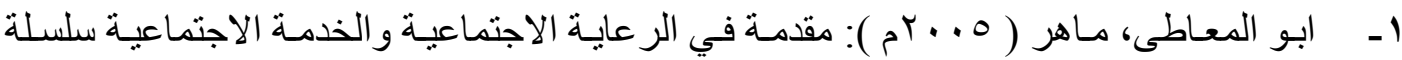

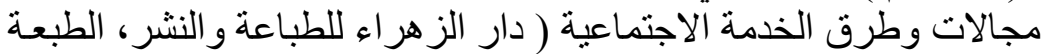

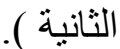

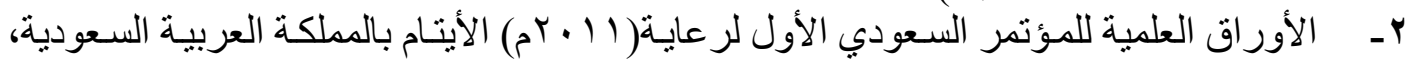
الجمعية الخيرية لر عاية الايتام إنسان.

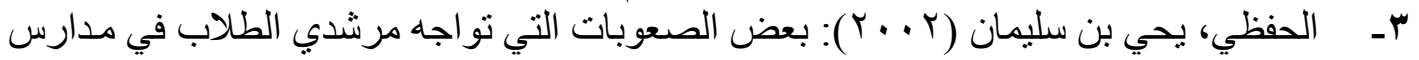

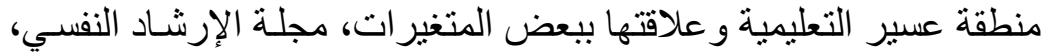

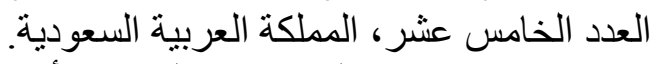

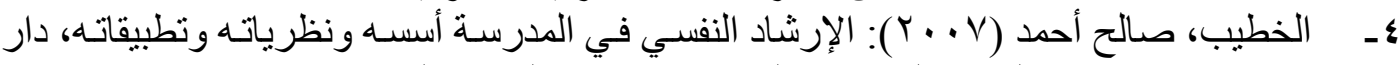

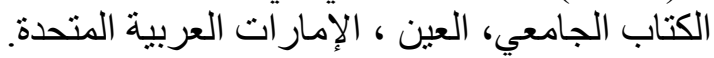

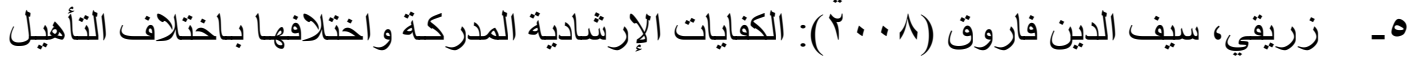

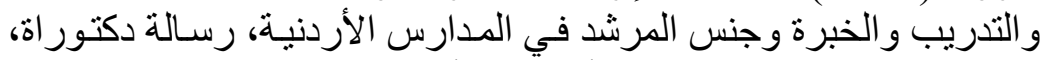

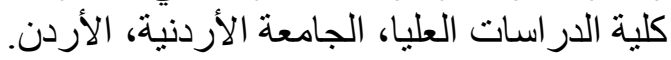

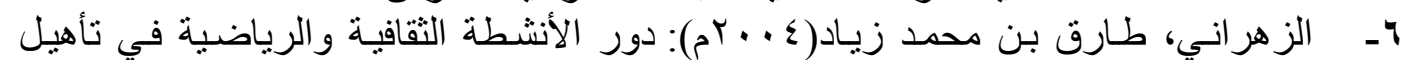

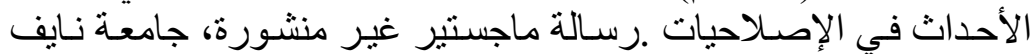

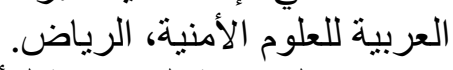

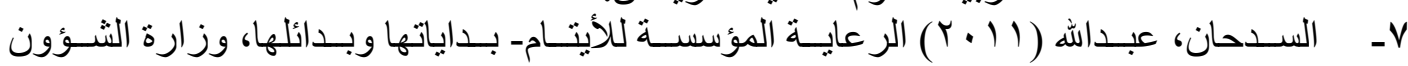

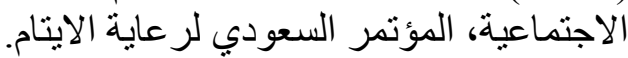

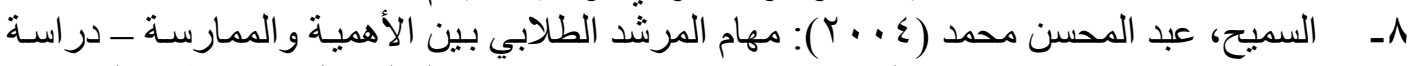

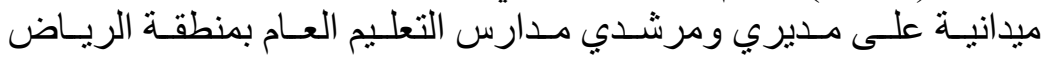

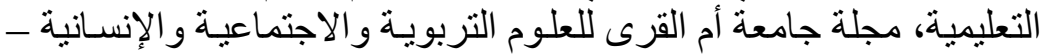

المجلد السادس عشر ، العدد الأول، الرياض، المعلة الملكة العربية السعودية.

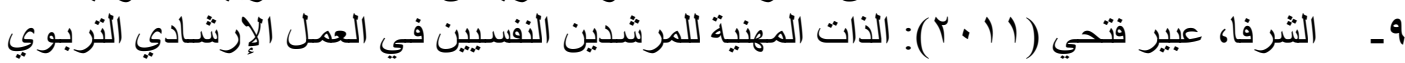

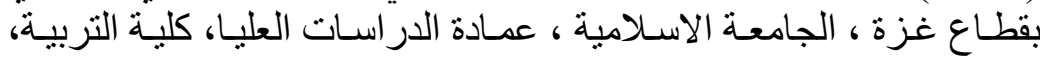

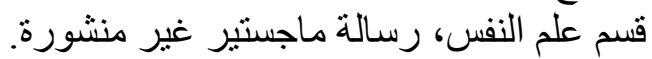

• 1 الشـناوي، محمد محروس بحوث في التوجيـه الإسـلامي للإرشــاد، و العـلاج النفسـي القـاهرة: 


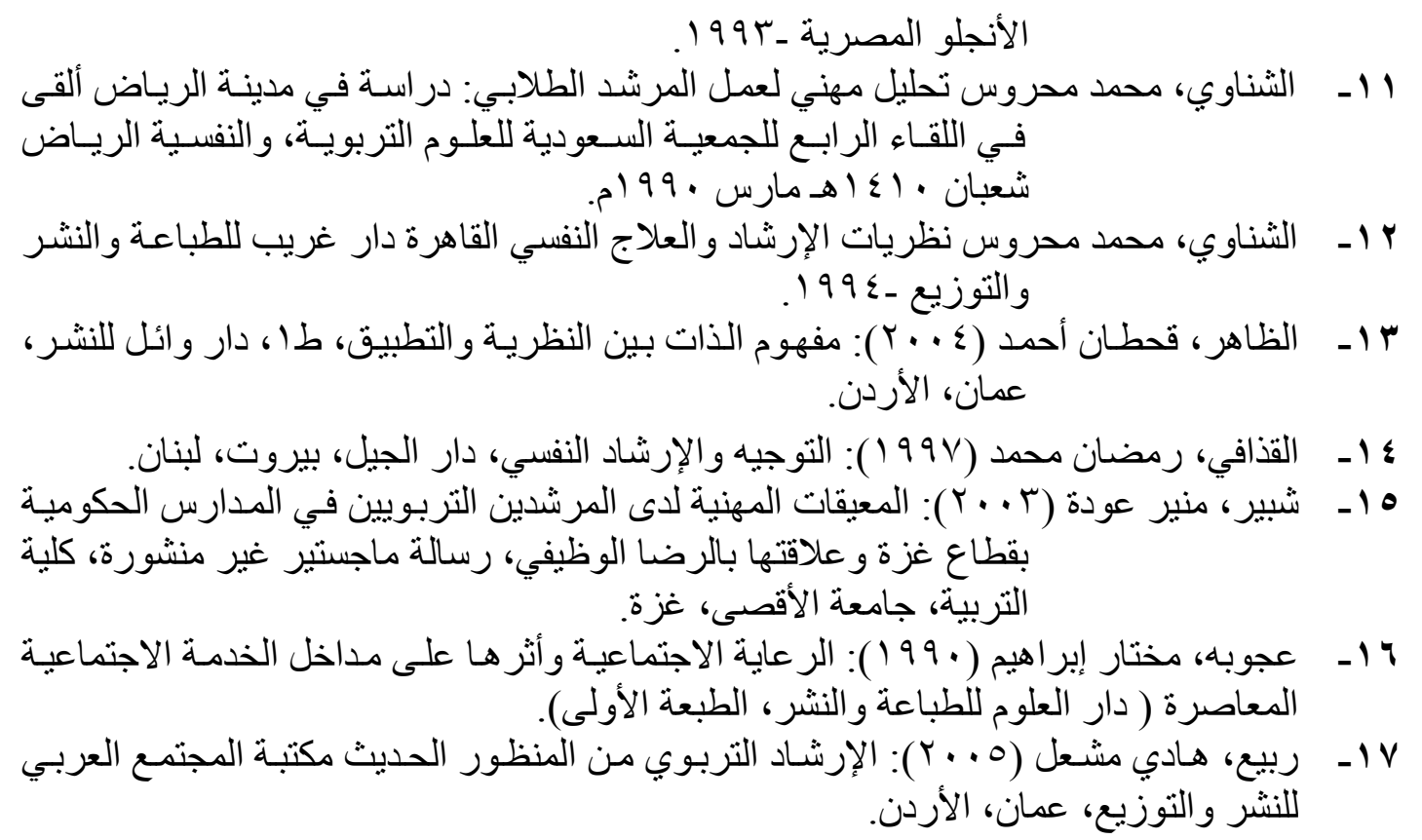

18 - Brammcr, L. M. \& Shostrom, E. L. "1982" Therapeutic Psychology: Fundamantals of Counseling and Psychotherapy.

19 - Englewood Cliffs, N J: Prentice - Hall.

20 - Brown, S. O \& Lent, R. W. "Eds1 1992" Handbook of Counseling Psycholog. New York: John Wiley \& Sons.

21 - Cormier, W. H. \& Cormier, L. S: "1985" Interviewing Strategies for helpers "2 nd ed" Monterey, C A. Brooks / Cole.

22 -Roy, B.E.(1980): Personality and attitude characteristics effect counselor, supervision and client perspective, dissertation abstracts international. vol 14 no.

23 - Muccuistion, P., (1997), The Construction of counseling Skills \& Techniques Inventory using the Development, Doctoral Dissertation Abstract.

24 -Coustantine, M, (2001), Theoretical Orientation, Empathy, Multicultural Counseling Competencies, Journal of Professional Counseling .14.5.332-365.

25 -Goodnough, P and Carolyn J, (2001), A national survey of school counselor preparation program, Journal of Counselor Education \& Supervision, 40, 4: 252-262.

26 -Urofsky, R., (2000), An exploration of Counseling Ethics: A Qualitative study, University of Virginia, Doctoral Dissertation Abstract, PP: 225 
مقياس معوقات الإرشاد النفسي والاجتماعي الفعال بمؤسسات الرعاية الاجتماعية

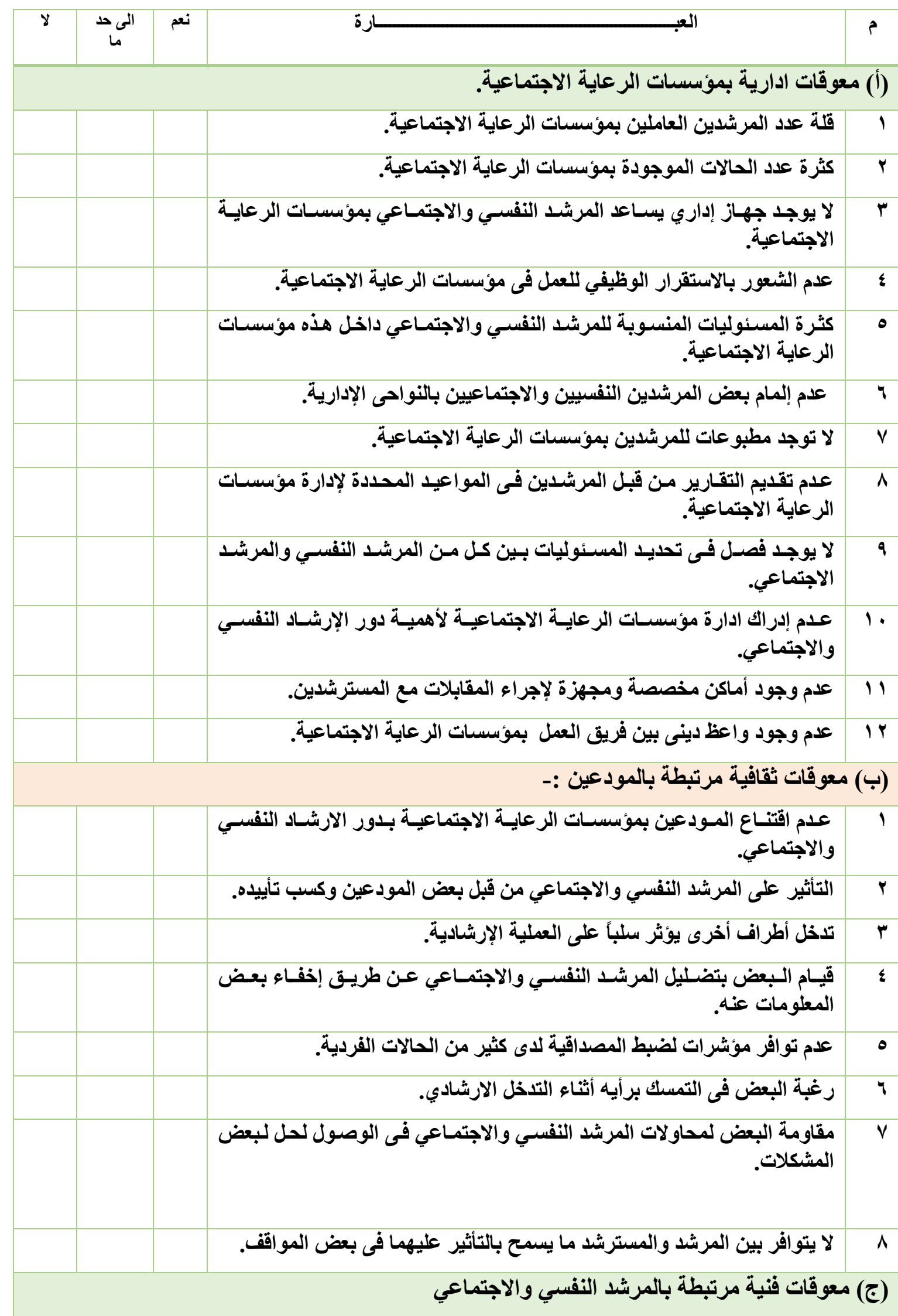




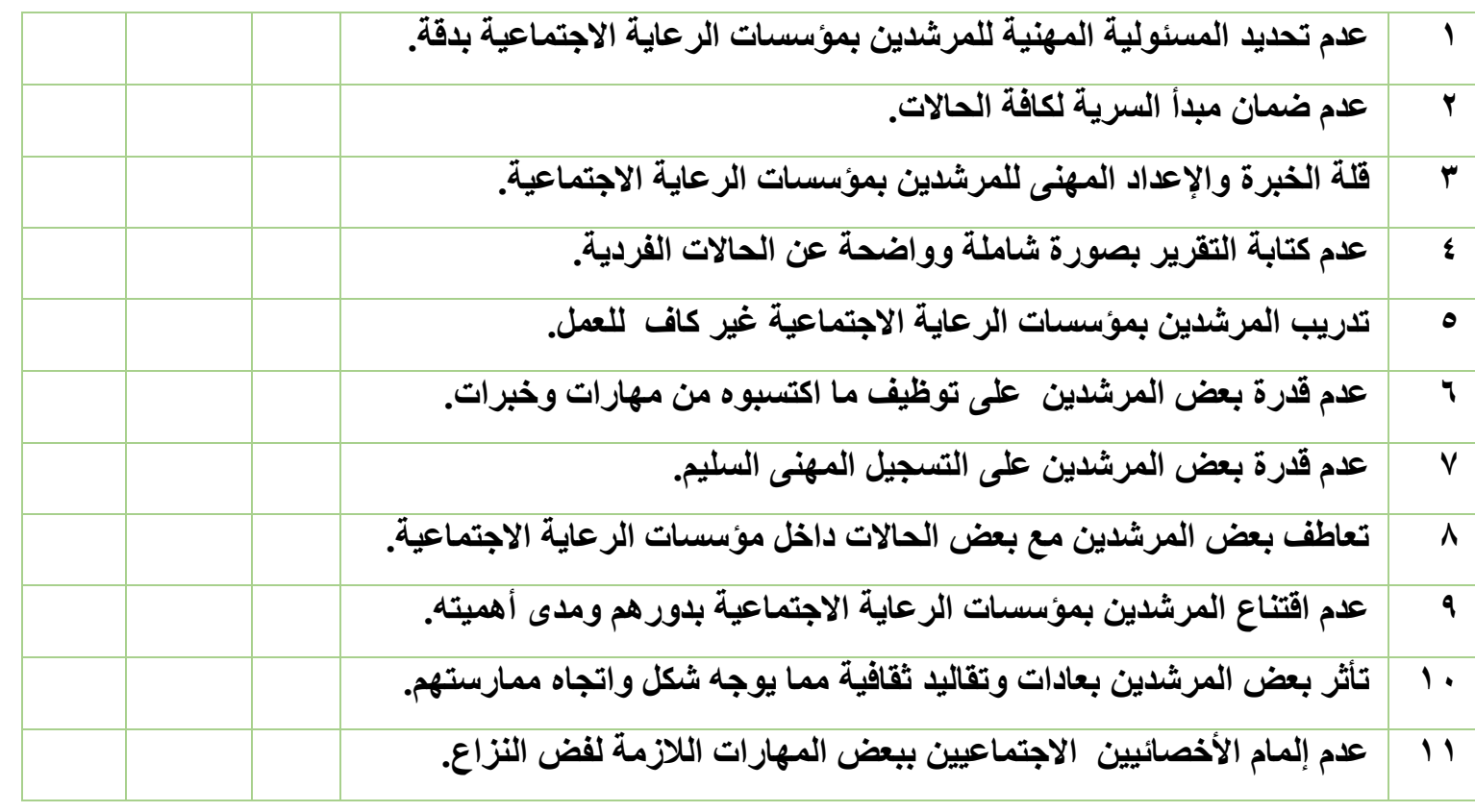

بطاقة مقابلة: للخبر اء والمختصين للتعرف على متطلبات الإرشاد النفسي والاجتماعي الفعال بمؤسسات الرعاية الاجتماعية في ضوفي منطو التحديات الإنيات المعاصرة.

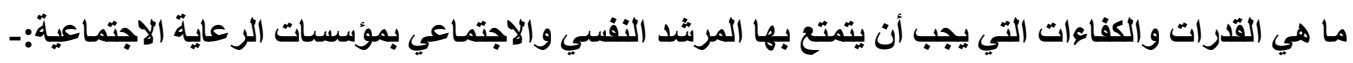

( ) ما هي مهارات المرشد النفسي والاجتماعي بمؤسسات الرعاية الاجتماعية في ضوء التحديات المعاصرة ؟ 
(־) ماهي الاخلاقيات المهنية الواجب توافرها في المرشد النفسي والاجتماعي بمؤسسات الرعاية الاجتماعية ؟ 